\title{
Tulane University final report
}

\author{
M. Celeste Marin \\ Anastasia J. Gage \\ Suhaila Khan
}

Follow this and additional works at: https://knowledgecommons.popcouncil.org/departments_sbsr-rh

Part of the Demography, Population, and Ecology Commons, International Public Health Commons, and the Public Health Education and Promotion Commons How does access to this work benefit you? Let us know!

\section{Recommended Citation}

Marin, M. Celeste, Anastasia J. Gage, and Suhaila Khan. 2004. "Tulane University final report," FRONTIERS Final Report. Washington, DC: Population Council. 


\title{
FRONTIERS IN REPRODUCTIVE HEALTH
}

\author{
Tulane University Final Report
}

\author{
Tulane University \\ School of Public Health and Tropical Medicine \\ M. Celeste Marin \\ Anastasia Gage \\ Suhaila Khan
}

December 2004

This work was funded by the US AGENCY FOR INTERNATIONAL DEVELOPMENT (USAID) under the terms of the Frontiers in Reproductive Health Cooperative Agreement Number HRN-A-00-98-00012-00 and Population Subagreement Number AI98.57A with the Tulane University School of Public Health and Tropical Medicine. The opinions expressed herein are those of the authors and do not necessarily reflect the views of USAID. 


\section{TABLE OF CONTENTS}

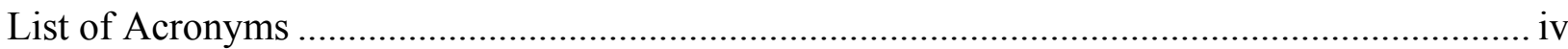

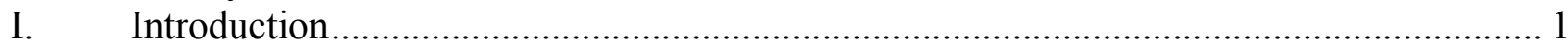

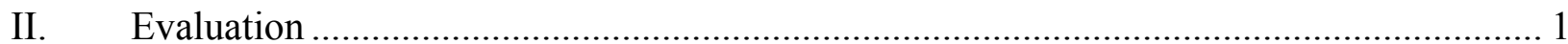

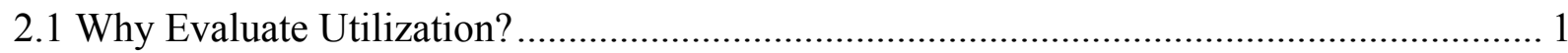

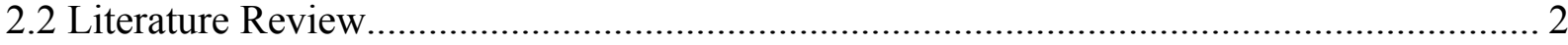

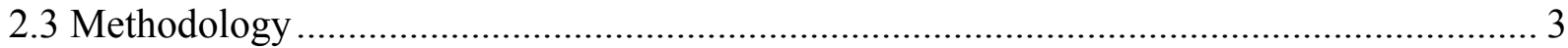

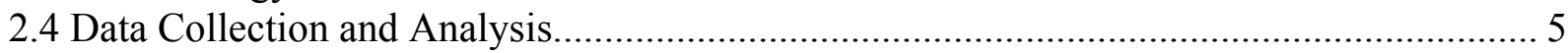

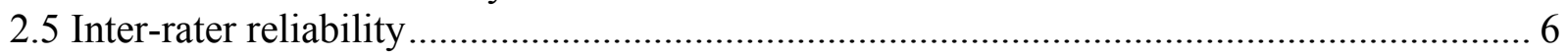

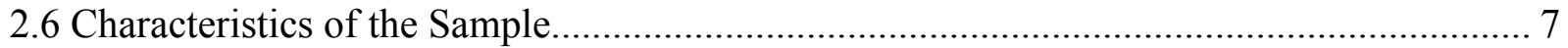

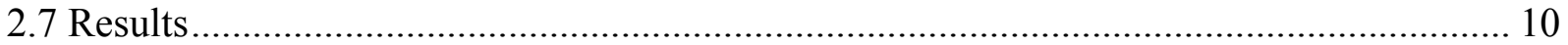

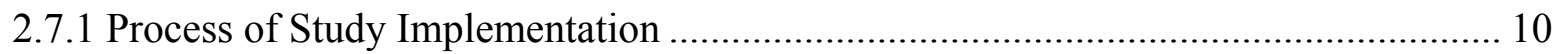

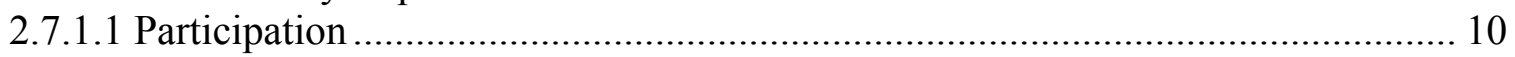

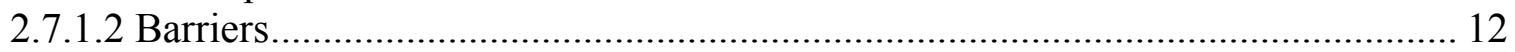

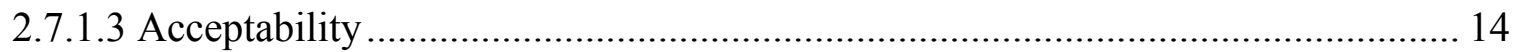

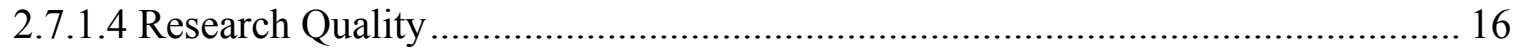

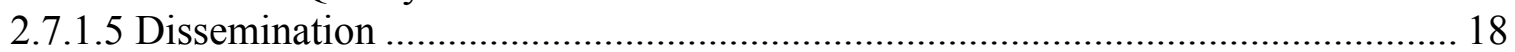

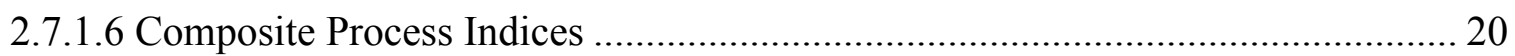

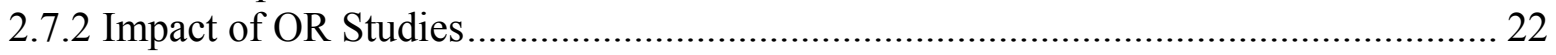

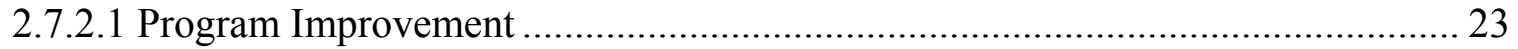

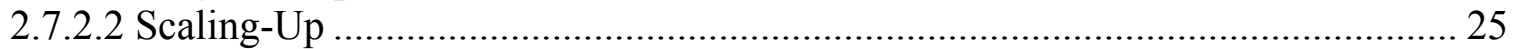

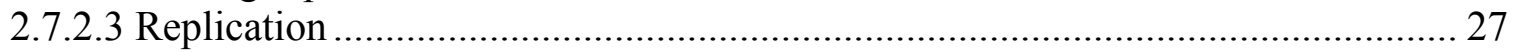

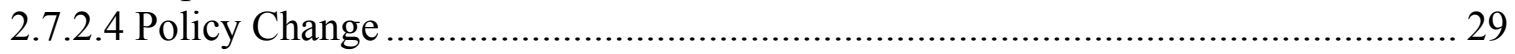

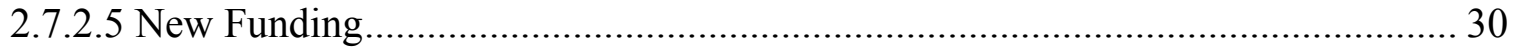

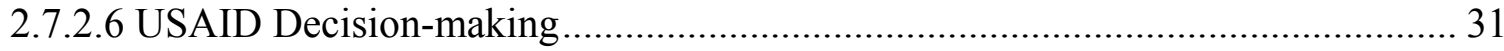

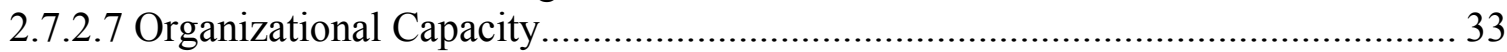

2.7.3 Factors Influencing Utilization of OR Results.......................................................... 34

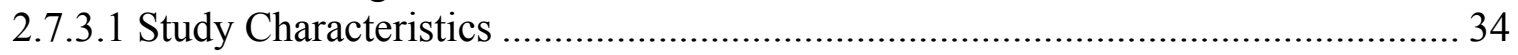

2.7.3.2 Operations Research Process …………………............................................... 37

2.7.3.3 Facilitating Factors Identified by Monitors ......................................................... 41

2.7.3.4 Inhibiting Factors Identified by Monitors ............................................................ 43

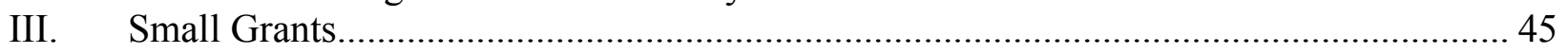

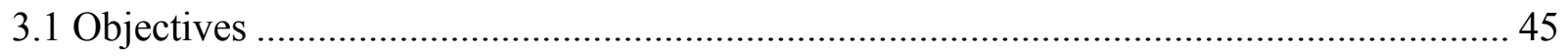

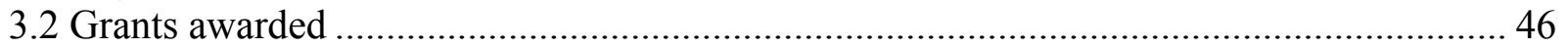

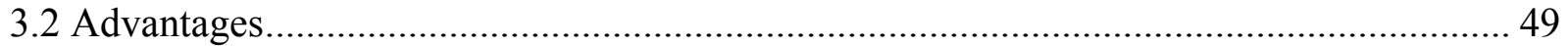

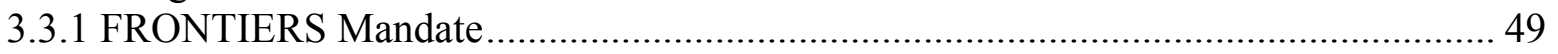

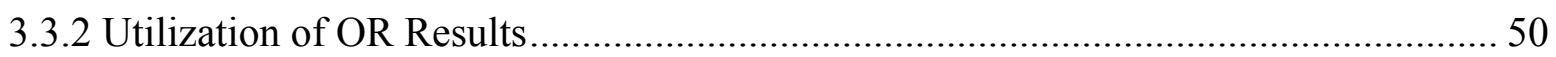

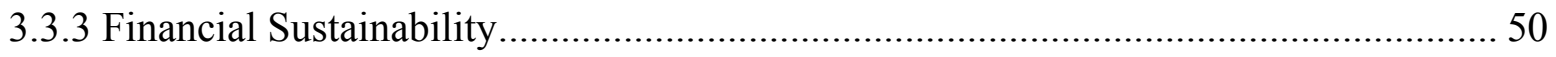

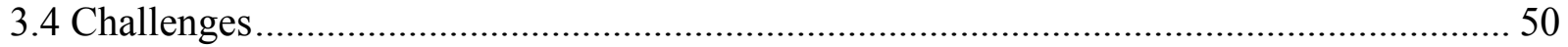

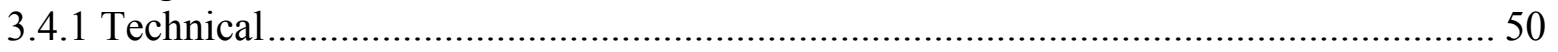

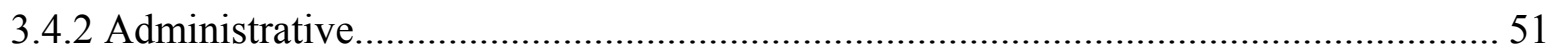

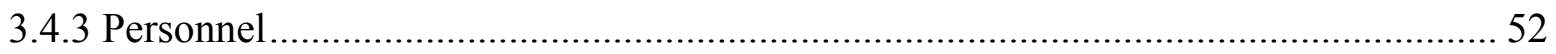

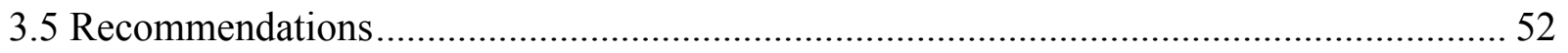

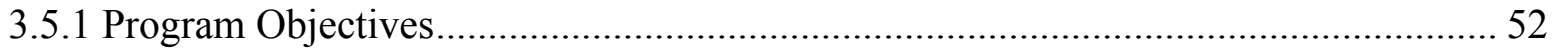

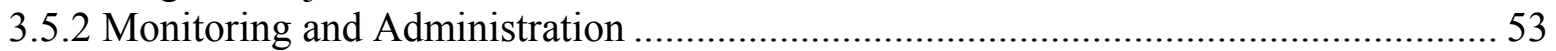




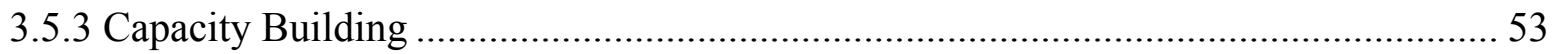

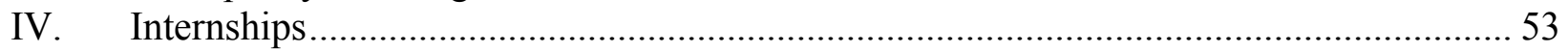

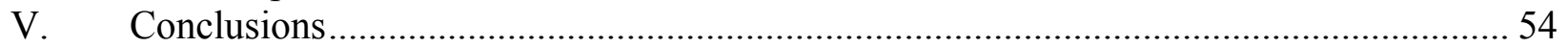

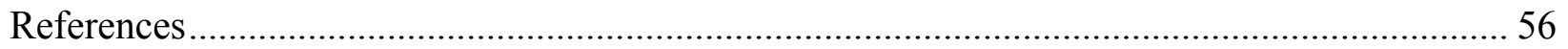

Appendix A: Critical Review of Literature on Utilization of Research Results....................... 58

Appendix B: Estimating Inter-rater Reliability............................................................ 75

Appendix C: Relationship between OR Process and Results Utilization ................................. 76 


\section{List of Acronyms}

ASHONPLAFA

ARFH

CBD

CEMOPLAF

CIDEM

CEFOREP

CREHPA

DFID

DISH

DMPA

EC

FGC

FRHS

GTZ

HIV/AIDS

IGSS

INOPAL

IR

IRESCO

IUD

JHU/CCP

KARHP

LAM

MEXFAM

MIS

$\mathrm{MOH}$

MYWO

NGO

PAC

PATH

PCI

PPAG

PROSIN

SFPS

SNSR

STI

WHO

ZNFPC
Asociación Hondureňa de Planificación de la Familia

Association for Reproductive and Family Health

Community-Based Distribution

Medical Center for Orientation in Family Planning (Centro

Médico de Orientación y Planificación Familiar)

Center for Information and Development of Women

Centre de Formation et de Recherche en Santé de la Reproduction

Center for Research on Environment, Health and Population

Activities

Department for International Development

Delivery of Improved Services for Health

Depo medroxyprogesterone acetate

Emergency Contraception

Female Genital Cutting

Foundation for Research on Health Systems

Gesellschaft für Technische Zusammenarbeit

Human Immunodeficiency Virus/Acquired Immune Deficiency

Syndrome

Guatemalan Institute of Social Security

Operations Research and Technical Assistance in Family

Planning and Reproductive Health in Latin America and the

Caribbean (Investigación Operativa en Planificación Familiar y

Salud Reproductiva en América Latina y el Caribe)

Intermediate Result

Institute for Behavioral Studies and Research

Intrauterine Device

Johns Hopkins University Center for Communication Programs

Kenya Adolescent Reproductive Health Program

Lactational Amenorrhea Method

The Mexican Family Planning Association

Management Information System

Ministry of Health

Maendeleo Ya Wanawake Organization

Non-Governmental Organization

Postabortion care

Program for Appropriate Technology in Health

Project Concern International

Planned Parenthood Association of Ghana

Proyecto de Salud Integral

Santé Familiale et Prévention du Sida

National Reproductive Health Services

Sexually Transmitted Infections

World Health Organization

Zimbabwe National Family Planning Council 


\section{Introduction}

The Frontiers in Reproductive Health Program (FRONTIERS) is a 10-year cooperative agreement between the United States Agency for International Development (USAID) and the Population Council in partnership with Family Health International (FHI) and Tulane University School of Public Health and Tropical Medicine. Begun in 1998, FRONTIERS followed previous operations research and technical assistance contracts awarded to the Population Council by USAID in three regions of the developing world. Similar to these programs, FRONTIERS tests innovative interventions to ensure high-quality, client-centered family planning and reproductive health services, but it is global in scope and has a broader reproductive health mandate than the regional contracts.

Tulane had two primary roles in FRONTIERS: impact evaluation and the implementation of a small grants program. Specifically, Tulane was charged with developing and implementing an evaluation plan for FRONTIERS based on the program's results framework. This approach would track the impact of the operations research studies conducted under FRONTIERS, defined as the extent to which individual OR studies result in changes in service delivery or policy action in the country in which they are conducted, and are replicated elsewhere.

With regard to the Small Grants program, Tulane managed the selection of studies and monitored their implementation jointly with the Population Council. In the Small Grants program as well as the evaluation component, FRONTIERS/Tulane collaborated with FRONTIERS colleagues based in the US and in the field, cooperating agencies (CAs) and USAID while taking advantage of their institutional skills and experience.

A third component of the Tulane partnership was an internship program, in which MPH and $\mathrm{PhD}$ candidates gained professional experience through six to nine-month placements at the FRONTIERS office in Washington DC. These fellows worked on global agenda, economic evaluation, and communication and dissemination projects, and went on to positions at USAID and cooperating agencies in the US and abroad, as well as to pursue doctoral degrees.

This report summarizes the main activities undertaken by Tulane University under its subagreement with the Population Council on the Frontiers in Reproductive Health Project from 1998-2004.

\section{Evaluation}

\subsection{Why Evaluate Utilization?}

Operations research (OR) in reproductive health is a tool for deciding how to make program more effective or efficient. It consists of five steps:

1. Identifying a problem within control of the manager,

2. Proposing alternate solutions to the problem,

3. Testing the solutions to determine which one is best,

4. Disseminating information about the findings, and

5. Using the results to improve the program. 
As such, operations research can only be considered complete, or successfully accomplished, after a program acts on the results, either maintaining or expanding the solution tested, or discontinuing it if it proves not to work. Nevertheless, in OR as in other types of research, researchers have tended to consider their work done once a report or journal article was published on the study findings.

The United States Agency for International Development (USAID) has provided support for OR in family planning for over 25 years, but with relatively little systematic assessment of the effect of OR projects on national programs. Rather, evaluation has consisted of counting the number of projects completed or best practices identified within a given timeframe. This sort of evaluation has demonstrated that work is indeed being done, but has said little about whether service delivery improved or reproductive health policies changed as a result. To address this shortcoming, USAID charged the Frontiers in Reproductive Health Program with developing an innovative approach to evaluating the process and impact for its portfolio of OR projects.

\subsection{Literature Review}

In the literature on utilization of research results, OR is the only discipline that always attempts to link research utilization with specific interventions. Other disciplines allude to this link but specific examples are hard to find from the available literature. Even within OR specific examples are scarce mainly because so few studies are available. Some exceptions are Solo et al.'s (1998) examination of OR studies in nine sub-Saharan African countries and country-level case studies such as Haaga and Maru (1996) on health services integration in Bangladesh and Hegazi (1997) on postabortion care in Egypt. A detailed outline of the publications summarized in this literature review section, as well as others relating to utilization of research results in other areas of health, can be found in Appendix A.

The determinants of research utilization may be broadly categorized into research-specific factors on the one hand, and attributes of the innovation, individual or organization on the other. Some research-specific factors that influence research use are relevance of research, quality of research, credibility of researcher, skills of local researchers/research institutions, dissemination of research findings, accessibility of research, interaction and communication between researchers and potential users (i.e., decision-makers), and large scale testing of innovation. Relevance of the research topic and dissemination are the two factors most discussed in the literature. Relevance alludes to the different priorities set by practitioners, decision-makers and academically oriented researchers. If the research topic is relevant to potential users, there is higher use of the findings, but if the topic is not relevant or timely research findings are less likely to be used (Agarwala-Rogers 1977; Frenk 1992; Hegazi 1997; IFPRI 2001; Solo et al. 1998). Testing interventions on a large scale also seems to create momentum, making utilization of findings more likely (Corwin et al. 1982; Haaga and Maru 1996).

Aspects of research quality that have been found to influence the utilization of study results include methodology, study design and process of implementation. If the study design is methodologically sound, strong research findings are more acceptable and use is more probable. However, perceived quality may be more important than actual quality. In their study of 67 
policymakers in Mexico, Trostle et al. (1999) report, "Decisionmakers in particular, but also many researchers, attributed quality more often to the identity of the researcher than to the study design or content of the data themselves."

During the dissemination process, the utilization of research findings may be influenced by the different levels of presentation (international, national, regional, local) of research results, frequency of presentation, (once or multiple times), and language used in presentations and reports (technical versus non-technical). Research use is generally higher when study findings are presented multiple times, in simple non-technical non-strident language (Goldstein et al. 1978; Sigel et al. 1985; Solo et al. 1998; Trostle et al. 1999) and/or in the country's local language (Hegazi 1997). The nature of recommendations is also very important in influencing research use: recommendations for incremental changes meet less opposition than radical changes to programs or policies.

Some organizational characteristics that influence research use are setting, availability and support of administration/institution, availability of funding, and political climate. Research and research use is affected if there are unplanned personnel change or frequent staff turnover. Organizational resistance to proposed changes related to deeply held beliefs and values affect the policy outcome of evaluation studies (Sigel et al. 1985; Weiss et al. 1980). Resistance to change may occur if program staff feels threatened by the study results. Political considerations can influence the use of research findings depending on whether the study conclusions support or contradict particular actions or policy decisions. These challenges may be internal to organizations or pertain to external national issues. This is evident from most of the OR studies undertaken. Consistent and clear policies also influence use of research findings depending on whether the study recommendations are in support of or contradict those policies (Corwin et al. 1982). When funding is withdrawn or there are other resource constraints, interventions may not be scaled up even if study findings are positive (Anderson et al. 1999; Askew et al. 2001; Davis et al. 1996).

\subsection{Methodology}

The overall methodology for assessing utilization of OR studies was developed using a case study approach, where external evaluators collected data on all Population Council OR projects conducted in a given country in the previous ten years, through review of project documents and structured in-depth interviews with individuals knowledgeable about a study and its outcomes. Evaluators developed and tested indicators for assessing OR process and impact in the first round of case studies conducted in 1999. Kenya, Philippines and Peru were purposively selected as representative of the three major geographic regions of the previous USAID-sponsored OR projects and because they had a sufficient number of completed projects. The data collection approach and indicators were further refined in Honduras, Senegal and Bangladesh in 2000 and FRONTIERS/Tulane developed an "assessment form" containing 14 process indicators, 11 impact indicators and 6 contextual questions on other factors related to the studies' implementation and outcomes. These indicators are presented in Table 1 below as well as in the FRONTIERS Evaluation Manual (Marin and Bertrand, 2000). 


\section{Table 1 Indicators for Assessing the Process and Impact of Operations Research}

\section{Process Indicators}

P-1: Did the implementing/collaborating organization(s) actively participate in the design of the OR project?

P-2: Did the implementing/collaborating organization(s) actively participate in the implementation of the OR project?

P-3: Did the implementing/collaborating organization(s) participate in developing programmatic recommendations?

P-4: Did the study accomplish its research objectives?

P-5: Was the intervention implemented as planned (or with some modifications)?

P-6: Was the study completed without delays (or other adjustments to the timeline) that would compromise the validity of the research design?

P-7: Was continuity in key personnel maintained over the life of the OR project?

P-8: Was the study design methodologically sound (free of flaws that could have affected the final results)?

P-9: Was the research design feasible in the local context?

P-10: Did the implementing/collaborating organizations judge the OR technical assistance to be useful and provided in a collegial manner?

P-11: Were results of the OR study judged to be credible/valid in the local context?

P-12: Was the research relevant for the national program?

P-13: Were the results disseminated to key audiences, including policy makers, program managers, service providers, and donors?

P-14: Are the results readily available in written form?

$\underline{\text { Impact Indicators }}$

I-1: Did the results indicate that the intervention was effective (i.e., that it improved service delivery in areas identified by the OR study)?

I-2: Did the implementing/collaborating organization(s) "act on" the results (i.e., continue to implement the activities tested in the OR study after its completion if effective or not implement/discontinue this activity if ineffective)?

I-3: (If the intervention was effective and continued after the study) Were the activities tested under the intervention still observable 24 months post-implementation?

I-4: If the intervention was effective and continued after the study, was the intervention scaled up by the original implementing/collaborating organization in the same country?

I-5: If the intervention was effective and continued after the study, was the intervention adopted by another organization within the same country?

I-6: Was the intervention replicated in another country?

I-7: Was there a change in policy that can be linked to the OR project?

I-8: Did the implementing/collaborating organization conduct subsequent OR studies?

I-9: Did the implementing/collaborating organization conduct subsequent OR studies without the Population Council?

I-10: Did the original donor fund new program activities based on the results of the OR study?

I-11: Did other donors provide new or expanded funding based on results of the OR study?

\section{Contextual Factors}

C-1: Were there other factors (not mentioned above) that facilitated the conduct of the research project?

C-2: Were there other factors (not mentioned above) that facilitated the utilization of results from this operations research project?

C-3: Were there other factors (not mentioned above) that hindered the conduct of the research project?

C-4: Were there other factors (not mentioned above) that hindered the utilization of results from this operations research project?

C-5: Did USAID use the data from the OR study for a specific purpose? (Explain)

C-6: Did the study include an assessment of the costs of the intervention? 


\subsection{Data Collection and Analysis}

Two-person evaluation teams selected key informants for the case studies based on their knowledge of specific research projects and the local reproductive health context. An attempt was made to interview individuals in a variety of roles including:

- Program managers and providers in the service delivery organizations that stood to benefit from the OR;

- Policymakers and key decision-makers;

- Donor agency staff; and

- Researchers, especially Principal Investigators.

Evaluators attempted to interview a minimum of two people per study, using the Assessment Form as an interview guide, though not all key informants were equally able to respond to all indicators. Evaluators then reconciled and summarized responses to complete a single Assessment Form for each project. Each indicator was scored "yes" or "no" and an explanation provided for each indicator. The advantage of this format was that it yielded a single score on each item as well as a narrative description of the reasoning behind the score, and it ensured that each project was assessed using a standard set of questions. A complete discussion of the methodology and results can be found in Bertrand and Marin (2001).

An important recommendation arising from the case studies was to change the scoring from a simple "yes/no" to a format that allowed distinctions between those projects that demonstrated a certain characteristic only slightly, for example developing recommendations in a moderately participatory manner or acting on one of the recommendations, and those that showed more positive, conclusive results. Therefore, the following three-point scale was adopted for assessing OR process and impact:

$$
\begin{aligned}
& \mathbf{1} \text { - Slightly or not at all (up to } 1 / 3 \text { of potential) } \\
& \mathbf{2}-\quad \text { Somewhat (1/3 to } 2 / 3 \text { of potential) } \\
& \mathbf{3} \text { - } \quad \text { A great deal ( } 2 / 3 \text { to full potential) }
\end{aligned}
$$

While case studies were an efficient way of gathering information about large numbers of previously completed studies, they were less so for a prospective review of ongoing OR activities. Expanding the reporting role of field-based project monitors was considered to be a more feasible method for collecting data on a routine basis. The project monitor is generally not the principal investigator or study coordinator, but is responsible for providing technical assistance to the implementing or collaborating organization, ensuring that the study progresses according to protocol, and producing the final report. The project monitor is ideally situated, therefore, to get external input on the indicators and complete the Assessment Form. Thus, at the end of each study, FRONTIERS project monitors complete a Process Assessment Form, which they send to the Regional Associate Director who oversees all Population Council program activities in the region. After the Regional Associate Director reviews the Assessment Form and necessary revisions are made, the Form is sent to the Washington, D.C. office for review by program staff and entry into the database. Two years following the end of the project, the monitor or an appropriate substitute consults with project stakeholders, potential users of 
research results and others working in the reproductive health field to complete the Impact Assessment Form which describes how the study recommendations have been incorporated into programs and policy and provides specific evidence of use. ${ }^{1}$

All completed process and impact assessment forms were entered into an evaluation section of the FRONTIERS administrative database. The database (which is in ACCESS format) includes information on each OR study such as start and end dates, study type, substantive topics, prime monitor, and geographic location. By including evaluation data in this database, evaluation staff was able to avoid duplicating the efforts of administrative staff and ensure consistency in all background data for a particular OR study. The database also facilitated the implementation of the assessment methodology. For example, in sending out reminders to staff that an evaluation was due, it was important to know if a project's monitor changed or if the project end date had been extended, which could be ascertained with a simple query in the database. One potential use of the database that has yet to be explored is the identification of best practices for USAID or other interagency initiatives.

\subsection{Inter-rater reliability}

One of the limitations of the methodological approach used for evaluating the utilization of OR study results is that the key informants are FRONTIERS monitors; hence their assessment as to how the findings of OR studies have been utilized may be considered somewhat subjective. To address this issue, FRONTIERS/Tulane undertook a study of inter-rater reliability for a subsample of FRONTIERS studies in 2003. Only process assessments were included, as an insufficient number of projects had been completed two years prior to include impact assessments. The assessment of the consistency and level of agreement between raters was based on twenty-four studies in thirteen countries.

With the assistance of FRONTIERS field staff, FRONTIERS/Tulane identified three key informants for each of 40 projects. Key informants were:

- Project staff hired locally by the Population Council;

- Members of the implementing or collaborating organizations, including researchers, administrators and service providers; and

- Other decision-makers or stakeholders knowledgeable about study design and implementation.

Questionnaires in English, French and Spanish were sent directly to respondents and returned via e-mail or fax. As the assessment of inter-rater reliability was a FRONTIERS initiative, it was possible to obtain a one hundred percent response rate from Population Council staff. Ninetytwo other key informants were contacted, of whom only 38 responded.

\footnotetext{
${ }^{1}$ If the project monitor was unavailable (having left the country or changed jobs, for example), the Regional Associate Director and Washington, D.C. program staff jointly identified an alternate who was familiar enough with the project and local context to consult with key informants and complete the Impact Assessment Form.
} 
The weighted kappa statistic was used to assess inter-rater reliability for each of the 15 process indicators (see Appendix B for a more detailed description of the methodology and results). Overall, there was a moderate to high level of consistency in the ratings of the process indicators, with 50-91 percent of agreement between the raters for the same study (see Figure 1). The highest level of consistency is observed for the following indicators:

(a) The implementing/collaborating organization(s) actively participated in study implementation (P-2);

(b) The OR technical assistance (TA) provided by the Population Council was useful and collegial (P-10);

(c) The study results were judged to be credible/valid in the local context (P-11); and

(d) The research was considered relevant for the national program (P-12).

The lowest level of consistency was for the indicator reflecting whether the results were available in written form and could point to issues surrounding the dissemination of hard copies of the study report.

\subsection{Characteristics of the Sample}

Table 2 presents the characteristics of the studies that are included in the assessment of the process and impact of OR. Studies cover a range of substantive topics including communitybased distribution, communication, community participation, introduction of contraception, female-genital cutting, STID and HIV/AIDS. Over half of the studies focused on the following programmatic areas: quality of care, youth, postpartum care and contraception. Over 70 percent of the studies analyzed were intervention studies and 87 percent contributed to intermediate result (IR)-1 of the FRONTIERS project, which is "Innovative Research". Thirty-six percent of the studies were conducted in Latin America, a third in Asia/Near East and 26 percent in Africa. 
Figure 1 Percent of OR Projects Assigned the Same Rating by Process Indicator

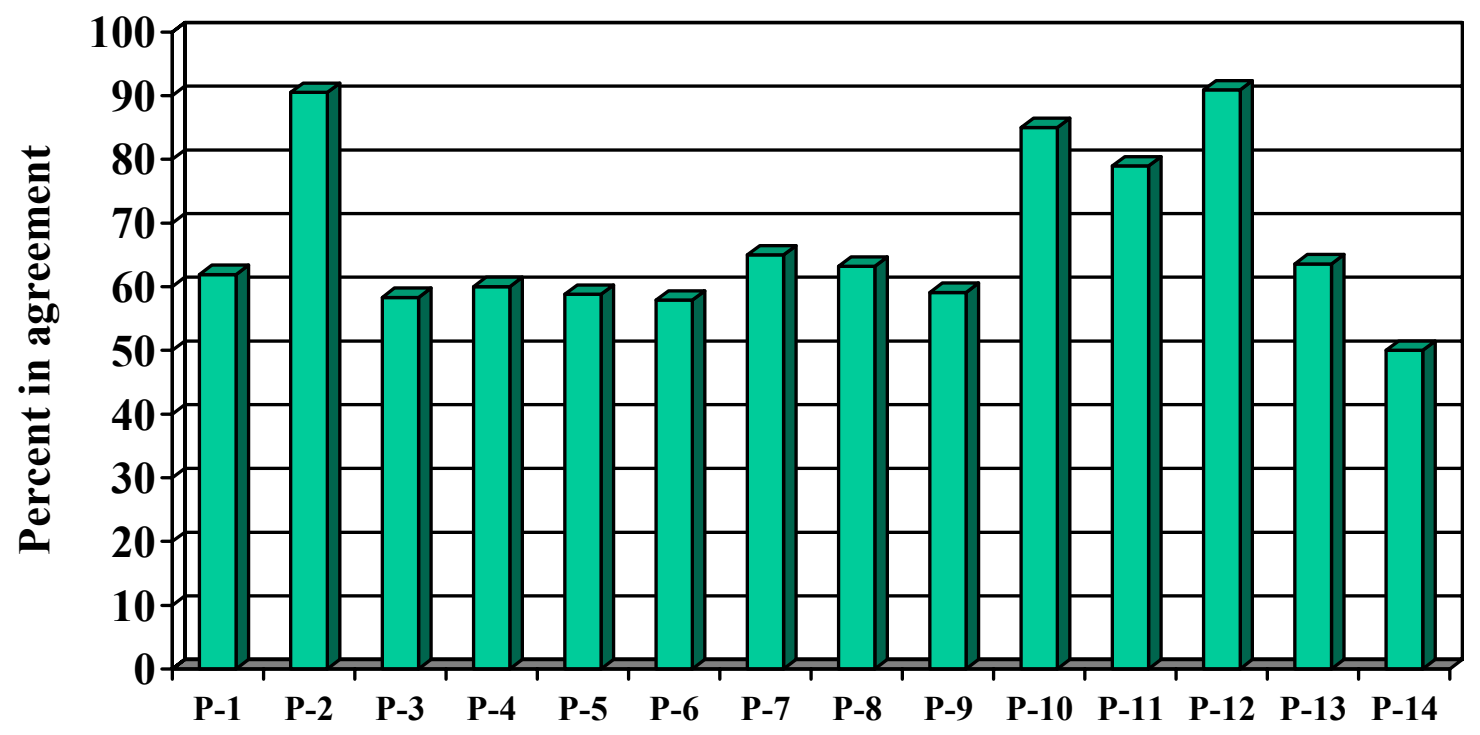

P-1 Participation in design

P-2 Participation in implementation

P-3 Participation in recommendations

P-4 Objectives accomplished

P-5 Intervention implemented as planned

P-6 No delays

P-7 Continuity in key personnel

P-8 Methodologically sound design

P-9 Feasible research design

P-10 Technical assistance

P-11 Credible/valid results

P-12 Research relevant

P-13 Results disseminated

P-14 Written report available 
Table 2 Characteristics of Studies Included in the Process and Impact Assessments

\begin{tabular}{|c|c|c|c|c|}
\hline & \multicolumn{2}{|c|}{ Process } & \multicolumn{2}{|c|}{ Impact } \\
\hline & $\begin{array}{l}\text { Number of } \\
\text { Studies }\end{array}$ & $\begin{array}{c}\text { Percentage } \\
\text { of } \\
\text { Studies } \\
\end{array}$ & $\begin{array}{l}\text { Number of } \\
\text { Studies }\end{array}$ & $\begin{array}{c}\text { Percentage } \\
\text { of } \\
\text { Studies } \\
\end{array}$ \\
\hline \multicolumn{5}{|l|}{ Substantive Topic } \\
\hline CBD & 2 & 3 & 2 & 4 \\
\hline Communication & 5 & 7 & 3 & 6 \\
\hline Community Participation & 2 & 3 & 2 & 4 \\
\hline Contraceptive Introduction & 6 & 10 & 5 & 11 \\
\hline Economic Evaluation & 4 & 7 & 3 & 6 \\
\hline Female Genital Cutting & 2 & 3 & 1 & 2 \\
\hline STI and HIV/AIDS & 3 & 5 & 3 & 6 \\
\hline Male Involvement & 3 & 5 & 2 & 4 \\
\hline Postabortion Care & 4 & 7 & 3 & 6 \\
\hline Postpartum & 8 & 14 & 6 & 13 \\
\hline Quality of Care & 10 & 17 & 8 & 17 \\
\hline Service Utilization & 2 & 3 & 1 & 2 \\
\hline Youth & 8 & 14 & 8 & 17 \\
\hline \multicolumn{5}{|l|}{ Study Type } \\
\hline Intervention & 38 & 66 & 36 & 77 \\
\hline Evaluation & 14 & 24 & 11 & 23 \\
\hline Technical Assistance & 2 & 3 & 0 & 0 \\
\hline Diagnostic & 4 & 7 & 0 & 0 \\
\hline \multicolumn{5}{|l|}{ IR Category } \\
\hline IR 1 - Innovative research & 49 & 83 & 41 & 87 \\
\hline $\begin{array}{l}\text { IR } 2 \text { - Dissemination \& } \\
\text { Utilization }\end{array}$ & 5 & 9 & 3 & 6 \\
\hline $\begin{array}{l}\text { IR } 3 \text { - Capacity Building \& } \\
\text { Economic Evaluation }\end{array}$ & 4 & 7 & 3 & 6 \\
\hline \multicolumn{5}{|l|}{ Geographic Region } \\
\hline Africa & 15 & 26 & 12 & 26 \\
\hline Asia Near East & 21 & 36 & 15 & 32 \\
\hline Europe \& Eurasia & 3 & 5 & 3 & 6 \\
\hline Latin America & 19 & 33 & 17 & 36 \\
\hline TOTAL & 58 & $100 \%$ & 47 & $100 \%$ \\
\hline
\end{tabular}




\subsection{Results}

The indicators used for assessing FRONTIERS projects fall into two main categories: the implementation process and impact. Findings regarding the implementation of FRONTIERS studies are presented in several ways in this section:

- First, the overall result for each indicator (expressed as the number of projects of the total reviewed that receive the highest score, that is, a value of 3 ) is presented as a bullet, in bold. Although 59 studies had completed process assessments, the denominator for "total number of studies" drops as low as 49 in those cases where information was unavailable or the question is not applicable (e.g., not technical assistance was provided).

- Second, a bar graph shows the breakdown of scores on each process indicator. Each project is scored on each indicator using a scale of one to three, and the graphs allow the reader to distinguish between those studies that performed well (3), those that performed satisfactorily but with notable problems (2), and those that did not perform satisfactorily on the relevant indicator (1).

- Third, after each graph we have provided a more qualitative assessment of the point, including direct quotes from Process Assessment Forms. Unless otherwise specified, all quotes are taken from assessments by FRONTIERS staff who were either prime study monitors or regional staff with sufficient involvement in the study to provide relevant information. In order to preserve confidentiality, precise identifying information may not be given.

Within the broad categories of process and impact, certain indicators cluster naturally and have been combined to present a clearer picture of patterns of utilization of OR results. These groupings will be discussed in subsequent sections. We also collected data on six contextual factors, but rather than presenting them in the same format as the process or impact indicators, we have woven them into the text where they are relevant, most notably in the discussion of factors influencing the utilization of OR results. The contextual factors are not used to "rate" a project per se but to enhance our understanding of specific circumstances and factors beyond the control of program managers and researchers that affect a study's implementation and utilization of its results.

In general, OR studies performed well on the process indicators, particularly those related to the participation of study partners and acceptability of research topics and approaches. The projects assessed had somewhat lower levels of continuity in key personnel or timely completion, and more than one-third had had only limited dissemination of study results by the time of the assessment.

\subsubsection{Process of Study Implementation}

\subsubsection{Participation}

- In 39 out of 58 studies (67\%), the implementing organizations actively participated in the design of the study. 
- In 52 out of 58 studies (90\%), the implementing agencies actively participated in the implementation of the study.

- In 47 out of 58 studies ( $81 \%$ ), the implementing organization actively participated in developing programmatic recommendations.

Figure 2 Scores on indicators measuring participation of implementing and collaborating organizations in different phases of the research process

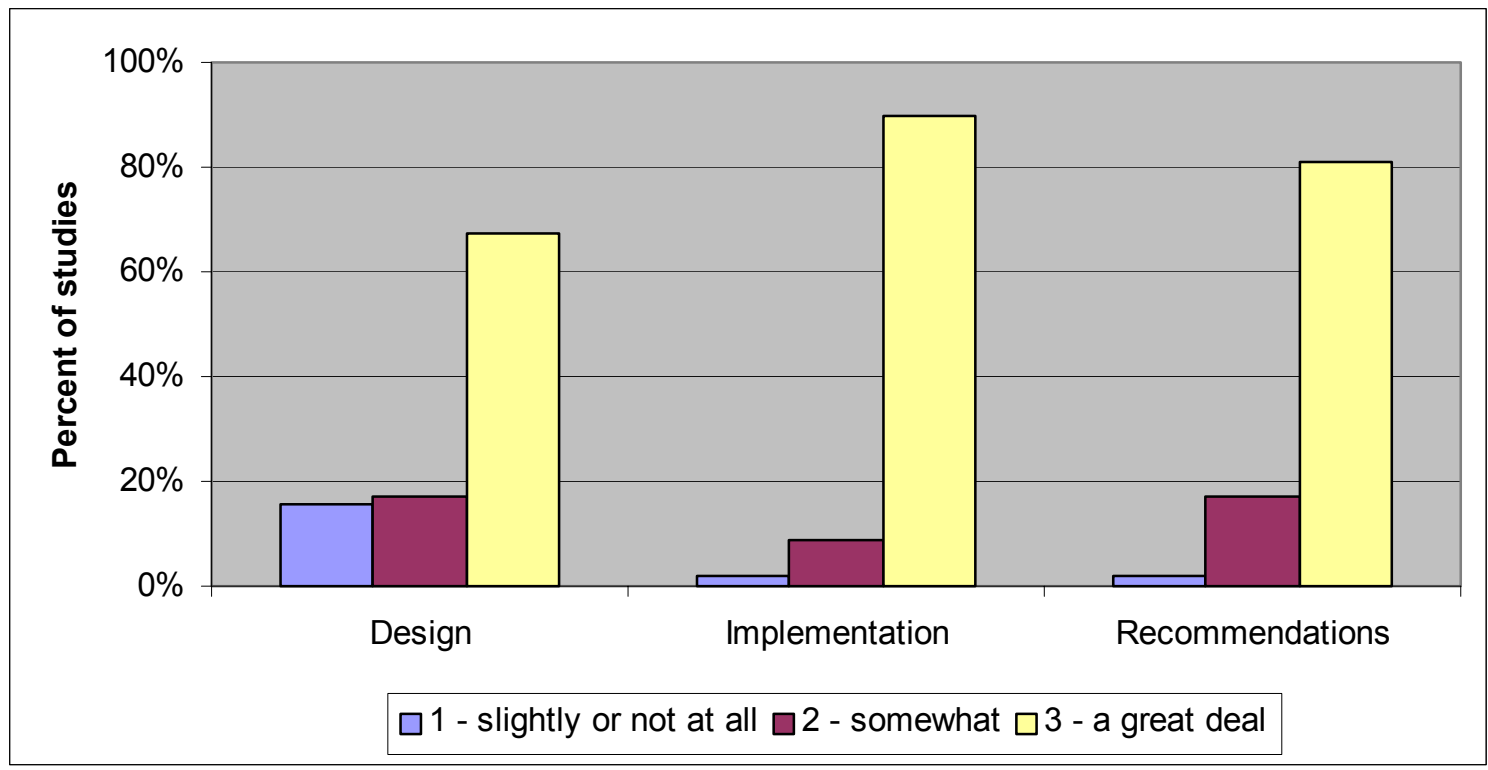

As Figure 2 shows, FRONTIERS studies had high levels of participation by local service delivery and research counterparts at all stages. In the project design phase, participation often took the form of identifying program problems or research questions, securing official permission to conduct the study, or serving on a technical committee to plan the study and later review its progress during implementation. In several cases, Population Council researchers proposed a study design to the partners, who then had the opportunity to give feedback and make modifications, as described in the quote below from an assessment of a project in the West Bank/Gaza.

FRONTIERS staff tried to involve West Bank/Gaza partners in developing the studies' design, but found out that this process is very time consuming and partners lack technical capacity needed. However, FRONTIERS staff were keen to answer all questions and comments raised by implementing agencies on studies' design, and even provided some more details and justification in order to promote capacity building.

The nine studies receiving the lowest scores on participation in the design phase were in Asia Near East and Latin America, and included both interventions and evaluations. Nearly all of these studies began in the first two years of FRONTIERS. 
The majority of studies were implemented by a partner organization, with FRONTIERS providing research technical assistance. Implementing organizations developed instruments and materials, provided services, and trained and supervised personnel. In his assessment of the Global Agenda adolescent study in Kenya, the monitor described the important role played by one of the implementing agency staff.

One of the main factors influencing the success of this project was the work of the on-site data manager. He managed all of the survey work ... and his efforts helped to ensure that data collection activities were done correctly and on schedule.

Many implementing organization collaborators also collected and analyzed data, and prepared or contributed to reports and presentations of findings. An informant from a local counterpart organization in South Africa credited "teamwork and emphasis on buy-in at the local level with all role players" for the accomplishment of study objectives, despite substantial initial challenges.

Most implementing organizations had an active role in developing programmatic recommendations based on the research findings, either as a part of writing the final report or at a dissemination workshop. A FRONTIERS monitor in Kenya provides an example below.

To ensure participation of the collaborators and other stakeholders in Kenya, a series of workshops and small group meetings were organized to interpret data, present study findings and develop programmatic recommendations. [Kenya NGO] MYWO and PATH staff participated in these workshops and meetings and one small group meeting specifically targeted MYWO staff.

\subsubsection{Barriers}

- In 41 out of 58 (71\%) studies, the research design was feasible in the local context.

- In 33 out of 58 cases (57\%), the study was completed without delays (or other adjustments to the timeline) that would compromise the validity of the research design.

- In 35 out of 58 studies $(60 \%)$, there was continuity in key personnel over the life of the project.

Figure 3 provides some insight into the proportion of studies that experienced some barrier at the implementation stage. When the set of indicators was being refined following the case studies, a suggestion was made to drop P-9 ("Was the intervention feasible in the local context?") because, presumably, studies that are not feasible would not be implemented. However, this indicator was retained. The studies analyzed showed that while that conclusion was somewhat true - no study received the lowest score on this indicator-there were occasionally unanticipated circumstances that led to complications in a study that had seemed feasible when designed. For example, an earthquake in Gujarat, India made it impossible for researchers to follow up on a large proportion of women in a panel study on DMPA, and runaway inflation caused CEMOPLAF in Ecuador to indefinitely postpone a willingness-to-pay study. An extreme example was the resumption of violence in West Bank/Gaza in 2000 while seven studies had yet to be completed. All of these 
projects were excluded from the impact assessment for obvious reasons (although all but the CEMOPLAF study were completed).

Figure 3 Scores on indicators measuring absence of barriers to research implementation

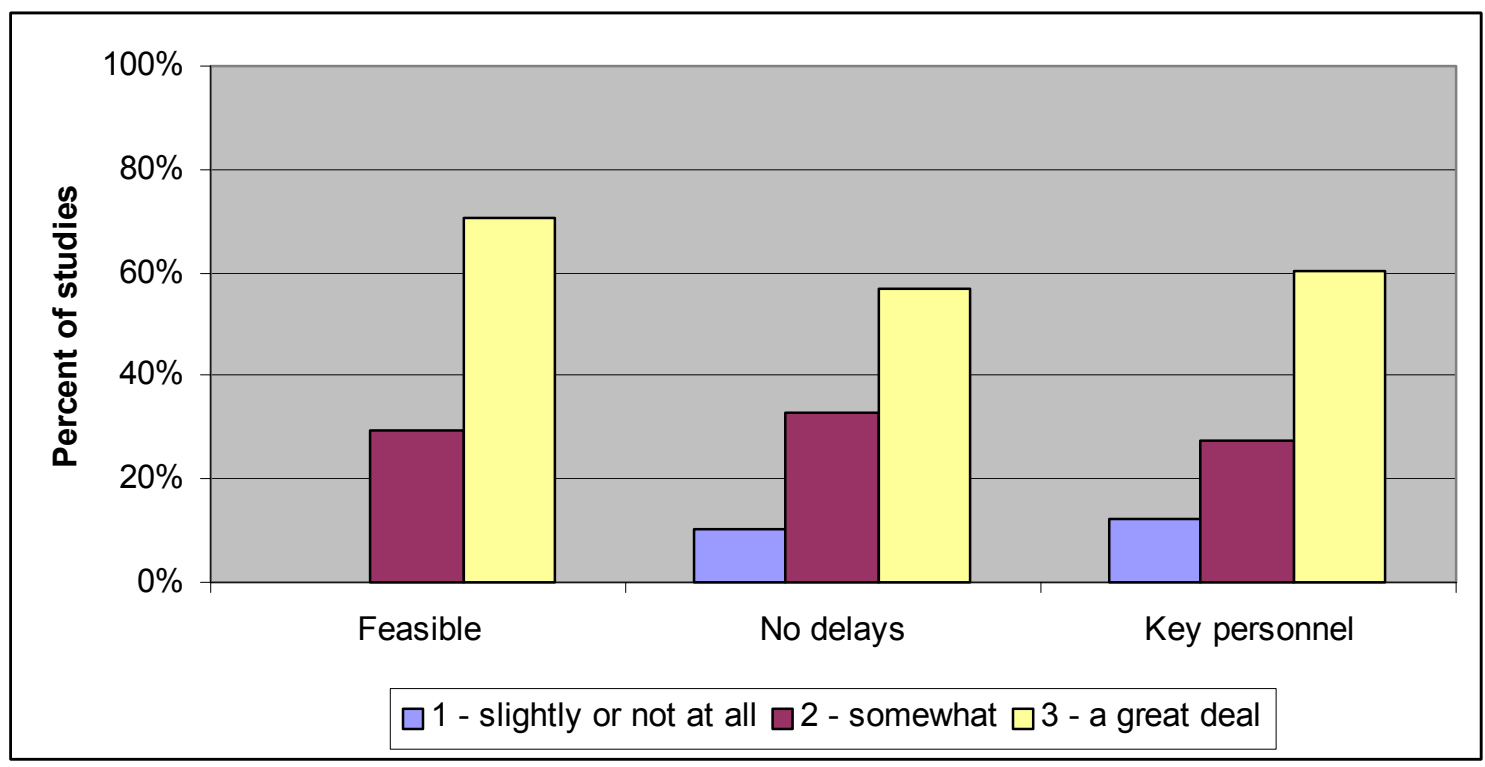

A number of other studies had less dramatic challenges to feasibility, more often related to specific aspects of an intervention or data collection. The next quote describes a situation where an unanticipated cultural barrier prevented researchers from obtaining the data needed to accomplish all the studies objectives. Rather than rely on inadequate data to draw conclusions, the researchers chose to leave the relevant objective out of the final analysis of this study on female genital cutting (FGC) in Kenya.

Apart from assessing the cost of the Alternative Rites interventions in the study sites, the study accomplished all the other objectives. At the early stages of data collection, it was observed that MYWO staff [members] were not comfortable providing cost information and this focus ... was abandoned due to incomplete data.

The Global Agenda studies, which employed a single study design for multiple single-country studies on youth, client-provider interaction and men in maternity care, illustrate some of the feasibility problems that arise from imposing a standard design in varied contexts. Despite a considerable amount of local adaptation in every case, a number of non-FRONTIERS key informants complained that the designs were too rigid, as the following comment from one counterpart demonstrates:

The conceptual framework was not flexible enough to allow for cross-sector collaboration. It was insufficient for adapting to, for example, new resources or strategic changes resulting from problems in the intervention sites. 
However, over two-thirds of studies experienced minimal or no problems in terms of feasibility. A typical response to this indicator was:

The design was feasible as it was developed by the local implementing organization with (the) assistance of a local consultant who understood the program operations and the socio-cultural and political context within which the study was to take place.

The dedication of key personnel was often cited as an important factor contributing to feasibility. A FRONTIERS monitor in Senegal noted:

Participation by the head nurse at each post, despite many difficulties, contributed greatly to project implementation.

A great number of FRONTIERS studies experienced delays, but delays in data analysis, report preparation and dissemination were more common than delays that might have had a negative impact on the validity of the research. The most common scenario involving a change in timeline that threatened the validity of the research design was a delay in the start-up of the intervention, which later required a rush to complete the study on time, perhaps cutting the intervention short, or evaluating its effects after too little time had elapsed.

Changes in key personnel occurred at Population Council offices, partner organizations and among other stakeholders such as Ministry of Health officials. Many of the transitions were smooth, although some were not, as the two contrasting quotes below testify.

The principal investigator and principal research assistant remained through the project's end. At the MOH, however, there were changes. While the same program director remained throughout instrument design, data collection, and preliminary analyses, there were more than five turnovers thereafter. The length of the project and political instability combined to cause this situation.

The Research Supervisor dropped out when the study was approaching its completion. However, all other team members, including the Team Leader continued working on this study through all phases of study implementation. The Team Leader was much more involved in this study's activities in particular, and therefore the study's implementation wasn't much affected by absence of the Research Supervisor at the later phases of the study.

\subsubsection{Acceptability}

- In 40 out of 54 studies (74\%), the results were judged to be credible and valid in the local context.

- In 50 out of 56 studies (89\%), the research was judged relevant for local program managers.

- In 44 out of 48 studies (92\%), the counterparts in the implementing agencies judged that the technical assistance was useful, methodologically sound, and provided in a collegial manner. 
Figure 4 Scores on indicators measuring acceptability of research

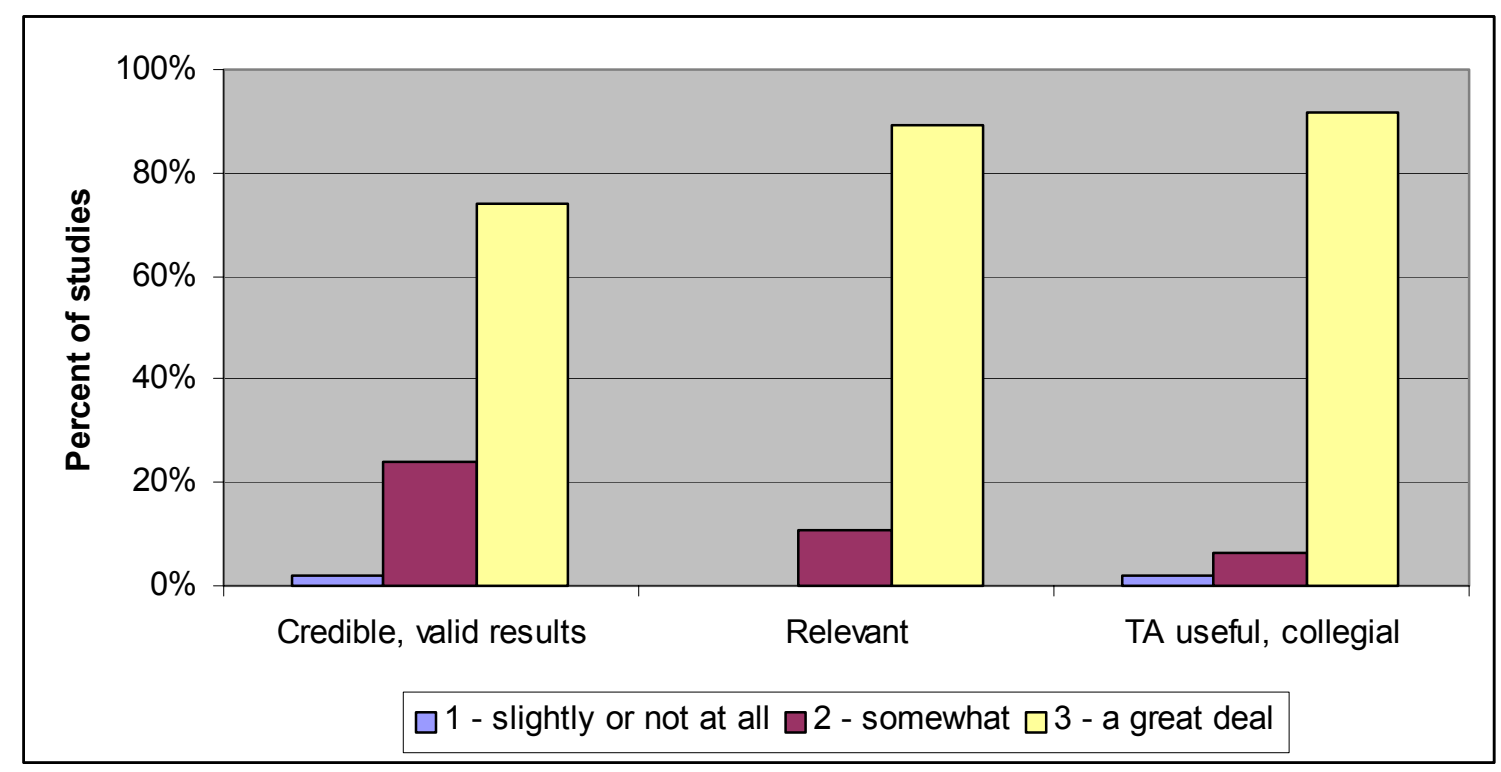

Figure 4 presents the distribution of scores on indicators measuring the acceptability of the research. The importance of researching a problem that is considered relevant in the local context is well understood by FRONTIERS staff; all studies were considered at least somewhat relevant to the national program, with most considered highly relevant. This quote from the Kenya Global Agenda youth study describes the study's relevance to numerous stakeholders.

Each of the three ministries (involved), and particularly the Ministry of Health, has expressed much interest in learning more about the results and their implications for the specific ministries. When the project started, both the Ministries of Health and Education had very restrictive policies on which adolescent $R H$ issues could be addressed and how. This study has given each ministry indications of ways to work within these policies creatively.

High scores on acceptability indicators are closely related to the collaborative process of study design and implementation. The country case studies described a "halo effect" for Population Council research, where results were often considered valid because of the organization rather than an individual study's merits. This was somewhat evident with FRONTIERS studies as well, in assessments by both Population Council staff and external informants. However, many monitors and informants mentioned study-specific factors that contributed to the credibility of results.

The results were judged to be serious and scientifically valid by internal and external standards because of the collaboration, the methodology, and the consideration of real community needs with socio-cultural and technical conditions in mind. External observers have deemed them credible. 
Conversely, when credibility or validity of findings was doubted, it was often related to unique contextual factors, as described below:

Since [the findings] did not show much impact, there is a reluctance to accept them. Those who are new to the program do believe in them, those who were during most of the project and are not already with [the program] don't believe in the results. The problem is that the research showed the interventions to be ineffective. It is easier to cast doubt on the research than on your beloved program.

The technical assistance indicator was much criticized as being the most biased in the assessment approach: FRONTIERS monitors who provide the technical assistance are asked to rate the implementing organization's impressions of its technical competence as well as whether it was provided in a collegial manner. While a number of monitors did note the presence of tension in relations, only one questioned whether the TA was sufficient. Others said they were unable to provide a score or that the organization did not receive sufficient technical assistance to judge (this was true for a number of small grants as well as other studies) which accounts for the lower denominator on this indicator than the others. Despite these limitations, the analysis of interrater reliability demonstrated that assessments by Population Council staff and external informants were quite consistent on this indicator. Most monitors provided some qualification for positive scores, such as this quote from a study in Senegal:

SNSR [The Ministry of Health Reproductive Health Unit] strongly felt that the OR technical assistance was very useful and provided in a collegial manner. When asked about this indicator, the informant said "This activity was a team work from the start to the end. The planning workshop gave the opportunity to the regional health staff not only to improve their computing skills, but also to propose indicators to include in the data analysis and to participate in the definition of regional workshop agendas and its implementation process".

\subsubsection{Research Quality}

- In 43 out of 58 cases (74\%), the study accomplished the research objectives.

- In 41 out of 57 studies (72\%), the study design was judged to be methodologically sound (free of flaws that could have affected the final results).

- In 27 of the 51 studies (53\%), the intervention was implemented as planned (or with some modifications).

Maintaining a balance between rigorous scientific methods that stand up to international peer review and feasible study designs and analysis plans given available resources has often been a challenge to operations research programs. Sophistication of study designs and analysis plans varied according to setting as well as according to researcher and stakeholder interests and experience. Some complex designs were implemented in locations with more mature national programs, while more modest diagnostic and evaluative studies were considered more 
appropriate in other areas. The distribution of scores on indicators measuring perceived research quality shows that a higher proportion of studies scored the maximum on "sound research design" and "accomplished objectives" than on "implemented as planned".

\section{Figure 5 Scores on indicators measuring perceived quality of research}

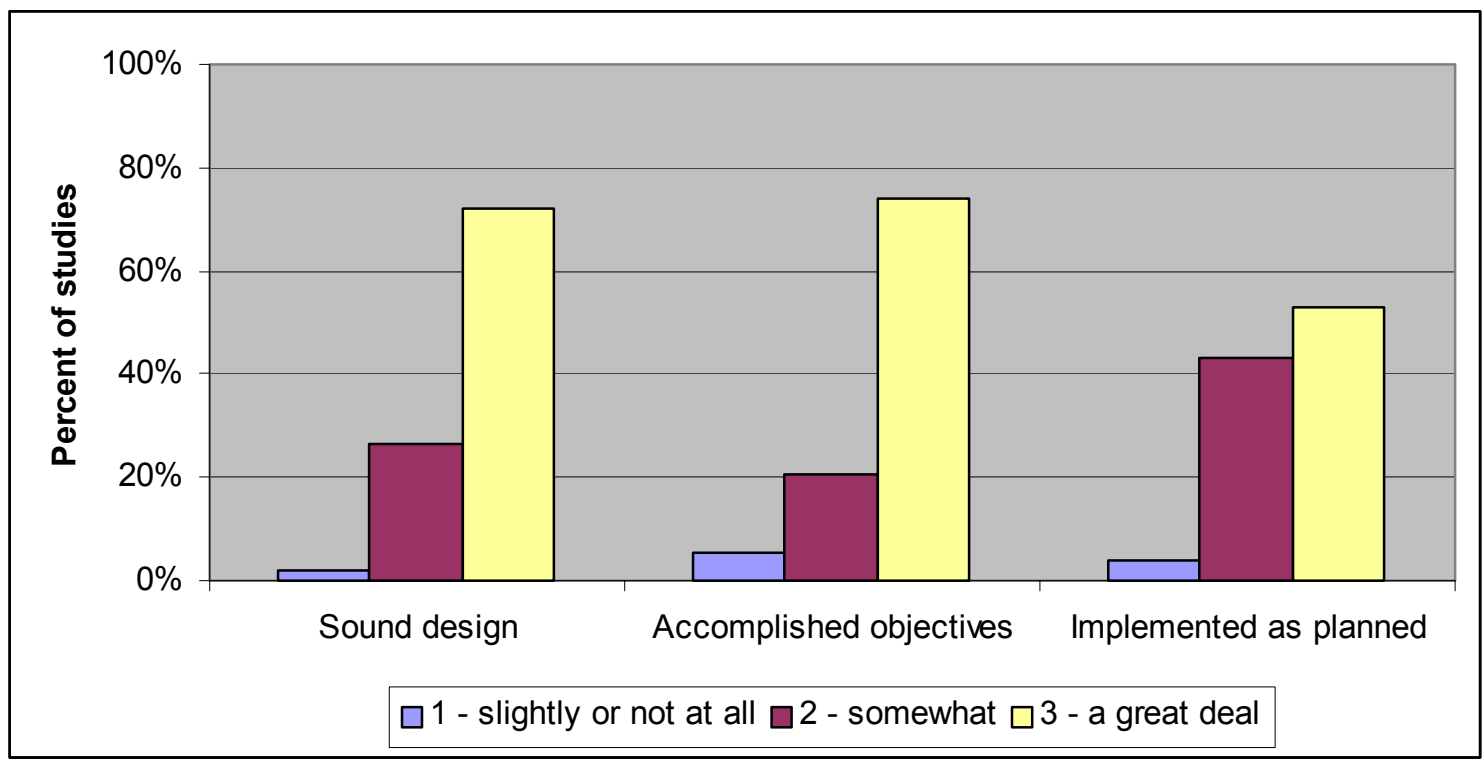

FRONTIERS staff generally tried to employ quasi-experimental designs but sometimes faced constraints such as limited capacity of local partners, or pressure to meet the demands of donors and other stakeholders expecting prompt responses to their questions or having political or practical reasons for selecting certain sites as intervention and others as control areas. Such constraints were often compounded by inadequate management information systems (MIS) requiring upgrading as part of a study.

Some stakeholders wanted to answer multiple questions and develop ambitious interventions that which would require complex study designs and sophisticated statistical techniques. Even relatively simple designs sometimes ran into problems related to weak MIS or data collection. Following is one example among many where the respondent mentioned potential or actual problems with contamination.

It was difficult to control for instrumentation effects as subjects learned from interviews; also there may have been contamination as people moved from study group to study group.

Partner organizations do not always understand study designs requiring a control area, and thus their staff may not adhere to the design strictly if they feel there is a need that can be filled in the control area, as expressed in this quote from the Global Agenda adolescent study in Mexico: 
[The intervention] was feasible and it was already being conducted. However, for [Mexican NGO] MEXFAM it made little sense to stop working in schools. As it turned out, they didn't completely stop until the second year. Doing this was difficult for them, because since the federal curriculum had just been introduced, many schools were interested in receiving technical assistance from MEXFAM and MEXFAM's staff felt that not responding to these requests was costly in terms of their standing in communities.

Such situations might be avoided through participatory planning and study design, so that program goals are addressed in the short term without compromising longer-term research goals. One FRONTIERS researcher described the importance of a design that is mutually agreeable and understood:

The understanding of program staff about the research project-if the implementing agency can differentiate "What is research" and "What is program"-is the biggest facilitating factor for a research project.

Accomplishing objectives was greatly influenced by the feasibility of the research study. All of the studies where the interventions were fully implemented accomplished at least some of the research objectives, while most accomplished all. (It is important to note that accomplishing research objectives does not necessarily mean that the intervention was successful.) Most of the objectives that were not achieved were related to cost assessments; many monitors mentioned problems obtaining or analyzing cost data, which points to a need to develop the capacity of researchers and programs in economic evaluation. Another type of objective that several FRONTIERS studies had difficulty accomplishing was measuring long-term outcomes, for example contraceptive continuation or repeat abortions after one year.

The third indicator in this group, "The intervention was implemented as planned," attempted to measure the strength of the intervention. Changes between the proposal and implementation of the intervention frequently occur and often are for the better. Rather than penalize an organization for making modifications, the indicator seeks to ascertain that some meaningful change was made in service delivery (that there was "something to evaluate"). When an intervention study fails to show any change in the desired outcome, there are two plausible reasons: (1) the intervention was never implemented or it was implemented so weakly that the study hardly constituted a fair test of its potential effectiveness, or (2) the intervention was fully implemented but failed to show the expected results. This indicator attempts to eliminate the first possibility by determining that all of the activities specified in the intervention were carried out, allowing for some change in response to local realities. As such, the indicator was considered "not applicable" to many evaluative studies, in particular evaluations of full-scale national programs.

\subsubsection{Dissemination}

- In 36 out of 57 studies (63\%), results were disseminated to key audiences, including policymakers, program managers, and service providers by the project end date. 
- In 32 out of 56 studies (57\%), results were readily available in written form to interested local audiences at the study's end.

Figure 6 Scores on indicators measuring dissemination

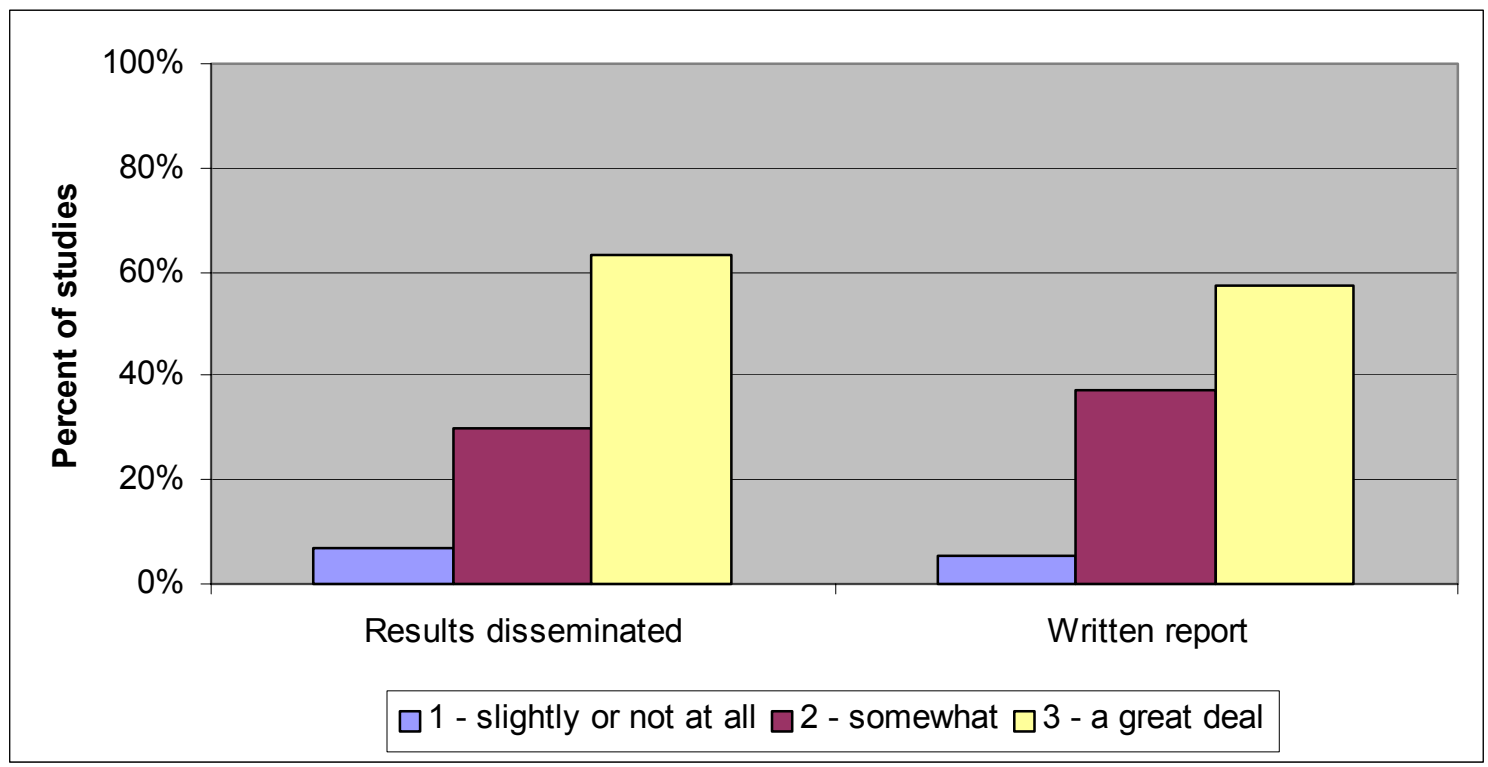

All the projects analyzed had an English final report and virtually all had disseminated results locally. The seemingly low scores for the two dissemination indicators reflect the timing of dissemination: some process assessments were conducted before one or both activities were completed (that is, local dissemination and production and distribution of the English report; therefore many monitors scored the responded "somewhat" as opposed to "a great deal" (see Figure 6). However, from a utilization perspective, it does point to potential shortcoming: that is, if research results are not available in a timely manner, policymakers may find them less useful, a case described by one monitor below:

Timing for producing the final report. This study was a joint collaboration effort with FHI, and timeline communication missed during the analysis phase; Vision of analysis differs between both institutions (OR vision versus academic vision). This creates a very long time for producing the final report. Partners' interest decreased. Activities on utilization that should be conducted were delayed.

The four projects that reported no dissemination were cases where a deliberate decision was taken to limit dissemination. Such decisions were made, for example, where implementation barriers raised questions about the validity of the research results.

A half-day workshop with study participants and members of the reproductive health community to jointly develop recommendations was the standard end-of-project dissemination activity for FRONTIERS studies. However, researchers increasingly used other methods to communicate results to key audiences. Some, for example, conducted small group meetings with $\mathrm{MOH}$ or 
staff meetings at service delivery points. Others used participatory techniques to reach potential beneficiaries, such as those described in the quote below from Kenya.

The interventions were developed to be feasible within the existing ministry structures and community representatives were consulted to ensure that social norms concerning this sensitive issue were appropriately addressed. When presented at the community, district and national levels, the way in which the results were communicated to the different audiences was individualized so as to be viewed as credible and understandable. For example, at the community level, theatre groups were used, whereas at district and national levels, representatives from the ministries who had been involved in the project made presentations.

Again, high levels of participation by partner organizations facilitated dissemination, as described in this quote from a researcher at the Reproductive Health Research Unit in South Africa, among others.

\section{Excellent relations already existed between the RHRU and all of the collaborating organizations, and this helped not only in implementing the study but also in disseminating the results}

The variety of written materials available has expanded as researchers recognize that busy policymakers and administrators prefer a two-page summary with graphs that succinctly explain the research findings to a full project report. FRONTIERS centrally produces a two-page OR Summary for international and U.S. dissemination most intervention and evaluation studies. Most field offices or partners also prepare briefs or bulletins highlighting results and recommendations in a simple format in the local language, sometimes at several key points during study implementation. Some studies have led to the publication of behavior change communication (BCC) materials for the community-for example, describing the rights of clients related to informed consent in choosing a contraceptive.

\subsubsection{Composite Process Indices}

As was previously discussed, the process indicators cluster naturally around certain critical components of the OR process: participation, lack of barriers to study implementation, acceptability, perceived research quality, and dissemination. In order to develop an analytical framework, we constructed five indices around these components of the OR process. Each index consists of three variables (with the exception of dissemination, which has only two variables) and is calculated by counting the number of responses of " 3 - a great deal" for those indicators. A score of 3 on a process index (or 2 for dissemination) is considered "high" while all other scores are considered low. ${ }^{2}$ Table 3 below shows the components of each index and the percent distribution of the OR studies assessed.

\footnotetext{
${ }^{2}$ We chose this approach rather than using the mean of the three indicators because the mean did not discriminate between high- and low-scoring studies on any index.
} 
Table 3 Percent distribution of studies by process index

\begin{tabular}{|c|c|c|c|}
\hline Index $(n=58)$ & High & Low & Missing \\
\hline $\begin{array}{l}\text { Participation Index } \\
\text { - } \quad \text { Participation in design } \\
\text { - } \quad \text { Participation in implementation } \\
\text { - } \quad \text { Participation in developing recommendations }\end{array}$ & 62.1 & 37.9 & 0 \\
\hline $\begin{array}{l}\text { No-barrier Index } \\
\text { - } \quad \text { Research design was feasible } \\
\text { - } \quad \text { Study completed without delays } \\
\text { - } \quad \text { Continuity in key personnel }\end{array}$ & 31.0 & 69.0 & 0 \\
\hline $\begin{array}{l}\text { Acceptability Index } \\
\text { - } \quad \text { Results were credible/valid in local context } \\
\text { - } \quad \text { Research was relevant to national program } \\
\text { - } \quad \text { TA judged useful, sound and collegial }\end{array}$ & 46.6 & 27.6 & 25.9 \\
\hline $\begin{array}{l}\text { Perceived Research Quality Index } \\
\text { - } \quad \text { Research objectives accomplished } \\
\text { - } \quad \text { Methodologically sound design } \\
\text { - Intervention was implemented as planned }\end{array}$ & 32.8 & 53.4 & 13.8 \\
\hline $\begin{array}{l}\text { Dissemination } \\
\text { - } \quad \text { Results disseminated to key decision makers } \\
\text { - Written report available }\end{array}$ & 52.7 & 47.3 & 0 \\
\hline
\end{tabular}

Low to medium correlations were observed between the process indices that we constructed. As Table 4 shows, the highest correlation was obtained between the perceived research quality index and the no-barrier index $(\mathrm{r}=0.338)$, followed closely by the correlation between perceived research quality and dissemination $(\mathrm{r}=0.333)$. This implies that the indices are measuring somewhat different aspects of the OR process. Interestingly, the correlations between the participation and no-barrier indices, and between participation and acceptability, were negative, though not large.

Table 4 Correlations between OR process indices

\begin{tabular}{|l|c|c|c|c|c|}
\hline & Participation & No barrier & Acceptability & $\begin{array}{c}\text { Research } \\
\text { quality }\end{array}$ & Dissemination \\
\hline Participation & 1.000 & & & & \\
\hline No barrier & -.013 & 1.000 & & & \\
\hline Acceptability & -.104 & .157 & 1.000 & & \\
\hline Research quality & .165 & $.338^{*}$ & .064 & 1.000 & \\
\hline Dissemination & .193 & .040 & .097 & $.333^{*}$ & 1.000 \\
\hline
\end{tabular}

$* \mathrm{p}<.025$ 


\subsubsection{Impact of OR Studies}

Seven main types of utilization were examined.

1. Application of results and recommendation to improve service delivery programs

2. Scaling up of the intervention tested by the original organization

3. Replication of the intervention by another organization

4. Change in national or organizational policy

5. Availability of new funding to continue intervention activities

6. Use of results and recommendations by USAID Mission

7. Improvement of organizational capacity for research or evidence-based decisionmaking

Results are presented somewhat differently in this section from the previous. Under each type of utilization, a graph shows how FRONTIERS studies performed overall and offers some comparisons of performance by project end date and study type. Studies ending in the first three years of FRONTIERS are compared to those ending in the last two year (most of which ended less than one year prior to assessment) to see if the shorter time lapse represents decreased utilization. Studies are also separated into: (a) Global Agenda, (b) Small Grant, and (c) Regular (i.e., all other) studies because these study types had dramatically different implementation strategies. Small Grants were largely simple intervention studies implemented entirely by partner organizations, with limited technical assistance and monitoring from FRONTIERS. The Global Agenda studies, in contrast, tested a new approach to conducting OR by employing a standard intervention across countries. They benefited from a great deal of investment in coordination and stakeholder buy-in and had multiple, complex interventions. "Regular studies" encompasses all other studies. They do not form a homogenous group, but were developed individually at the country level by FRONTIERS staff and local partners. Following the graph, each section has a description of general trends across the portfolio and some specific examples of how FRONTIERS results and recommendations have been utilized.

The sample of studies in the impact assessment differs slightly from that of the process assessment. The process assessment included four projects that were essentially diagnostic studies or "desk review" evaluations, whose impact would not be appropriately assessed using this set of indicators. In addition, we excluded three studies where the intervention was not fully implemented and four studies in West Bank/Gaza because, given political circumstances, we considered it unreasonable to expect their results to be utilized in a manner comparable to the other studies. Finally, one study in the process assessment ended July 31, 2003, beyond the cutoff date of June 7, 2003, the end of the first five years of FRONTIERS.

While the methodology is based on a two-year-post assessment of utilization, we assessed studies that had been completed as little as nine months ago for several reasons. First, we wanted to present a complete picture of the portfolio of a five-year OR program, but threequarters of the projects ended within the last 24 months of this period. Second, many of the more recently completed studies already showed relatively high levels of utilization, and we did not believe that their inclusion would skew the overall rates of utilization when compared with earlier studies. Because so few studies were completed for as long as two years, we have not included sustained change as a utilization outcome in this report, although we consider this to be an important part of the potential impact of OR. 


\subsubsection{Program Improvement}

- In 44 out of 47 studies (94\%) the local implementing partner acted on study results and recommendations to improve service delivery.

Although the intensity of the intervention sometimes decreased after the research ended, the vast majority of programs either continued the intervention tested, or modified or reoriented their services based on the evaluation. As Figure 7 shows, levels of utilization did not vary substantially by study end-date or type.

Figure 7 Percent of studies leading to program change, by study characteristics

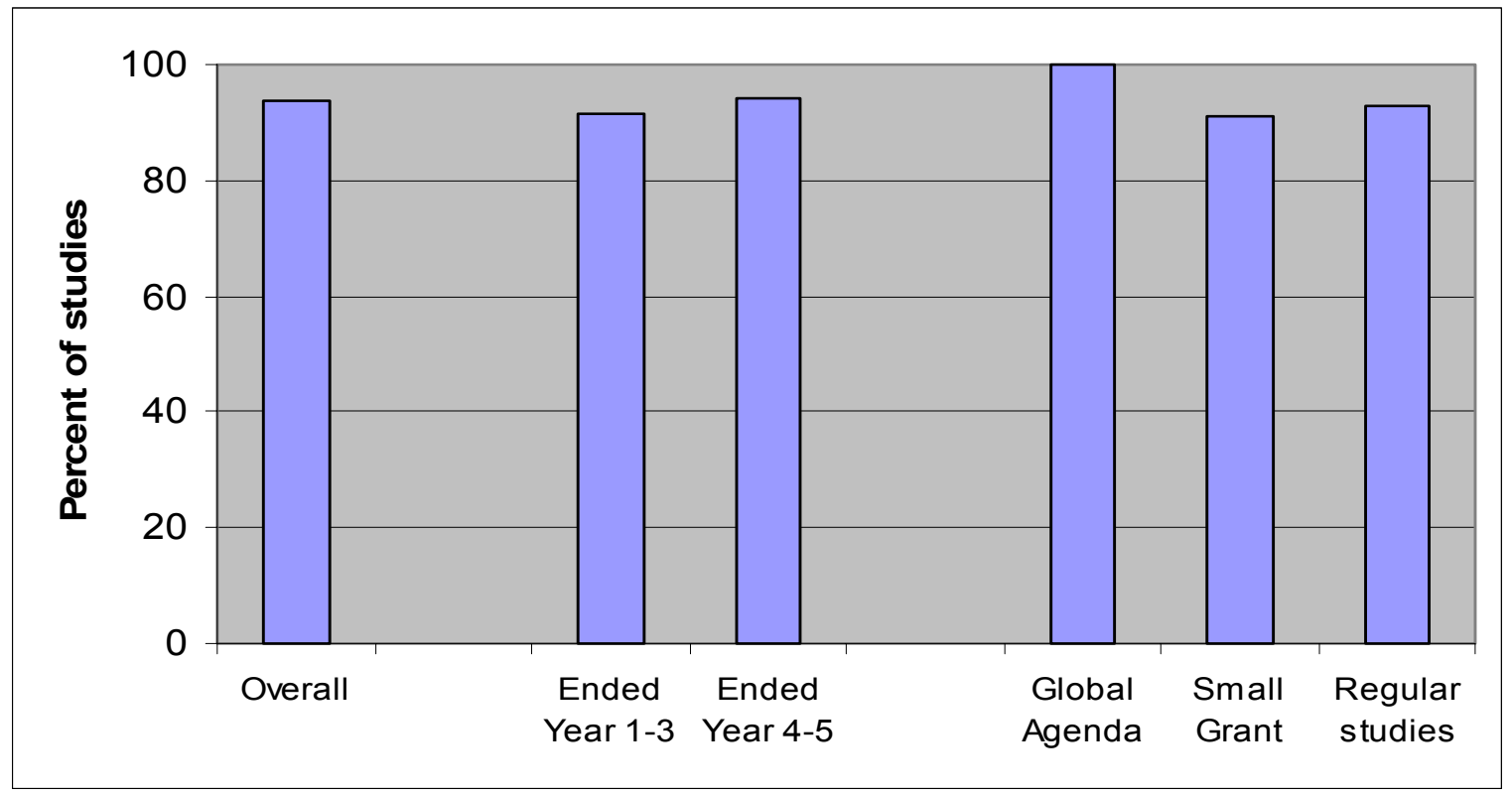

Below are some examples of how organizations implemented changes recommended by intervention studies during the subsequent two years:

- The study "Counseling Family Planning Clients About Sexuality and the Use of Barrier Methods. An Exploratory Intervention Study in Egypt" assessed the impact on client and provider knowledge and attitudes when providers received training to help them discuss sexual matters with family planning clients.

In the preparatory phase of the project, some MOH staff were holding negative attitudes to introducing counseling in sexuality to FP counseling session. However, by the end of the project, there were improvement in these attitudes, and the Ministry did not object adding training in sexuality issues to the training content provided by the Regional Center for Training in Reproductive Health to $\mathrm{MOH}$ staff. 
- Nurse auxiliaries in Honduras trained to provide clinic-based family planning methods continue to do so. Indeed, an evaluator visiting this project noted:

The re-visit to this project was made after approximately 24 months of the intervention. It was very interesting to observe continuation of IUD insertion, and supervision by highly motivated nurses in communities where service providers did not know the Population Council's project had ended.

- National community-based distribution programs in Zimbabwe, Ghana and Burkina Faso used evaluation results and recommendations to increase their efficiency by improving training and record keeping and modifying the roles of agents, in particular to incorporate STI and HIV/AIDS into their scope of work, as demonstrated in the following quotes from Ghana and Zimbabwe.

The findings of the study have improved PPAG's [Planned Parenthood Association of Ghana] CBD service delivery. The program has implemented some recommendations and is in the process of addressing some of the service delivery limitations observed during the study. The steps so far identified include: a revision of the $C B D$ training manual, introduction of a community diagnosis and mapping exercise for each agent; improved record keeping and reporting procedures; establishing stronger links with referral clinics; and enhancing the availability of educational materials for use when counseling clients.

Within the revised CBD program, ZNFPC (Zimbabwe National Family Planning Council) has added a new set of responsibilities to the traditional family planning focus of the agents. The new roles for the CBD agent and the Depot-Holders are reflected in the revised 'Training and Procedure' manuals. These manuals reflect all of the recommendations made by the OR study.

- At the request of the USAID/Peru mission, FRONTIERS/Peru collaborated with the $\mathrm{MOH}$ in 1999 and 2000 to conduct two evaluations of provider compliance with current $\mathrm{MOH}$ quality of care guidelines at the national level. Both evaluations revealed an overall adherence to quality of care norms, but identified areas for improvement (for example, focusing too much attention on all methods available and too little on the one chose by the client) as well as isolated areas of concern (confusion on the part of providers in one area regarding national family planning goals). The project monitor described the MOH's response to study findings as follows:

The MOH's participation in the initial utilization of partial study results was rather constructive. The program director at the time traveled to a site revealed as problematic by the study, promoted corrective actions among providers, and appointed a communications specialist to cooperate with FRONTIERS in the design of a corrective radio campaign for the community. The program director ... made specific recommendations in addition to personally implementing FRONTIERS suggestions to introduce corrections in the health directorate in which pressures on clients had been detected. 
In response to the more general need for better counseling skills, FRONTIERS/Peru worked with the MOH to develop a balanced counseling strategy, which combined a job aid and improved training. The strategy was first tested in 2000 in government clinics in Peru. It was refined in subsequent intervention studies in collaboration with the Peruvian NGO, EsSalud, the Guatemalan MOH, and Institute of Social Security (IGSS).

\subsubsection{Scaling-Up}

- In 25 out of 34 studies (74\%) the original implementing partner scaled up the successful intervention.

Figure 8 Percent of interventions that were scaled up, by study characteristics

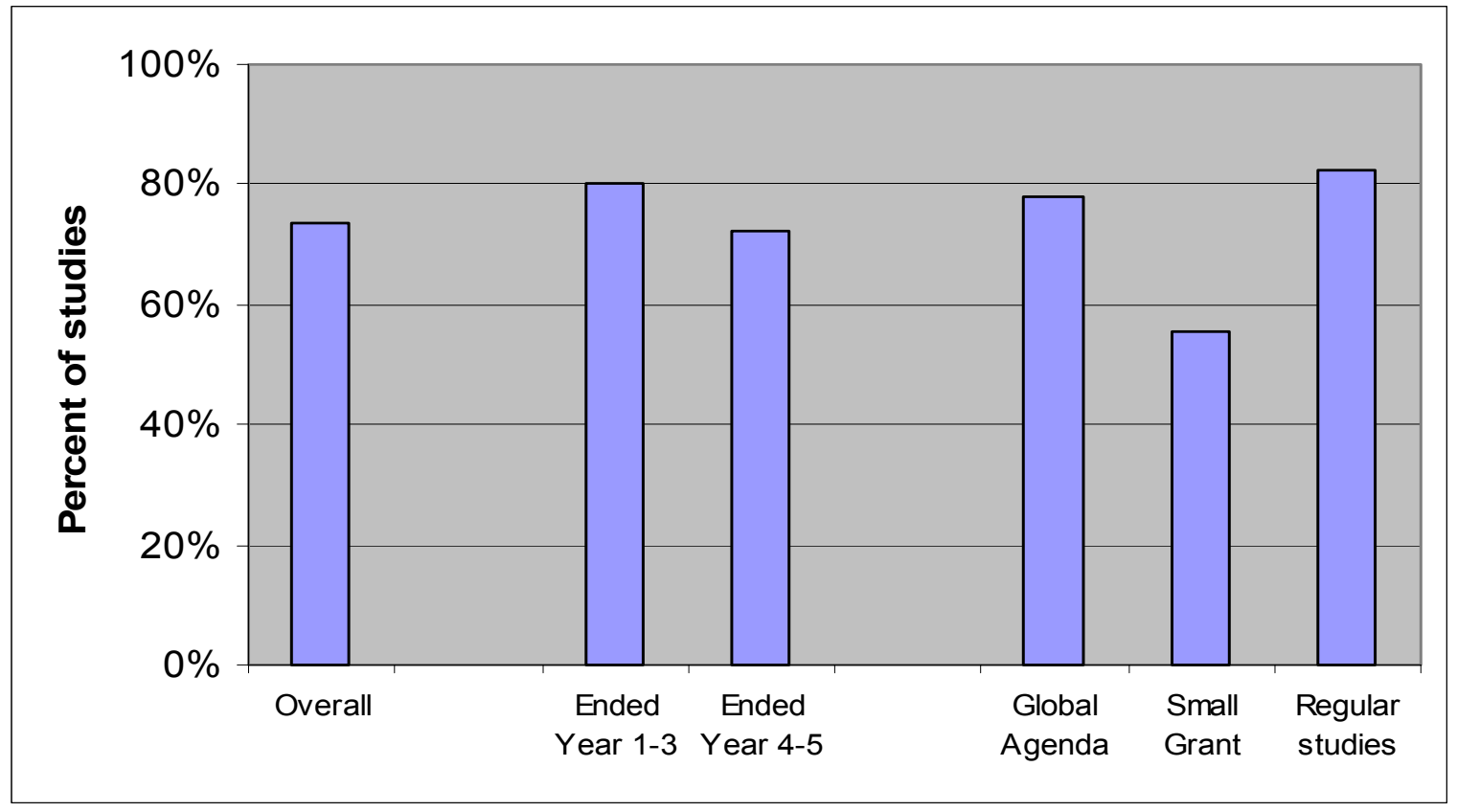

This indicator was only applicable for studies that tested an intervention and found it to improve service delivery. Evaluations of full-scale existing programs, such as the three CBD programs mentioned above, or intervention studies carried out at scale were not eligible. Scaling up was defined as either expanding an intervention to new sites, or implementing an intervention more fully at the original sites (for example, training all facility staff instead of selected members). The definition did not require that an intervention be fully scaled up within an organization or national system. Indeed, scaling up was generally undertaken in phases, and often implemented in context of follow-on OR project; few interventions could be considered completely scaled up at the time of the assessment.

Expanding interventions under the OR program allows program staff to modify and refine components with sufficient supervision and evaluation to determine whether the intervention achieves the same results as the original study in a different setting or at a different scale. The 
2003 postabortion care study in Senegal, for example, achieved less striking results than a 1998 study in urban referral hospitals, providing important lessons for program managers intending to scale-up the intervention. The initial study demonstrated dramatic improvements in terms of changing medical procedures and reducing length of hospital stays, but the intervention strategy showed more modest improvements in district health centers where trained providers were not always available, providing researchers insight into circumstances that could arise when taking the intervention to scale.

In response to growing evidence that study recommendations are most likely to be implemented when there is continuing technical assistance available, FRONTIERS also developed a formal mechanism to provide TA to promote institutionalization and scaling-up of interventions. In the first year of the program's five-year extension, approximately 10 ongoing projects were of this type and involved topics as varied as youth reproductive health, male involvement in maternity care, IUD use, and emergency contraception (EC).

- Kenya Adolescent Reproductive Health Project (KARHP) began a two-year project to sustain and scale up the successful components of the global agenda youth study in September 2003, working with FRONTIERS and PATH to build the capacity of the Ministries of Education, Health and Gender, Sports, Culture and Social Services to sustain the activities technically and financially.

- The Men in Maternity study in Delhi tested the feasibility, effectiveness and cost of a new, gender-sensitive model of maternity care where husbands were encouraged to participate in counseling sessions with their wives during antenatal and postpartum clinic visits. Using the same methodology, Employees' State Insurance Corporation and FRONTIERS are testing the feasibility and effectiveness of male involvement in maternity care in a rural setting in northern India.

- The emergency contraception study in Bangladesh demonstrated that providing women emergency contraceptive pills in advance led to timely and correct use: about 45 percent of clients who had unprotected sex used EC, and use was five times higher when the pills were supplied as a prophylaxis than when they were provided on demand. All the women who used EC were married and about 85 percent were family planning users. After EC use, 92 percent reverted to the method they were previously using or adopted a new method. According to a key informant, this project was "one of the most successful studies ever conducted by the Population Council in the Asia Near-East countries, including Bangladesh, that has scaled up in the National Family Planning Program. It has achieved all its objectives ... and has significant national level impact." With TA from FRONTIERS on training, educational materials and monitoring, the Bangladesh $\mathrm{MOH}$ is scaling up the intervention in 17 of 64 districts with its own resources. Once EC has been available for one year in these 17 districts, the program will be extended throughout the whole country.

- In their Small Grant study, the Kazakhstan Academy of Preventive Medicine demonstrated that an intervention to train maternity hospital providers in the Lactational Amenorrhea Method (LAM) of family planning led to increased rates of exclusive breastfeeding and correct LAM use, and fewer unintended pregnancies than in control hospitals. Since the 
study's end, the intervention has been introduced in control hospitals as well as in other regions, and a LAM training program for physicians was incorporated into the permanent curriculum at the Postgraduate Training Institute for Doctors in Kazakhstan. The evaluation also revealed that hospitals certified as Baby-Friendly according to WHO guidelines have much better outcomes for mother and infant than ordinary hospitals, and another outcome of the study has been to promote certification of all participating hospitals.

\subsubsection{Replication}

- 16 out of 36 successful interventions ( $44 \%)$ were replicated by another organization, in the same or a different country.

Figure 9 Percent of interventions that were replicated, by study characteristics

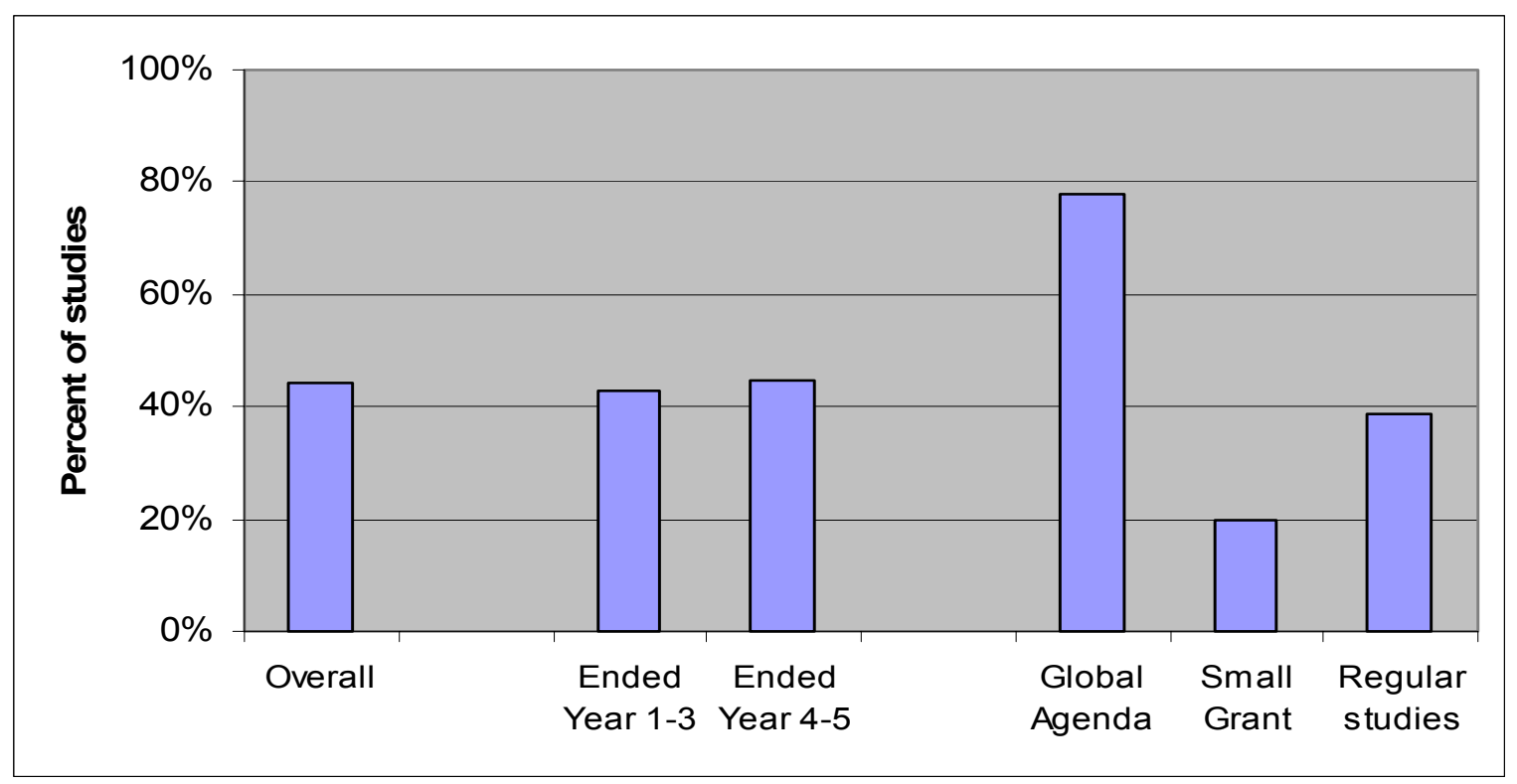

The questions relating to replication asked, "If the intervention was effective, was it replicated?" Ineffective interventions were not expected to be replicated, nor were evaluations whose objectives were to modify existing programs. Thus, eleven studies were considered not applicable for this indicator. It is possible that there were replications of which FRONTIERS staff was aware. Unless there was a clear, direct link to the original study, such as in the quotes provided, the mere existence of a similar intervention in another organization was not considered evidence of replication.

The 16 studies whose interventions were replicated include cases where an organization adopted a particular tool, curriculum or model developed in the OR study, or requested technical assistance from study partners in implementing the intervention. Organizations often adopted selected elements of an intervention. Some of the replications were FRONTIERS-supported OR studies; others were not. The following excerpts illustrate how OR studies were replicated in various countries. 
- Following the end of the Honduras study "Expansion of the Role of Nurse Auxiliaries in the Provision of Family Planning Services: Phase 2" in 2001, EngenderHealth adopted the program. Two years later, they continued to train and supervise nurse auxiliaries in providing clinical family planning methods.

- The Global Agenda study on quality of care in Uganda tested measures to improve the delivery and management of family planning services at a number of government health clinics, including the "Yellow Star" franchising approach. The intervention was initially implemented under the USAID-supported Delivery of Improved Services for Health (DISH II) project but was later replicated, as described below by the FRONTIERS monitor.

The Yellow Star Program continues to be a key strategy in improving quality of family planning services in Uganda. Efforts to replicate the strategy to other districts that did not fall under the DISH II project are currently underway through the USAID bi-lateral project call UPHOLD (Uganda Program for Human and Holistic Development).

- IPAS/Bolivia has maintained their postabortion care (PAC) intervention in three hospitals and 86 health centers in four departments and expanded services to secondary-level hospitals and primary health care centers, with support from DfID. Pathfinder International has also adopted a similar model, expanding PAC services to four other departments in Bolivia, with technical assistance from FRONTIERS. The intervention is being replicated in Paraguay as well, as described by a key informant from IPAS.

In June 2003, a team from IPAS Bolivia conducted a workshop in Paraguay to train 37 providers, of whom 35 were obstetrician-gynecologists and 2 nurse-midwives. This event signals the beginning of technical assistance activities to the Ministry of Health of Paraguay to be provided by IPAS Bolivia in the coming two years.

The majority of interventions tested in studies prior to or during the implementationof FRONTIERS have not been replicated outside the country in which they were conducted, but there have been notable exceptions in addition to the example above:

- The Global Agenda study on client-provider interaction in Peru developed a "balanced counseling strategy" and a job aid for family planning providers to improve the quantity and quality of information provided to women choosing contraceptive methods. FRONTIERS staff in Peru, Guatemala and Mexico collaborated to test the intervention in Guatemalan Ministry of Health and Guatemalan Institute of Social Security (IGSS) clinics in 2001-2002, and began scaling up the successful model in both institutions in 2003.

- As part of the INOPAL OR/TA program, a systematic screening algorithm was tested in Peru to reduce missed opportunities for providers to offer clients reproductive health services. The algorithm was later refined in a series of studies in $\mathrm{MOH}$ clinics in the Guatemalan highlands in the late 1990s. The Guatemala case study conducted by Tulane in 2001 also found that NGO clinics in the region had adopted the systematic screening algorithm as part of routine services. In 2003, FRONTIERS capacity-building staff 
developed a "Standardized Protocol for Systematic Screening" to teach researchers and managers data collection, instrument design, intervention monitoring, data processing and analysis using a simple pre/post-test design. The Honduran Planned Parenthood affiliate ASHONPLAFA began testing a version of the job aid in 2003, and have been joined by PROSIN in Bolivia, State Health Services in India and Ministry of Health in Senegal in 2004, all with assistance from FRONTIERS.

\subsubsection{Policy Change}

\section{- 25 of 47 studies (53\%) contributed to a change in policy.}

Policy change was defined as "national legislation or system-wide changes in an organization's norms, protocols, regulations or guidelines." As Figure 10 shows, a smaller proportion of the Small Grants as compared to Global Agenda or Regular studies led to policy change. The majority of FRONTIERS studies did not explicitly lead to policy change as they did to program change. This was due, in part, to the fact that influencing policy was often considered a secondary goal. When studies did have an impact on policy, findings tended to be used primarily to establish or modify operational policies related to a specific service, rather than to guide national positions on reproductive health, as shown below in the quote from the Egypt NORPLANT $^{\circledR}$ study.

The research was ... regarded as very useful. The research findings provided many useful guidelines and directions to strengthen NORPLANT ${ }^{\circledR}$ program and fill the gaps noted in its subsystems.

\section{Figure 10 Percent of studies that led to policy change, by study characteristics}

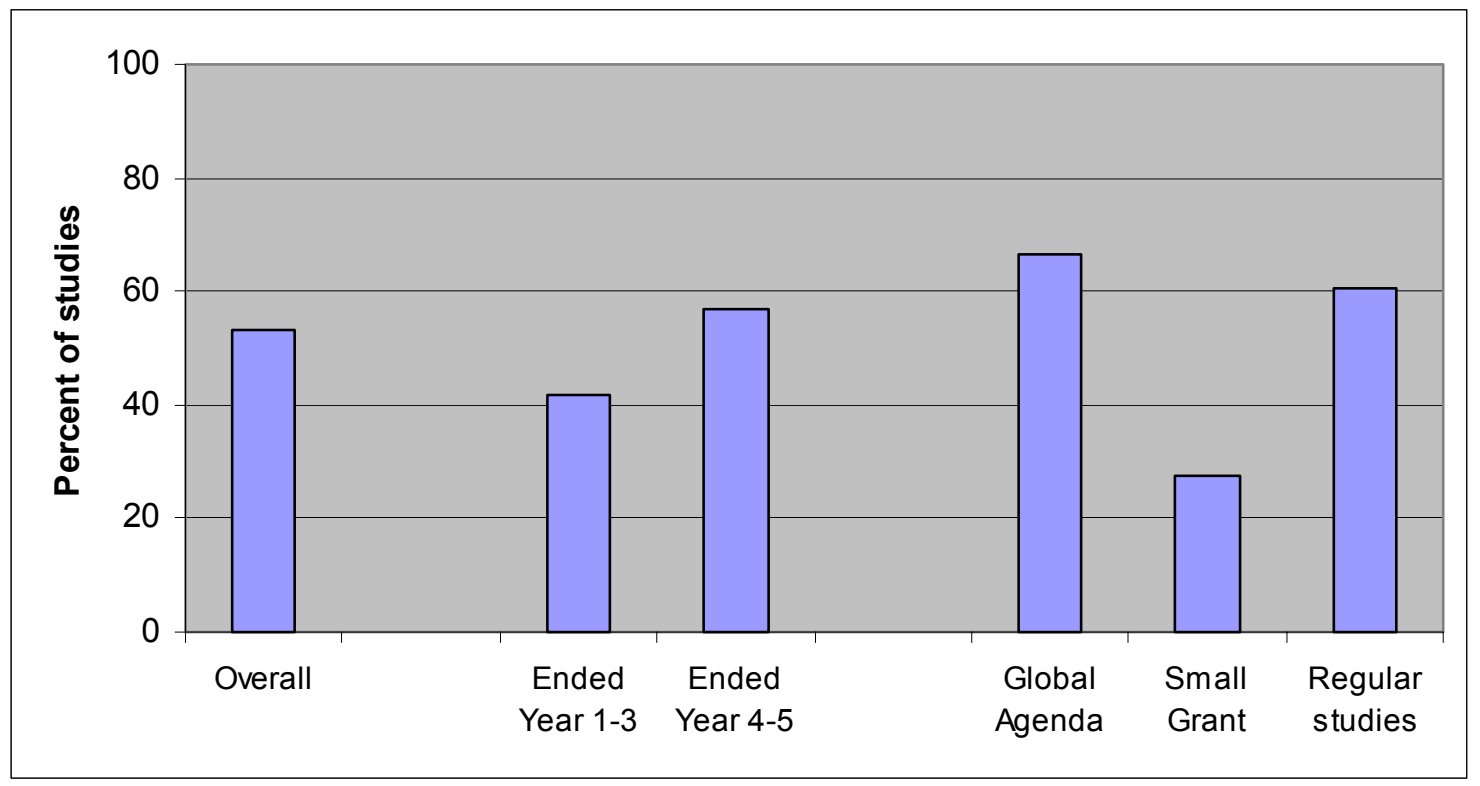


Results from a number of studies, particularly in the private sector, were used to set prices or determine reimbursement rates. Studies of newly-introduced contraceptive methods or reproductive health services were also likely to influence policy formulation, as was the case with emergency contraception in Bangladesh, postpartum family planning in Honduras and Guatemala, counseling for male partners in India and Bangladesh, counseling on sexuality in Egypt, and postabortion care in Russia, Bolivia, Peru and Senegal:

- A 2003 evaluation study of the sustainability of a 1998 PAC intervention in Peru reported that, not only were integrated services provided in a dedicated obstetric emergency ward, but the hospital had also lowered patient fees in response to the reduced cost of treatment demonstrated in the original study.

- Participants in the Bolivia PAC study worked with other organizations to develop a set of norms and protocols incorporating the OR recommendations, as described below:

IPAS, Pathfinder and the Ministry of Health developed national norms for 'hemorrhages during the first half of pregnancy.' The norms were published in 2001 and revised to bring them up to date with the Ministry of Health's new management model. Two consecutive state insurance plans (Basic Health Insurance and Universal Maternal and Child Insurance) incorporated the treatment of hemorrhage during the first half of pregnancy into services offered free of charge in all state hospitals and health centers.

- The policy change brought about as a consequence of the study testing the feasibility of providing women in Bangladesh with emergency contraceptive pills reached a population bigger than that of many countries, as the FRONTIERS monitor stated.

Based on the operations research findings, the Government of Bangladesh has approved introduction of emergency contraception in the National Family Planning Program. In the first phase, emergency contraception will be made available in all the service centers in 17 districts covering a population of about 50 million."

\subsubsection{New Funding}

\section{- 20 out of 47 studies $(43 \%)$ led to new funds to sustain or expand program activities tested.}

This indicator combined new funding from any source: the original donor, a new donor, or in the form of cost recovery for services provided. Funds for sustaining or expanding program activities or creating conditions for scaling up were included, while support for new research on a different topic and services not tested was not. Most FRONTIERS studies were collaborations with implementing organizations that financed the intervention with either their own or a third party's funds, while FRONTIERS financed the research portion of the project. When studies ended, over half of the organizations did not receive new funds to continue or expand the intervention, but instead had to reallocate their existing resources if they chose to do so. The quote below describes the attempt to gain funding to scale up a male involvement intervention in Bangladesh. 
The then-Secretary of Health and Family Welfare formally requested [NGO] NIPORT to scale [the intervention] up in 100-150 facilities. It is also included in the NIPORT operational plan for implementation budgeted at about \$US 85,000. However, although it is budgeted, this money has to come from some donor agency(s). MOHFW is trying to find funds for scaling up... TA to MOHFW in its scaling up is included in the [FRONTIERS/Bangladesh] Seventh Year work plan. We are waiting that MOHFW should find or allocate the requisite fund for scaling up.

As Figure 11 shows, a larger proportion of Global Agenda than Small Grant studies generated new funds. New funds that were received were often provided by USAID in the form of core and field support funds allocated either directly or through a service delivery program or CA (e.g., Advance Africa, EngenderHealth). Some non-USAID sources of funds were: government ministries, WHO, UNFPA, The Global Fund, DFID, GTZ, Oxfam UK, Plan International, Save the Children UK, and foundations including Macarthur, Buffet and Packard.

\section{Figure 11 Percent of studies whose results led to new funds, by study characteristics}

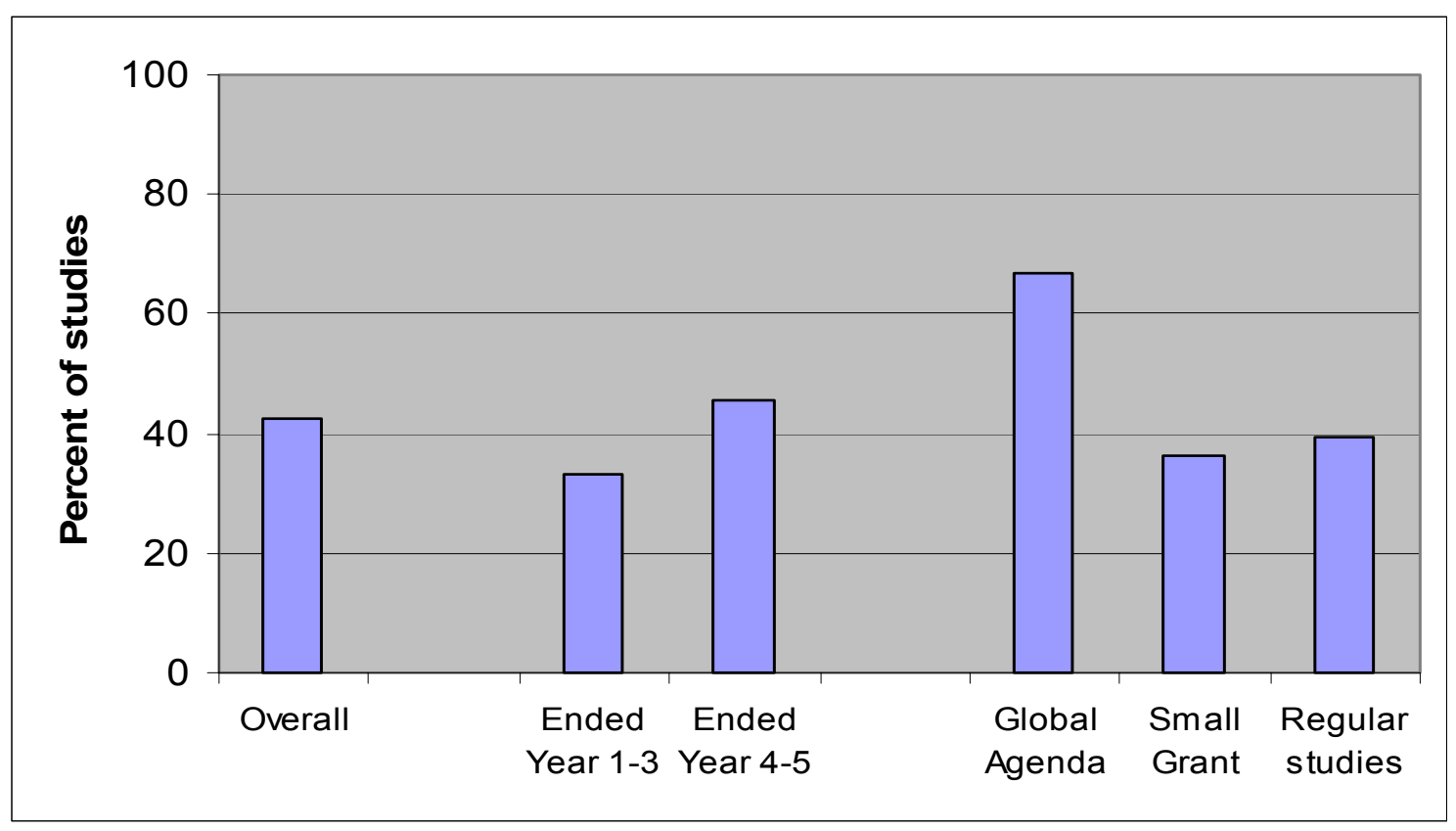

\subsubsection{USAID Decision-making}

\section{- In 17 out of 47 studies (36\%), the USAID Mission made decisions based on results.}

Findings were generally used by USAID Mission to allocate funding for institutionalization or scale up, or to modify country programs - for example, integrating HIV/AIDS into family planning programs. A number of the studies used for decision making were evaluations carried out at the request of the Mission, as illustrated by the two examples below, from the CBD evaluations in Zimbabwe and Ghana. 
USAID's principal interest in Zimbabwe was to support activities that could mitigate immediately the rising HIV crisis in the country. In the words of the USAID HIV/AIDS Technical Advisor in Harare, the agency felt that the OR study had been an "outstanding assessment," adding, "the report has been very valuable in guiding our thinking regarding the involvement of CBDs in HIV prevention and care."

This study was requested by USAID/Ghana and occasioned by increasing concern by the USAID Mission and the MOH about declining trends in the use of the IUD and the lack of understanding of the key factors affecting its use. Data generated by the study was important for informing the USAID Mission and USAID-supported Cooperating Agencies (EngenderHealth), as well as the MOH, on future directions for improving quality of care and contraceptive promotion and supply generally in Ghana, and specifically concerning the IUD

Use by USAID/Washington is not included in this indicator because FRONTIERS field staff conducted most of the impact assessments, and they were only able to respond to questions on use at the country level. (The recent addition of "global leadership" to the new strategic objective of the Global Health Bureau may help address this shortcoming.) In addition, a number of monitors responded that they had presented results to USAID but were uncertain whether any action had been taken as a result. While this was recorded as non-utilization, it is possible that in some cases study results and recommendations did influence decisions. As shown in Figure 12, more than 50 percent of the results of Global Agenda studies were reported to have been used by the USAID Mission.

Figure 12 Percent of studies that were used by the USAID Mission, by study characteristics

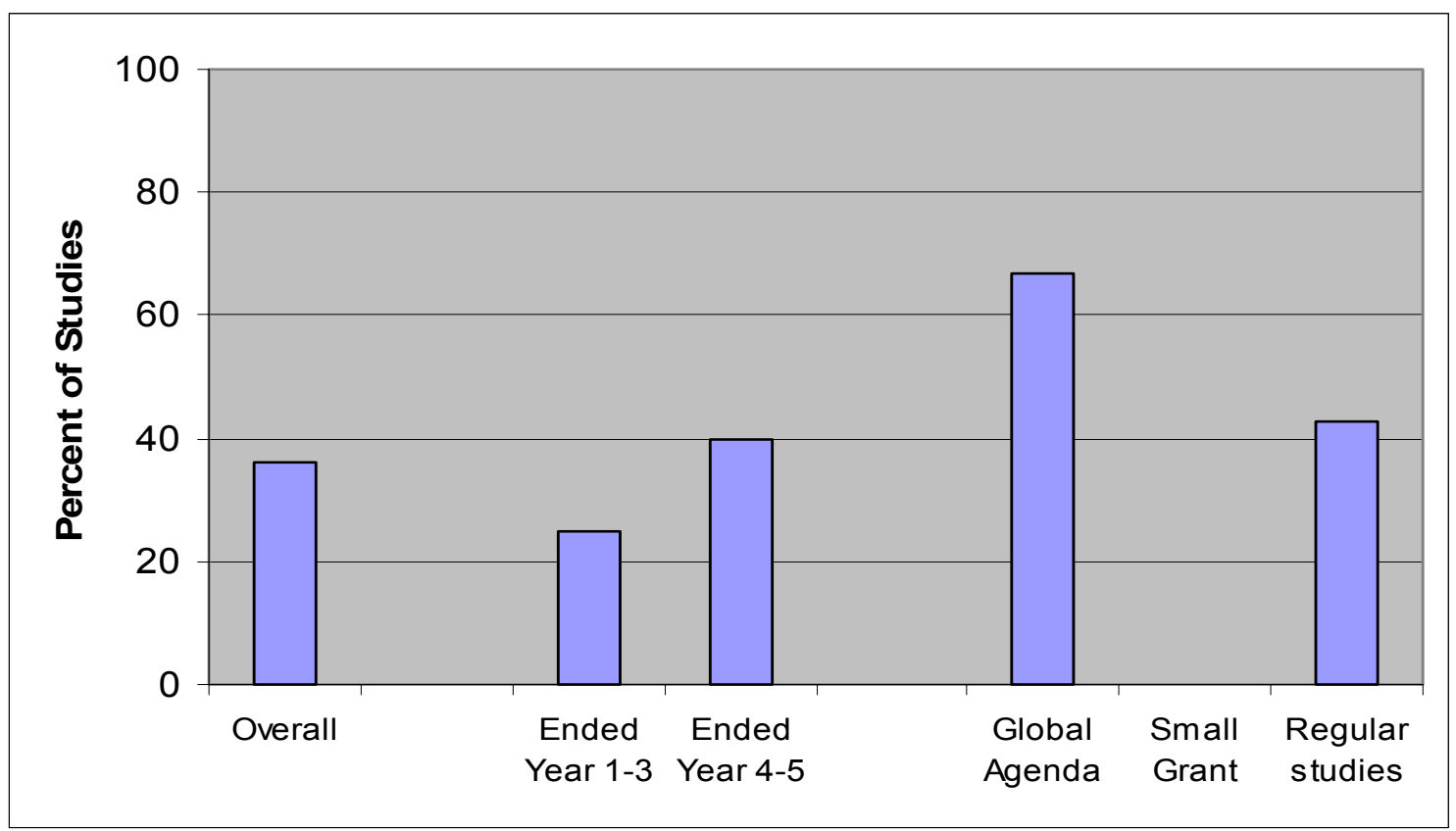




\subsubsection{Organizational Capacity}

- 32 out of 47 studies $(68 \%)$ helped strengthen organizational systems for producing and using evidence.

Figure 13 Percent of studies led to increased organizational capacity, by study characteristics

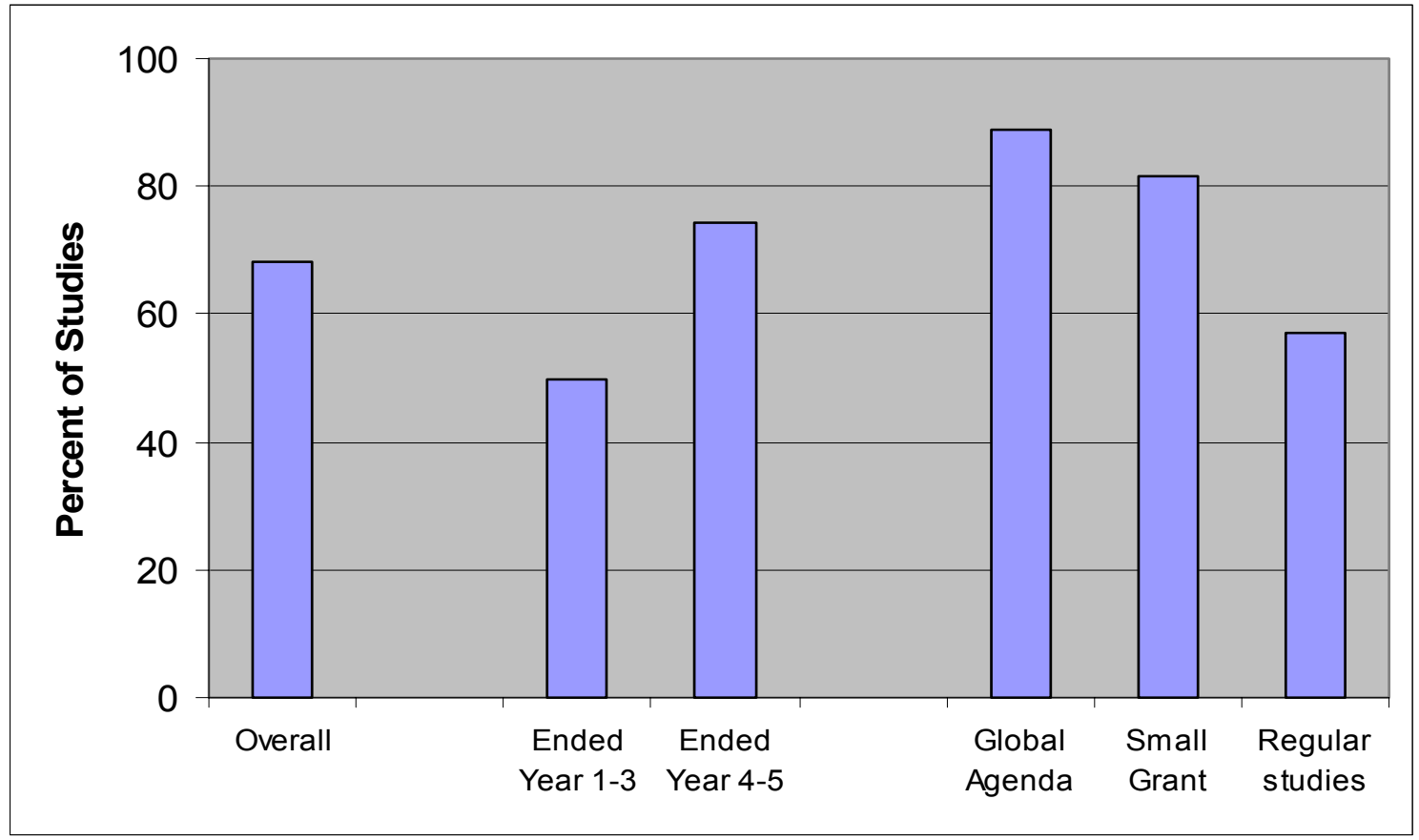

The capacity of a program or organization was considered improved if, as a result of their participation in the study, they increased their use of evidence for local decisionmaking, participated in subsequent studies on other topics in order to improve service delivery, or improved their supervision, monitoring and evaluation systems. Unlike the previous types of utilization, which were based on explicit questions in the assessment form, organizational strengthening was not included as one of the eleven impact indicators, except in the context of participation in subsequent research studies. Instead, it was usually mentioned spontaneously in the comments of monitors, and thus it is likely that a direct question about improved capacity would have yielded a higher proportion than $68 \%$.

A staff member from a partner organization in Mexico offered the following example of change in her organization.

This research permitted decisions to be made and proposals to be developed for new interventions that the organization had not considered (such as the youth-friendly pharmacies) as well as restructuring the internal information system, and adapting and redefining the content and terms of adolescent sexual health institutional environments. 
CEMOPLAF, the IPPF-affiliate in Ecuador, is an example of an organization that has institutionalized OR and evidence-based decisionmaking. For example, when an economic evaluation had to be abandoned because rapid inflation confounded the results, CEMOPLAF chose to suspend the study and conduct it later with their own funds.

In my experience, CEMOPLAF has the strongest commitment to OR of any organization with whom I have worked. [The] long history of successful collaboration with CEMOPLAF has left in place a well-developed research capability, a genuine interest in OR and a belief in the value of making decisions based on data.

While we thought this area of impact of operations research was important enough to be included, the research study is not the most appropriate unit of analysis, as change is often the outcome of long-term collaboration. FRONTIERS and non-FRONTIERS informants participating in a range of studies, such as this researcher from an NGO in Bangladesh, cited the benefits of a sustained partnership over time and multiple studies.

The culture of evidence-based decisionmaking has improved over the past years as a general trend; however, it would be an over-claim if one particular study claims the credit.

\subsubsection{Factors Influencing Utilization of OR Results}

The set of FRONTIERS studies was also examined to identify factors that influence utilization of OR results, both positively and negatively. Three types of analyses are presented here. First, we compared utilization outcomes of studies based on such characteristics as study type (intervention or evaluation), geographic region, source of funds, and the presence or absence of in-country staff. Second, we explored the relationship between high scores on the process indices and utilization of study results. Third, we compiled a list of the central facilitators and barriers to utilization identified by FRONTIERS staff assessing the projects.

\subsubsection{Study Characteristics}

Table 5 shows the percent of FRONTIERS studies reporting utilization of results by study characteristics and type of use. A comparison of utilization of intervention and evaluative studies revealed interesting differences on some indicators, but little or no difference on others. However, the small number of evaluation studies makes generalization difficult. Among the FRONTIERS studies examined, interventions were much more likely to lead to increased funding (50 percent compared to 18 percent) but less likely to be used by USAID Mission staff for decision making (33 percent compared to 46 percent). A comparison by study type of the tendency for OR studies to lead to scaling-up and replication is not included because these indicators were relevant to only one evaluation study.

The studies assessed were divided fairly equally among the three main regions where FRONTIERS works. Note that three studies were conducted in Europe and Eurasia were excluded from the regional analysis due to small sample size. In general, higher levels of utilization of OR results were noted in Africa and Asia than in Latin America. It is possible that regional differences evident in Table 5 reflect in part raters' attitudes. Anecdotally, monitors of 
studies in Latin America seemed to be most critical and hesitant to attribute change to FRONTIERS studies. Also, studies in Latin America tended to take place in more mature programs, where previous and contemporary interventions and research did indeed have their own, separate influence on programs and policy. The African context was very different, where several of the studies provided the only real information available nationally about a given service delivery approach, such as adolescent reproductive health, or the integration of HIV/AIDS into family planning programs.

Table 5 Utilization of $O R$ results by study characteristics

\begin{tabular}{|c|c|c|c|c|c|c|c|c|}
\hline & \multicolumn{8}{|c|}{ Percent of Studies Reporting: } \\
\hline & $\begin{array}{l}\text { Program } \\
\text { Change }\end{array}$ & $\begin{array}{l}\text { Scale- } \\
\text { up }\end{array}$ & $\begin{array}{l}\text { Repli- } \\
\text { cation }\end{array}$ & $\begin{array}{l}\text { Policy } \\
\text { Change }\end{array}$ & Funding & $\begin{array}{l}\text { USAID } \\
\text { decision- } \\
\text { making } \\
\end{array}$ & $\begin{array}{l}\text { Organiz- } \\
\text { ational } \\
\text { Capacity } \\
\text { Building }\end{array}$ & $\mathbf{N}$ \\
\hline $\begin{array}{l}\text { Study type } \\
\text { Intervention } \\
\text { Evaluation }\end{array}$ & $\begin{array}{l}92 \\
100\end{array}$ & $\begin{array}{l}72^{\mathrm{a}} \\
-\end{array}$ & $\begin{array}{l}49^{b} \\
-\end{array}$ & $\begin{array}{l}50 \\
64\end{array}$ & $\begin{array}{l}50 \\
18\end{array}$ & $\begin{array}{l}33 \\
46\end{array}$ & $\begin{array}{l}64 \\
82\end{array}$ & $\begin{array}{l}36 \\
11\end{array}$ \\
\hline $\begin{array}{l}\text { Region } \\
\text { Africa } \\
\text { Asia } \\
\text { Latin America }\end{array}$ & $\begin{array}{l}100 \\
100 \\
83\end{array}$ & $\begin{array}{l}71^{\mathrm{c}} \\
92^{\mathrm{d}} \\
58^{\mathrm{d}}\end{array}$ & $\begin{array}{l}63^{\mathrm{e}} \\
46^{\mathrm{f}} \\
42^{\mathrm{d}}\end{array}$ & $\begin{array}{l}58 \\
53 \\
53\end{array}$ & $\begin{array}{l}50 \\
40 \\
41\end{array}$ & $\begin{array}{l}58 \\
27 \\
29\end{array}$ & $\begin{array}{l}68 \\
60 \\
77\end{array}$ & $\begin{array}{l}12 \\
15 \\
14\end{array}$ \\
\hline $\begin{array}{l}\text { Funding source } \\
\text { Core } \\
\text { Field support }\end{array}$ & $\begin{array}{l}97 \\
90\end{array}$ & $\begin{array}{l}75^{g} \\
70^{h}\end{array}$ & $\begin{array}{l}48^{i} \\
37^{j}\end{array}$ & $\begin{array}{l}52 \\
55\end{array}$ & $\begin{array}{l}52 \\
30\end{array}$ & $\begin{array}{l}30 \\
45\end{array}$ & $\begin{array}{l}70 \\
65\end{array}$ & $\begin{array}{l}27 \\
20\end{array}$ \\
\hline $\begin{array}{l}\text { FRONTIERS field } \\
\text { presence } \\
\text { Country office } \\
\text { Country office closed } \\
\text { No country office }\end{array}$ & $\begin{array}{l}93 \\
90 \\
100\end{array}$ & $\begin{array}{l}74^{\mathrm{k}} \\
75^{\mathrm{e}} \\
72^{\mathrm{c}}\end{array}$ & $\begin{array}{l}55^{\mathrm{h}} \\
25^{\mathrm{e}} \\
38^{\mathrm{e}}\end{array}$ & $\begin{array}{l}59 \\
50 \\
40\end{array}$ & $\begin{array}{l}44 \\
20 \\
60\end{array}$ & $\begin{array}{l}44 \\
10 \\
40\end{array}$ & $\begin{array}{l}70 \\
50 \\
80\end{array}$ & $\begin{array}{l}27 \\
10 \\
10\end{array}$ \\
\hline
\end{tabular}

$$
\begin{aligned}
& \mathrm{n}=32 \\
& \mathrm{n}=33 \\
& \mathrm{n}=7 \\
& \mathrm{n}=12 \\
& \mathrm{n}=8 \\
& \mathrm{n}=14 \\
& \mathrm{n}=24 \\
& \mathrm{n}=10 \\
& \mathrm{n}=25 \\
& \mathrm{n}=11 \\
& \text { Indicator applicable for } 2 \text { evaluation cases }
\end{aligned}
$$

During the reference period covered by the OR studies, FRONTIERS received the majority of its funds from the Bureau of Global Health, but also received field support in 17 countries for studies completing a process assessment. Among studies included in the impact assessment, 20 studies in eleven countries were partly or fully funded with field support. Six of these were in Guatemala, while the rest were fairly evenly split among the regions, with no more than two in any country. One might expect that studies funded through field support would be more responsive to country needs and thus more likely to be utilized by national programs, but that did not appear to be the case, as Table 5 shows. In fact, source of funding was associated with notable differentials in utilization in only two situations. The first concerned generating new 
funding to continue the activities tested ( 52 percent among core-funded studies compared to 30 percent among field-support funded studies). USAID Missions were more likely to use the study results for decisionmaking if they had funded the study than if it was core-funded. However, the level of utilization of OR results by USAID as measured by the assessment form was not very high.

The Population Council's operations research programs have long had a strong regional focus, and prior to FRONTIERS had their headquarters close to their work in Lima, Nairobi and New Delhi. In addition to the Washington, D.C. headquarters, FRONTIERS maintained between 10 and 13 field offices, with the majority of staff being nationals of those countries. In order to explore the effect of FRONTIERS in-country presence on utilization of OR results, we divided studies into the following three categories: (a) no country office; (b) country office present for at least one year after the study's end date; and (c) country office closed within one year of the study's end date. The 'no country office' category included countries with a Population Council office but no FRONTIERS staff. Thus, studies conducted in the same country but at different times might fall into two different categories. Countries in which offices had closed included Burkina Faso, Honduras, Indonesia, Peru, Philippines, and West Bank/Gaza (note that West Bank/Gaza studies are not included in this analysis). These FRONTIERS offices were closed out of necessity, often following a loss of field support funds.

As shown in Table 5, the closure of FRONTIERS offices was associated with the lowest levels of utilization of OR results, a conclusion that is supported by the quote below from a regional staff member about a FRONTIERS study in Honduras.

The results were discussed throughout the life of the project with USAID and MOH officials. There was an end-of-project conference (that I did not attend) where the results were presented to the main stakeholders and other RH organizations. However, since the project ended at the same time that the office closed, little follow-up dissemination followed.

This association suggests that extra effort may be necessary in order to foster utilization of research results in the wake of an office closing.

This simple analysis may not tell the whole story. While the figures in Table 7 suggest that there is no clear benefit in terms of utilization to having a country office, numerous comments by monitors disagree. The presence or absence of local FRONTIERS staff to monitor and provide technical assistance was frequently mentioned among contextual factors that influenced the implementation of a study or the utilization of recommendations as illustrated by the excerpt below.

Monitoring the study from Nairobi was a very demanding task particularly in view of the fact that it took a long time for [implementing agency] PPAG to respond to requests to provide required data, clarify some issues or even provide financial and program reports as required by the contractual agreement. In addition, a lot of the work was done only when the monitor visited Ghana. The monitor from Nairobi ended up undertaking all the major monitoring activities while she was not designated as the principal study monitor. 


\subsubsection{Operations Research Process}

Figures 14-20 depict the relationship between aspects of the OR implementation process and utilization of research results. Chi-square statistics were also calculated to assess the statistical significance of the level of research utilization that was observed for each of the OR process indices. The results of these analyses are presented in Table A1 of Appendix C. Most striking is the lack of any consistent association between the process and utilization indicators: of the 35 bivariate analyses, only three were significant at the 0.05 level, and none at the 0.01 level. Studies that scored "high" on the dissemination index tended to lead to program change. Similarly, studies with higher perceived research quality were significantly more likely to be replicated, and studies with fewer barriers were significantly less likely to be used by USAID for decision-making. The absence of barriers was also negatively associated with scaling up $(p<$ 0.1 ). This is in contrast to a similar analysis using data from four country case studies of preFRONTIERS Population Council OR projects ${ }^{3}$, which found both the research quality index and no barrier index to be positively associated with program change, scaling up/replication and policy change (data not presented). For example, a change in policy was linked to the OR results in nine percent of cases if the absence of perceived barriers was low, compared to 46 percent of cases if absence of perceived barriers was high. Additionally, dissemination was associated with program change in these earlier studies, and high scores on the acceptability index were related to program change $(\mathrm{p}<0.1)$ and replication/scaling up.

The lack of a strong statistical relationship between OR process and utilization may indicate that the aspects of the research process measured are not strongly associated with utilization outcomes. However, it may also reflect the consistently high performance of FRONTIERS studies on the process indicators. It is possible that the process indicators or indices would be better predictors of utilization if the quality and implementation of the sampled studies were more variable, and certainly a larger sample size would increase the confidence level of some of the relationships visible in Figures $14-20$ below.

\footnotetext{
${ }^{3}$ Two indices were changed between the two analyses: "Technical assistance was considered to be sound and provided in a collegial manner" was added to the acceptability index, while the technical assistance indicator was dropped from the perceived research index, along with "Results were considered credible/valid in the local context", and replaced by "The intervention was implemented as planned". These modifications ensured that no indicators were repeated in more than one index, and that all indices expect for the dissemination index had three elements.
} 
Figure 14 Proportion of OR studies whose results led to program change, by type of process index

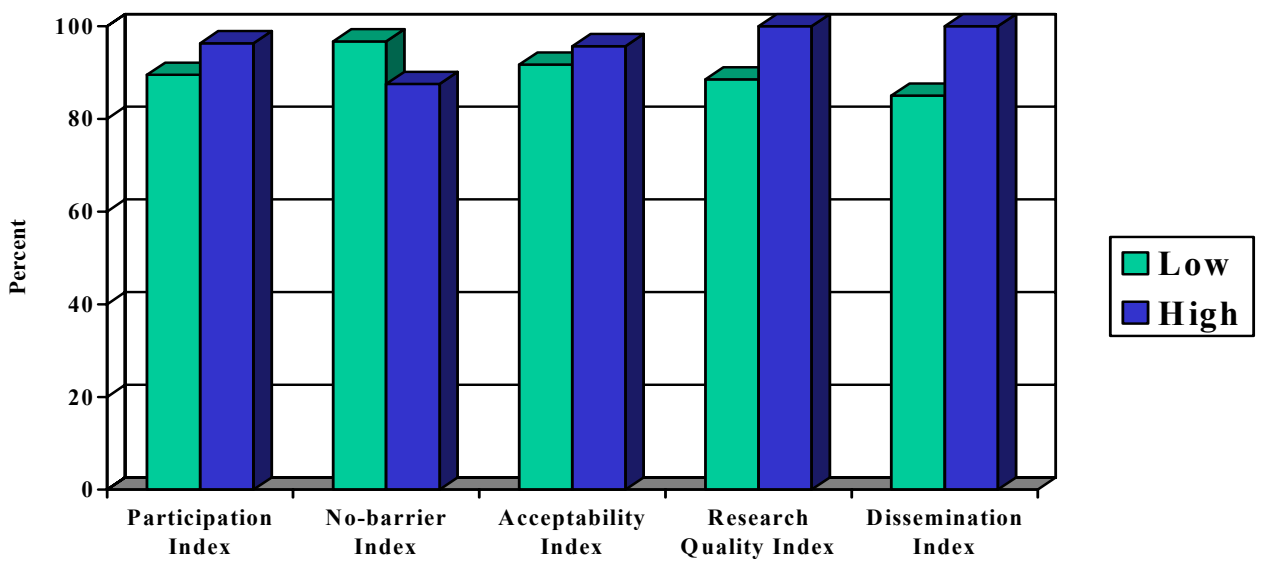

Figure 15 Proportion of OR studies that were scaled up, by type of process index

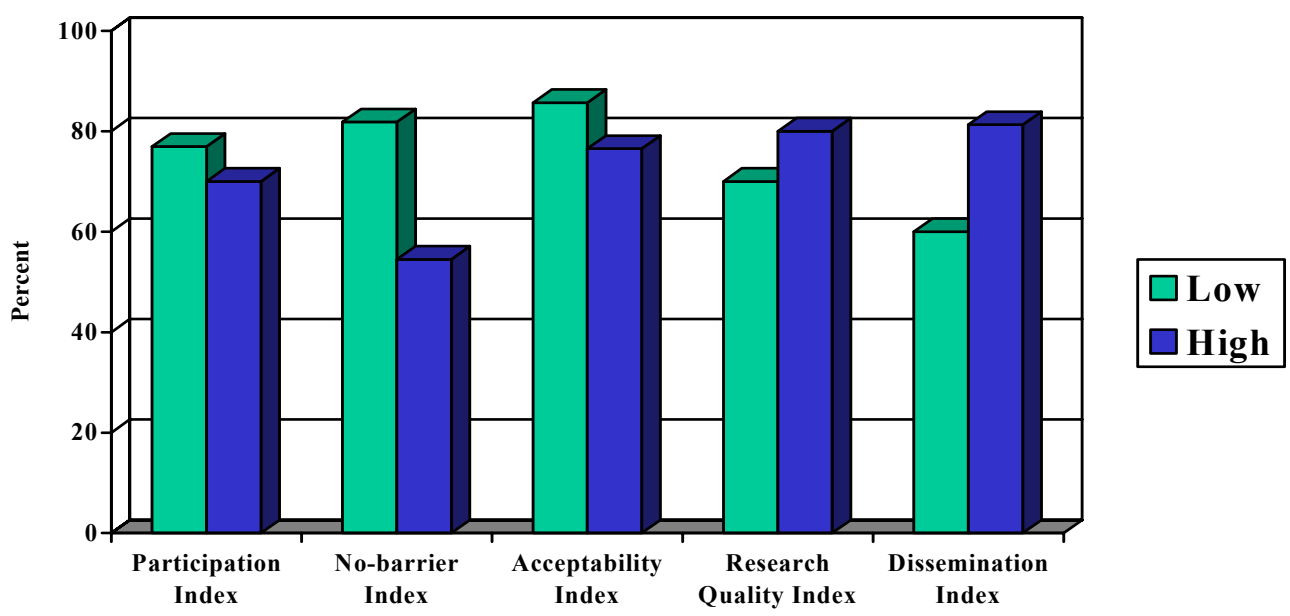


Figure 16 Proportion of OR studies that were replicated, by type of process index

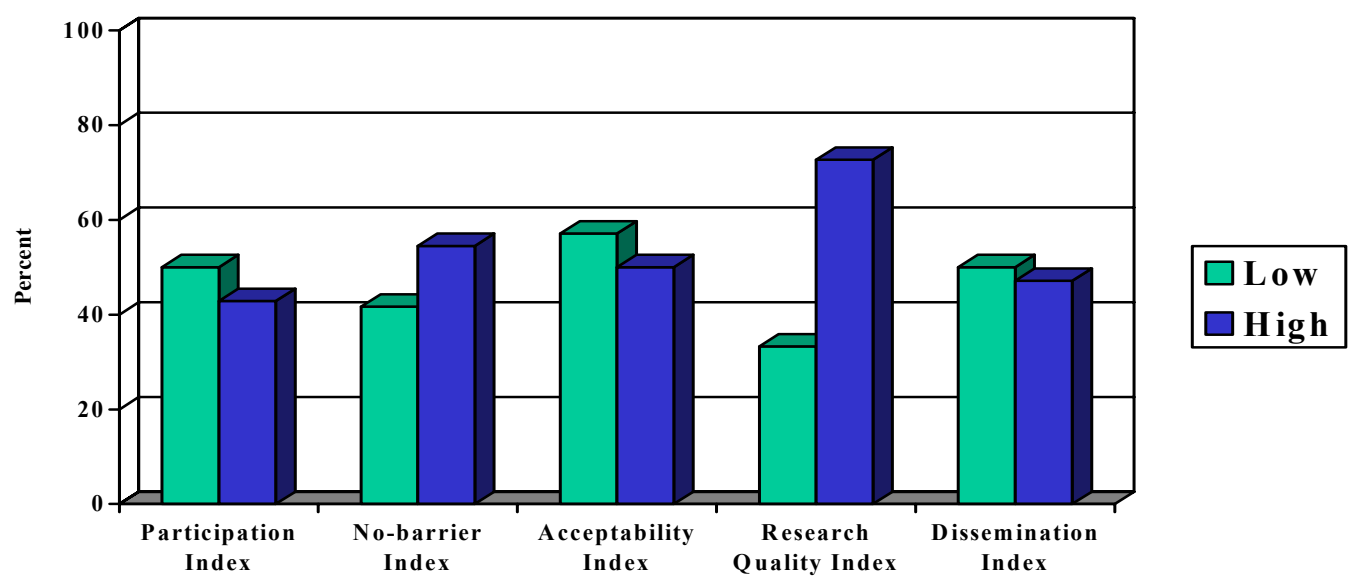

Figure 17 Proportion of OR studies that led to policy change, by type of process index

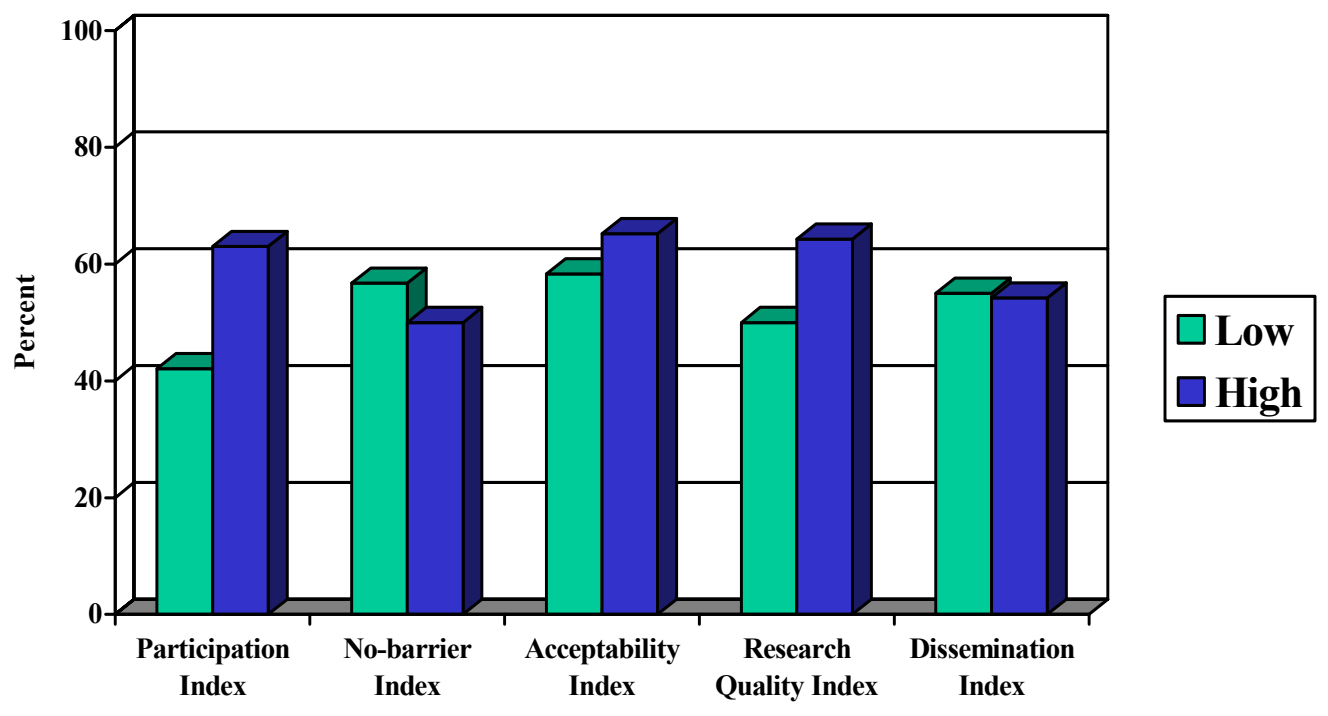


Figure 18 Proportion of OR studies that led to new sources of funding, by type of process index

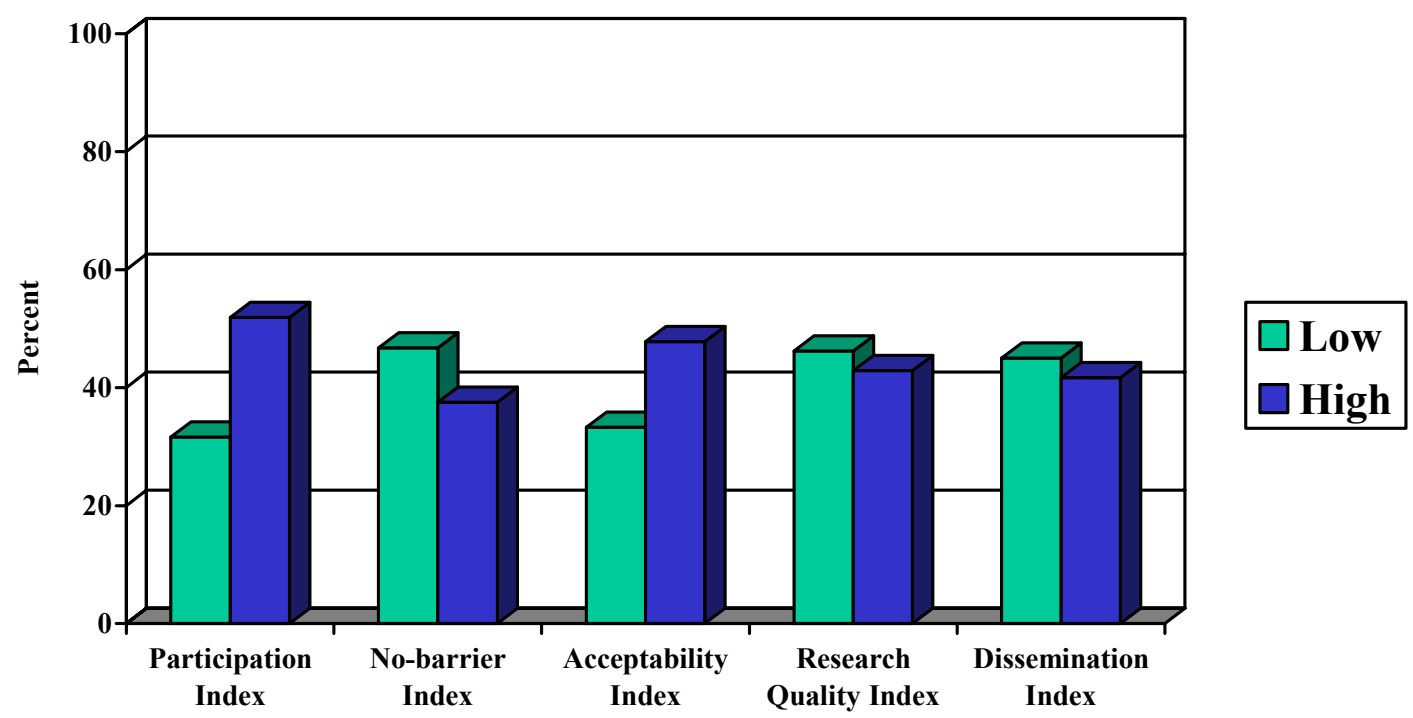

Figure 19 Proportion of OR studies that the USAID Mission used for decisionmaking, by type of process index

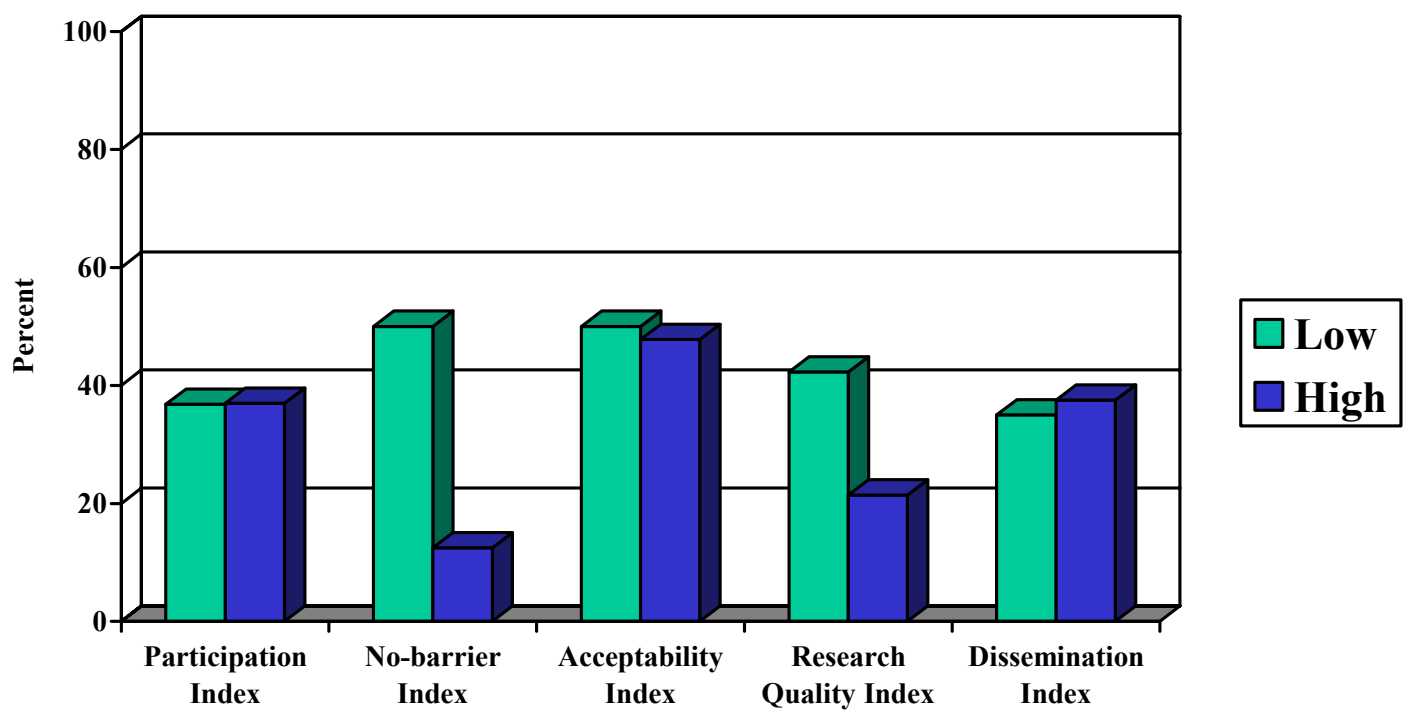


Figure 20 Proportion of OR studies that increased organizational capacity, by type of process index

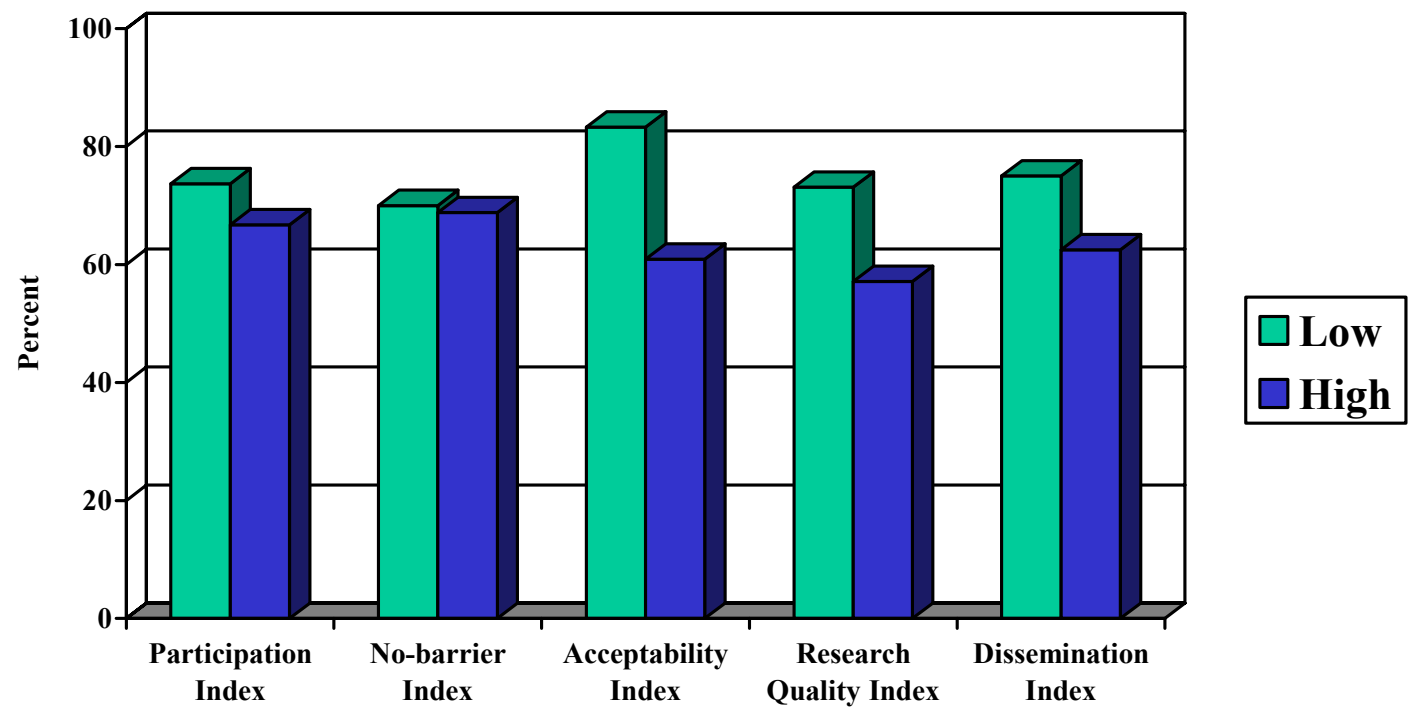

\subsubsection{Facilitating Factors Identified by Monitors}

Presented below are those reasons most cited by monitors to explain the impact of a particular OR study. This is not an exhaustive list and it is based on the subjective assessment of the field staff rather than statistical correlations. The list was created systematically by compiling the factors spontaneously cited in the greatest number of studies. Following a description of each factor are excerpts to put the generalizations in the context of FRONTIERS OR studies.

- Salient Topic: Stakeholders are more likely to utilize research when they consider a problem a high priority and want information to improve policies or service delivery. An example is adolescent reproductive health. Several countries started scaling up youth curricula being tested in the Global Agenda studies even before evaluation was complete, because they felt an urgent need to do something and thought the curriculum was the best tool available.

The study was conducted just at the right time as the new adolescent health office was created within the $\mathrm{MOH}$ in Senegal.

The re-organization of the Ministry of Health with the new Division of Reproductive Health and the creation of an Office for Adolescent for the first time. Without a clear content of strategy, staff from the Office for Adolescent follows with a strong interest this OR project in order to learn more on the subject and to identify strategy that could be replicable at the national level.

A contrasting example came from Indonesia, where family planning and reproductive health were not considered priorities during the crisis of the late 1990's. 
Coupled with extreme civil unrest and security concerns, it was most difficult to gain attention to the priorities of health sector research beyond human rights abuses and food security

- Compelling Results: Research that clearly demonstrates that an intervention is feasible, effective and sustainable is likely to be used. Stakeholders value results that are clear and easily visible. For example, an integrated postabortion care model is obviously more efficient, with better outcomes for lower costs than previous service models, as was demonstrated in three FRONTIERS studies (Bolivia, Peru and Senegal) as well as numerous previous OR studies conducted by the Population Council and other organizations. Once introduced, this model of care is almost always maintained.

Providers interviewed in the case study in Guatemala spoke of their increased job satisfaction when they could see a given intervention result in improved quality of care and client satisfaction. A program director attributed the successful implementation and institutionalization of a series of OR studies conducted by the Population Council's INOPAL project and FRONTIERS to the following:

Good relationship, good communication and what is most important, good results that benefit the clients of reproductive health services at IGSS.

- Collaborative Relationship: Research is more likely to be relevant and applicable, and therefore utilized, when research and program partners work together and actively collaborate. In particular, in countries where the Population Council had a long presence, monitors cited their relationships as an advantage in conducting studies that met the needs of their counterparts and in helping organizations use the results, as the following two examples show:

The excellent relationship between the MOH, Population Council, and all the other actors, and the involvement of operational staff, administrative staff and local politicians, as well as the community leaders, were factors in the success of the project implementation.

The FRONTIERS staff involved in the study had worked with the ZNFPC before on other studies so that a mutual trust and respect had grown over time.

External informants from partner organizations made similar comments.

The researcher(s) and external participants in the OR should know the intimacies of the institution where the OR study will take place. The selection of the institutional personnel who will implement the interventions should be done carefully. [They should be people] with a profile of leadership and continuity, who should get some recognition or incentive for participating. 
The total involvement of the policy makers, program managers, service providers, and donors since the conceptualization of the OR project to the subsequent implementation phases. The participation of these key players was real, effective and continuous, and this was the basis for the utilization of the results...

- Organizational commitment and leadership: The utilization of OR results is greatly facilitated by leadership and organizational commitment to making changes based on the evidence. Some organizations are more willing and able than others to use research as a management tool. Such organizations include IPPF affiliates and NGOs such as CEMOPLAF in Ecuador and APROFAM in Guatemala, who tend to be more flexible and autonomous than public sector programs. A MEXFAM staff member described some of the organization's characteristics that fostered program improvement in the following quote.

The creativity of field staff, the initiative and enthusiasm with which they carry out their responsibilities, the commitment of the voluntary promoters, the diversity of activities, not restricting oneself to the traditional operation of the program even if this leads to sanctions, and the inclusion of traditional customs as strategies for mass diffusion...

FRONTIERS monitors in Kenya and Bangladesh also pointed to partner organizations' characteristics.

The recruitment by PATH of an outstanding Study Coordinator based in the study sites, whose enthusiasm and tireless energy really motivated his ministry partners to implement the activities.

Keen interest taken by a top program manager of the government significantly increased the visibility and usefulness of the study.

\subsubsection{Inhibiting Factors Identified by Monitors}

The following factors were identified by Monitors as inhibiting the utilization of OR results:

- Unsatisfactory results: This includes both negative results and insufficient data. When a program is unhappy with the results of an evaluation, they are less likely to act on them than if they were favorable. When some important information is missing (cost information was frequently cited here) or not available in a timely manner, it limits the utilization of the research results.

We did show them some of the problems that their model had and tried to move them into solving this problem, but I am not sure if they did appreciate this help. ... There is a reluctance to accept [the findings]. 
The combination of politically incorrect findings with a politically and technically incorrect dissemination style is dangerous to the health of any research program, at least on the short-term.

Not all negative results were considered, however, with the same degree of skepticism, as evidenced by this quote from an evaluation in Egypt.

The type of problems/gaps in NORPLANT subsystems reflected by the study findings was expected, but the magnitude was to some extent shocking. MOH and CAs trust research generated by the FRONTIERS program and believe it is of good quality.

- Partner characteristics: Just as some organizational characteristics can favor utilization, others can inhibit it. Some examples are staff turnover, provider resistance to change, internal competition, rigid hierarchies and other management issues. The following example describes how the supervisory structure of the partner organization was a barrier to study implementation.

There were very few obstacles to the implementation of project activities. Perhaps the main one was the lack of supervision by the nurse supervisors in health districts, mostly as a consequence of lack of funds and lack of time to conduct the supervision visits.

There is a cost associated with making any sort of change, and organizations are most likely to make changes that are consistent with their mission and values. For example, as donor funding has become scarce and more competitive, NGOs have become increasingly interested in sustainability issues, such as charging for services. FRONTIERS collaborated with several organizations including APROFAM in Guatemala on a willingness to pay studies. Although the research suggested that raising prices would increase financial sustainability, APROFAM decided against doing so because it felt that this would conflict with its mandate to provide reproductive health services to all women.

- Inadequate transfer of responsibility: Once the study ends, there is a need for continued support for institutionalization or scaling up. A lack of technical or financial resources in the post-research phase can be an important barrier, as can researchers playing a limited role in the policy process. One program manager who had collaborated on several studies noted:

There is no doubt about the results. Often what is lacking is resources, for example the implementation of Norplant. Good results without institutional financial resources for continuity.

A non-FRONTIERS researcher in Bangladesh described a situation where study partners and stakeholders did not remain engaged in the utilization process, and so the study results were largely ignored. 
Some NGOs on a small scale utilized the findings. However, the main actor, i.e. government, acted just on the contrary. In other words, government programs policy just contradicted the findings. This was a deliberate political decision rather than scientific. Here I should add that in general USAID and its CAs did not advocate or work for policy change; not even now.

- Macro-level social and political context: As described above, several intervention and evaluation studies were not included in the impact assessment because external factors prevented their full implementation or potential utilization. Virtually all of these, as well as a number of projects that were included cited the larger political, economic or social context as a severe impediment. The quote below comes from an assessment of the first phase of what was to be a two-part project.

During the planning of the phase II of the project, the government plunged into political troubles with riots and instabilities; there was a politically motivated staff and short time change and turn over, which impaired not only this project, but most of the health sector programs of the period, leading to donors' complaints and pullouts.

Political and social change can also have a positive affect, and sometimes the same context can affect projects differently. The two studies from Indonesia quoted below offer an example of how a barrier to utilization for one study is an opportunity for another.

This study was an in-house literature review that was intended to provide senior government officials and donors with insights into the strengths and weaknesses of existing data sets' capacity to explain the effects of the economic and political crisis of the late 1990s in Indonesia. It was timed to respond to a particular need for information at a precise moment when very little critical analysis was available. Due to a change in personnel the study's report was delayed somewhat, which diluted the importance of the findings.

The macro social and political changes in Indonesia created a climate of where new journalists were flooding the press - the project was very timely. This project was one of several ongoing in the country.

\section{Small Grants}

\subsection{Objectives}

The Small Grants Program was designed as a complement to FRONTIERS' established OR activities. The objective was to expand the OR portfolio in terms of researchers, topics and geography. As conceived, it was not considered as a capacity building activity; rather, FRONTIERS expected the request for proposals to attract universities and research organizations 
with sufficient experience and institutional support to conduct studies independently, with no technical assistance from Population Council field offices.

Project proposals were selected for funding based on the following criteria:

- A strong operations research design to test a family planning intervention;

- Clearly stated objectives;

- Sound scientific methodology, with a description of the sample size, control group, and experimental or quasi-experimental design;

- A detailed budget;

- Evidence of organizational capacity to conduct the study;

- A detailed timeline of activities; and

- A plan for disseminating the findings.

\subsection{Grants awarded}

Over a two-year period, 159 proposals were submitted from more than 60 countries worldwide. The FRONTIERS review panel selected 12 grants for operations research projects. The average funding level was US\$71,250 per project and the average duration was two years.

Tulane's role changed as the Small Grants program progressed. Initially, Tulane advertised the program and handled the submission of proposals and concept papers. The selection panel included Tulane faculty as well as Population Council and USAID staff, with Tulane coordinating the review process and notifying applicants of the status of their proposal. When revisions were necessary, or when a concept paper was recommended to be submitted as a full proposal, Tulane also provided some assistance.

Once grants were awarded, each grantee entered into a sub-agreement with the Population Council, who was then responsible for administering the grant. Tulane was responsible for technical monitoring as well as joint administrative monitoring from the Washington DC office. Ethical monitoring visits and on-site technical assistance were provided by Tulane or Population Council staff, according to program needs and opportunities. Finally, each Small Grant was required to submit a final report and as technical monitor, Tulane was responsible for ensuring that the report met Population Council standards of quality for publication. As discussed further below, some reports required extensive revisions and for these projects, this was by far the most labor-intensive phase for Tulane.

A brief description of each of the Small Grants awarded follows. Final reports for each study are available from FRONTIERS and the implementing organization.

\section{Bangladesh}

From the Home to the Clinic: A New Reproductive Health Service Delivery Model for

Bangladesh. Researchers from John Snow, Inc. (JSI) studied the results of a shift from homebased reproductive health care (provided by community health workers) to care in public and nongovernmental clinics. 


\section{Bolivia}

Assessing the Impact of a Community-Based Intervention on Service Utilization in Family Planning and Reproductive Health in Bolivia. Researchers from the Center for Information and Development of Women (CIDEM) in cooperation with the Ministry of Health introduced a community outreach and education intervention in reproductive health clinics in marginalized rural areas around La Paz, combined with district-wide training and support for improved quality of care and mentoring. The goal of the project was to increase the use of health care facilities by underserved groups, particularly by adolescents, men, and non-pregnant women.

\section{Cameroon}

Peer Education as a Strategy to Increase Contraceptive Prevalence and Reduce the Rate of STDs/AIDS among Adolescents in Cameroon. In this quasi-experimental study with a comparison group, the Institute for Behavioral Studies and Research (IRESCO) tested an IEC intervention with the ultimate goal of reducing HIV and STI infection and unwanted pregnancies, by improving RH knowledge and reducing sexual risk behaviors among youth. The intervention consisted of developing and distributing publications, including comic books and a monthly magazine by and for teenagers; and a peer education network that worked with individuals and small groups and also organized cultural and sporting activities as venues for community dialogues on RH issues.

\section{India}

Increasing Community Involvement in Planning and Monitoring of Reproductive and Child Health Services: Operations Research in Family Planning and Reproductive Health. In 1996 the Government of India introduced a decentralized planning approach to decide services levels based on community's health needs, but assessments showed that community participation had not increased, mainly because of lack of guidance on how to involve community in this approach and sustain their interest in it. Thus, FRHS decided to undertake a research project to explore ways of involving the community in Karnataka, India. The objective was to form health committees that would act as a bridge between community and health staff, identify local health problems and increase the community's access to health services.

\section{Indonesia}

Impact of Client Communication Training on Client Participation and Contraceptive Continuation. Working with the Ministry of Health and Population, the Johns Hopkins University Center for Communication Programs (JHU/CCP) tested the acceptability and effectiveness of introducing the "Smart Patient" concept in which family planning patients are coached to ask more questions and increase their interaction with providers, which in turn was expected to improve quality of care.

\section{Kazakhstan}

Promotion of Lactational Amenorrhea Method and Breastfeeding Intervention Trial.

Breastfeeding is nearly universal in Kazakhstan, but many mothers breastfeed only for a short time or inconsistently. In order to expand the benefits of breastfeeding as a family planning option for women in the Republic of Kazakhstan, the Academy of Preventive Medicine tested the effectiveness of Lactation Amenorrhea Method (LAM) promotion among women in urban and rural hospitals. Researchers trained hospital staff in four maternity wards to provide patient 
counseling on the benefits of LAM as a family planning method. After the intervention, they observed the breastfeeding habits of 3,969 women and 4,003 children, following each for a 12month period.

\section{Nepal \\ Determining Effective and Replicable Communication Based Mechanisms for Improving Young Couples' Access to and Utilization of Reproductive Health Information and Services. The Center for Research on Environment, Health and Population Activities (CREHPA) tested two communications-based interventions to improve young married couples' (younger than 25 years) access to and utilization of reproductive health services and information. They compared the effects of strengthening existing Mothers' Groups, who meet monthly and discuss social issues including reproductive health, to forming new Youth Communication Action Groups, whose members were young married women and which had a greater focus on reproductive health issues as well as more training and support for leadership and communications skills.}

\section{Nigeria}

Promoting Dual Protection Practices Among Women and Their Male Partners in Lagos and Oshogbo, Nigeria. The Association for Reproductive and Family Health (ARFH) tested the effectiveness of training providers and conducting educational sessions with groups of male participants in increasing the use of condoms for dual protection against STIs and pregnancy. Participating men attended monthly discussions on reproductive physiology, family planning, STIs/HIV/AIDS and other health issues.

\section{Peru}

Information, Education and Communication Strategies Culturally Appropriate for Improving Adolescents' Reproductive Health in the Inca Region of Peru (Cusco). Comunicación Andina tested a communications intervention to improve rural, indigenous high school students' knowledge and attitudes relating to reproductive health and adolescence. The intervention consisted of a live bilingual radio program hosted by three local teens, supported by trained "peer promoters" in each school. Adolescencia y Sexualidad, a 20-minute daily program, included music and youth news features, as well as information about reproductive health, STIs/HIV, sexuality, and self-esteem, and included responses to questions submitted by listeners.

Sustainability of Postabortion Care. In collaboration with the Ministry of Health, IPAS conducted this study in 2000 to assess the sustainability of changes made during a 1997 intervention to improve postabortion care (PAC) at a large urban hospital.

\section{Romania}

Improving Health Care Providers' Knowledge, Attitudes, and Practices in Reproductive Health in Rural Romania. In collaboration with the Ministry of Health, Project Concern International tested an intervention to improve reproductive health care in rural health clinics. The project trained rural physicians and nurses in reproductive health, and one group received follow-up support through an experienced physician who served as a resource person.

\section{Senegal}


Taking Postabortion Care Services Where They are Needed: Testing Postabortion Care Expansion to Rural Areas. In a 1997 Africa OR/TA study, postabortion care was first introduced in three urban tertiary hospitals in Senegal. The study demonstrated clear improvements in quality of care, which led partners to expand the model to regional hospitals and the $\mathrm{MOH}$ to develop national standards of care for PAC services. In this small grant, EngenderHealth and CEFOREP tested the feasibility of applying these protocols to primary and secondary level district health centers and health posts.

\subsection{Advantages}

This section describes the advantages of the Small Grants approach in relation to the usual FRONTIERS OR studies, as well as the difficulties faced.

\subsubsection{FRONTIERS Mandate}

FRONTIERS, like any international program, can only work in a limited number of countries and with a limited number of partners. The Small Grants program was designed to complement FRONTIERS' research portfolio by expanding both the number of organizations and countries, and in this it succeeded. Studies were conducted in six countries that had no other concurrent FRONTIES activities and by eight organizations that did not collaborate with FRONTIERS on other studies. (The exceptions were IPAS, EngenderHealth, JSI and JHU/CCP.) Two of the three FRONTIERS studies in Europe and Eurasia were Small Grants, and the IRESCO study in Cameroon was one of a very few in Francophone Africa outside of Senegal.

Findings from the Small Grants contributed to the body of knowledge on a variety of FRONTIERS research priorities, such as youth, quality of care, contraceptive introduction, PAC, HIV/AIDS and sustainability of services. At the same time, they often adopted approaches that were not emphasized in most other FRONTIERS studies, such as community participation and novel communications strategies to reach youth. The Small Grants program was consistent with FRONTIERS IR3 as well as IR1, in that it expanded the use of OR; although all organizations had some experience in evaluating programs, this was the first opportunity for several to conduct an operations research study. The Small Grants program also coincided with capacity building activities in collaboration with WHO, in particular in Kazakhstan and Romania.

Many of the grantees designed their projects as a continuation of previous work supported by USAID or other donors. IPAS, for example, evaluated the longer-term changes brought about by a 1997 OR study with the INOPAL project. CIDEM tested the effect of adding a community involvement component to a WHO-sponsored quality improvement initiative. IRESCO's peer education initiative built on previous youth and communication activities under their "Entre Nous Jeunes" project, which received assistance from various sources including Tulane University (through SFPS), GTZ and WHO.

Projects were conceived of locally, by committed and enthusiastic organizations that had experience working directly with the beneficiary groups. This ensured that the research was directly relevant to local priorities, and allowed researchers to take advantage of established relationships and increase local ownership, a particular asset for community involvement. 


\subsubsection{Utilization of OR Results}

A history of working together also fostered a high level of collaboration with local authorities in getting research results utilized. While most Small Grants did not lead to national level changes in programs or policy (the exceptions being the Senegal PAC study and the Indonesia Smart Patient study), many local or district-level programs quickly adopted the new approach or intervention tested. Grantees were able to take advantage of existing dissemination networks, particularly if they worked in program implementation as well as research. Local NGOs and communities, with their sense of ownership, were also likely to sustain their efforts to promote utilization in the absence of continued external funding, thus requiring a shorter commitment by FRONTIERS or a USAID-supported service delivery CA.

\subsubsection{Financial Sustainability}

Virtually all recipients of Small Grants leveraged substantial funding from other sources to support their studies. All of the US-based CAs matched funding from own sources to cover staff time and travel, as well as equipment or implementation of the intervention. Some NGOs contributed their own resources or acquired external funding to expand activities beyond their original proposal. When PCI/Romania found their "warmline provider" intervention to have no effect, they used a no-cost extension of the USAID-supported Healthy Mothers, Healthy Babies project to provide the training and support that the warmline providers felt they needed to perform their role. IRESCO designed their intervention for Francophone youth but found a great demand for English translations of their comics and magazines, which they were able to provide with a grant from GTZ.

Grantees also tended to be smaller local organizations that can be more cost-efficient than some of the usual FRONTIERS partners in terms of travel, staff time and local transportation and field costs.

\subsection{Challenges}

The Small Grants Program was conceived as a mechanism to expand the use of OR without increasing FRONTIERS staff, offices or workload. Organizations receiving grants would plan, implement and evaluate intervention studies with limited monitoring from FRONTIERS. Technical assistance, if necessary, would be provided by their own institutions, which were expected to be largely universities, USAID collaborating agencies and local research groups. The knowledge generated could then be disseminated regionally by the grantee and globally by FRONTIERS.

\subsubsection{Technical}

The reality of the Small Grants Program was not so simple, beginning with the quality of the proposals. While some established research programs did apply, the bulk of proposal came from groups specializing in service delivery, education, communication and advocacy, with limited research experience. A large proportion of the proposals were either not related to family planning (focusing instead on HIV, for example) or not operations research. Many proposed KAP surveys or other demographic research, without any clear link to service delivery. 
Applicants in the first two rounds had the option of submitting a complete proposal or a concept paper to be developed into a proposal for the subsequent round, while in the third round only final proposals were accepted. All proposals in the third round had been previously submitted either as concept papers or proposals with recommended revisions. While reviewers considered all twelve proposals to be feasible and have sound study designs, many Small Grant studies faced unanticipated technical challenged in implementation. Several studies used sampling approaches that were not generalizable, while others faced problems with contamination of comparison groups, ranging from some of the youth in comparison areas being exposed to a communication intervention in one study to interviewers in another study counseling women from the control group on topics being measured in the survey. The latter problem arose because these women were not counseled by their providers and had questions. A few grantees also had difficulties collecting data that would adequately answer their research questions due to inadequate questionnaire designs, small sample sizes and, in one case, providers recording insufficient information in patient medical charts for researchers to determine whether they were applying skills learned in training.

It is worth noting that no single project faced all of the above challenges, and most problems (e.g. sampling) affected only a minority of studies. In only two cases was it impossible to determine whether the intervention was effective - in Nigeria because the intervention was too weak and the coverage was too limited, and in Cusco because the baseline and endline data were not comparable on enough indicators. However, virtually all the final reports presented a challenge to grantees and FRONTIERS/Tulane staff. (The exceptions were those written by fluent English speakers with US-based CAs, which were of exceptional quality even in relation to other FRONTIERS final reports.) Most Small Grant final reports required heavy editing for language and structure, or contained insufficient analysis or discussion. Overall structure and clear, meaningful presentation of data were the two principle problems.

\subsubsection{Administrative}

The technical challenges described above relate to individual studies, but the Small Grants program as a whole also had some inherent shortcomings. First, there was some confusion over the role of U.S.-based and regional FRONTIERS staff, especially among local researchers who had collaborated with Population Council on previous studies and were accustomed to a great deal of involvement. Regional FRONTIERS and Population Council staff were told that they were not responsible for monitoring Small Grant studies and so did not, which made some local researchers feel they were being ignored initially. Once this misunderstanding became evident, it was easily cleared up and no hard feelings remained. FRONTIERS staff were largely quite interested in the progress of the studies in their region, and were happy to be kept informed.

Because most recipients of grants were small NGOs, they were not able to start activities as quickly as larger, more established programs. In most cases, they needed to wait for their first payment to begin, to purchase equipment and contract and train personnel. Once equipment was purchased, there was sometimes a delay before it was available, or while materials and curricula were being developed.

As projects began, it was quickly apparent that some would require more technical assistance than had been anticipated, and thus a decision was made that FRONTIERS/Tulane staff would 
be responsible for providing assistance via phone and email, while visits would be made by either Washington-based or regional staff, according to their availability, expertise and geographic proximity. For example, FRONTIERS regional staff in Asia had previously worked with FRHS in India and CREHPA in Nepal and traveled to Katmandu and Mysore for other reasons, and so they were the most appropriate to conduct monitoring visits and attend dissemination meetings for these projects, while Tulane staff visited Kazakhstan and Romania, where FRONTIERS had not other projects or staff.

All studies were visited at least once as required by MPA guidelines, but without regular visits by FRONTIERS staff, it was sometimes difficult to ensure that work was being done and was of sufficient quality. Assistance was provided to organizations according to needs identified during these visits or in response to requests, although in all cases it was substantially less than that provided in even the simplest of the regular program of studies.

\subsubsection{Personnel}

Staff turnover or absences affected the Small Grants program much the same way as they affected all FRONTIERS studies, as described in process assessments by monitors. Principal investigators, other key implementing agency staff, and local partner organizations changed between the proposal and final report in a number of studies, as did relevant FRONTIERS staff. A few organizations prepared their proposals with the help of external advisors who were not able to remain involved throughout the study. But, as with other FRONTIERS studies, some transitions were smooth and others were disruptive. Personnel changes often slowed study progress and made monitoring and communication more difficult, but ultimately most did not affect study results.

\subsection{Recommendations}

Based on the above assessment of challenges and benefits of the Small Grants program, we developed recommendations in three categories: program objectives, monitoring and administration, and capacity building. Recommendations were originally presented to FRONTIERS and USAID in 2003 and were taken into account for the five-year extension of FRONTIERS. The recommendations are also relevant to other organizations considering adopting a similar approach to research programs.

\subsubsection{Program Objectives}

The number of proposals submitted and the enthusiasm and gratitude expressed by grantees demonstrate the great demand exists for opportunities for small organizations to conduct applied research studies. However, the program did not succeed in attracting universities and other established research groups to the extent hoped. A principle reason cited for the lack of interest shown by universities and established research groups was that the money was insufficient to implement studies of this kind. All four studies conducted by US-based CAs were jointly funded by FRONTIERS and the CA and could not have been implemented without additional funding, much of which was used for international travel, salaries and equipment purchases. Local organizations were able to implement studies more cheaply but less likely to have the capacity to do so independently. For a future Small Grants program, it would be important to decide on the target grantees: for American universities and CAs, the average award per project might need to 
be increased, while for developing country organizations, the costs of additional technical assistance should be budgeted.

\subsubsection{Monitoring and Administration}

An important weakness of monitoring the small grants was waiting too long after project start-up to begin. Increased communication and visits early on could have helped prevent potential problems. Grantees submitted technical progress reports every six months, which was not frequent enough to ensure that a two-year project was progressing along schedule. We think regular communication through email and phone calls and at least one visit during baseline data collection and the development of the intervention are essential to guarantee a high standard of research quality. Monitoring would need to continue throughout the study, though the initial phase is crucial. One option for providing this increased support would be for FRONTIERS to dedicate more staff time, while another would be to require grantees to include an advisor or mentor in their proposal. This person would be particularly important if research staff changed mid-project, as it did in several small grants.

\subsubsection{Capacity Building}

Although such was not its intention, the Small Grants program linked IR1 (innovative research) with IR3 (capacity building) and showed the difficulty for an organization to move from understanding the principles of OR to being able to implement a quality study. Clearly there is a need to provide such opportunities of actually conducting a research study if we hope to develop national capacity to produce as well as use OR. A modest amount of technical assistance, strategically provided, can make a big difference in study quality and ease of implementation, and would contribute to both intermediate results 1 and 3. A lower-cost approach would be to limit study types, by requiring simple designs or even through use of a standard protocol whereby individual researchers are provided with an outline for study design, intervention and analysis plan, which they can adapt and implement in their own program setting. This would reduce the expertise needed for technical assistance, while allowing new researchers to implement the project independently. As of June 2004, Population Council and Tulane staff had developed a standard protocol for systematic screening for reproductive health services, tested successfully in Peru and Guatemala under INOPAL, and four organizations in three geographic regions had approved proposals to begin six to twelve month studies. This short timeline and structured approach will facilitate monitoring by regional staff members who were directly involved in proposal development, and reduce potential research pitfalls, such as inappropriate questionnaire development.

\section{Internships}

A third element of the FRONTIERS/Tulane partnership was an internship program for students from the International Health Department of Tulane School of Public Health. The internship was based in the Population Council, Washington D.C. office. The internship provided an opportunity for the selected students to gain hands on experience on how to design, conduct, and manage the various aspects of operations research in reproductive health.

Although the duration of the fellowship was originally designated as six months, most interns extended their time at FRONTIERS. The longer period benefited both the individual and the 
program, by allowing fellows to work more independently and complete projects they had begun. The extra time also gave them flexibility in their subsequent job searches.

In total, eight interns participated in this program. They were: Jessica Gipson (December $1998-$ June 1999), Lorraine Anglin (July - December 1999), Laurette Cucuzza (March - December 2000), Kris Lantis (January - October 2001), Shalini Prabakhara (January - March 2001), Inoussa Kabore (October 2001), Kristin Banek (February - July 2002), and Suhaila Khan (November 2002 - June 2003). Specific activities and responsibilities varied according to the interests and abilities of the intern and the needs of the program. The first two internships concentrated on the Global Agenda, from helping to coordinate the submission and review of concept papers to assisting with study design and questionnaire development, among other tasks. With the Global Agenda studies well underway in 2000, the two subsequent interns were dedicated to communications, capacity building and economic evaluation. Shalini Prabakhara and Inoussa Kabore focused mostly on evaluation issues. As the Global Agenda studies gathered large amounts of data needing to be processed and standardized, the final two interns returned to the Global Agenda and provided support for these tasks. The FRONTIERS internship provided a unique opportunity for those entering the filed of reproductive health to learn about other organizations and programs; make personal contacts; participate in technical meetings, trainings and conferences; and occasionally travel to the field. Several interns authored publications and presented at national conferences.

All of the interns successfully completed their assignments. After finishing at FRONTIERS, both Jessica Gipson and Lorraine Anglin entered the Peace Corps, and Jessica Gipson is currently pursuing a PhD at Johns Hopkins School of Public Health. Laurette Cucuzza has specialized in training for HIV practitioners, first with faith-based groups through CEDPA's ENABLE project and more recently at Synergy. Kris Lantis is nearing the end of a Michigan Population Fellowship with USAID, including a two-year post as Health Officer at the Eritrea Mission. After two years at FHI in North Carolina, Shalini Prabakhara is studying medicine at the University of North Carolina. Inoussa Kabore manages global research and evaluation for FHI's IMPACT project. Kristen Banek worked as a researcher on a joint University of California-San Francisco and Makerere University malaria project in Uganda, then in 2004 moved to Liberia to work with International Rescue Committee on a malaria project for refugees. Suhaila Khan is completing her dissertation research for her $\mathrm{PhD}$ at Tulane, concentrating in reproductive health economics.

\section{Conclusions}

As a partner on the Frontiers in Reproductive Health Program from 1998 to 2004, Tulane furthered progress toward all three of the program's intermediate results. Tulane contributed to IR1, innovative interventions tested to improve reproductive health through the Small Grants program, which generated research, and through the evaluation component. In assessing utilization, Tulane helped research staff understand the impact of their studies on reproductive health policies and programs as well as factors that affect this impact. In identifying these factors, researchers are able to take a more proactive approach to promoting utilization, which is the focus of IR2, research results disseminated and utilized. In IR3, Tulane was involved in more discrete capacity building activities. These included working with FRONTIERS/Washington 
DC staff to modify the IR3 results framework according to new directions in capacity building after the first four years, developing a standard research protocol for systematic screening of services, and developing and facilitating a workshop on operations research for program managers. Through the internship program, selected Tulane students were provided opportunities to work on the design, implementation and management of operations research reproductive health projects. Currently, Tulane University is considering adding a course on Introduction to Operations Research to its academic program in International Health and Development. 


\section{References}

Agarwala-Rogers, R. 1977. "Why is evaluation research not utilized?" Evaluation Studies Review 2: 327-333.

Anderson, M., J. Cosby, B. Swan, H. Moore, H., and M. Broekhoven. 1999. "The use of research in local health service agencies." Social Science and Medicine 49: 1007-1019.

Askew, I., R. Miller, and J. Solo. 2001. Using operations research for producing and communicating knowledge about reproductive health services in sub-Saharan Africa. Paper presented at the IUSSP seminar on 'The Production and Circulation of Population Knowledge', March 2001, Brown University, USA.

Bertrand, Jane T. and M. Celeste Marin. 2001. Evaluating Operations Research: An assessment of process and impact. Washington DC: FRONTIERS/Tulane University.

Corwin, R. G. and K. S. Louis. 1982. "Organizational barriers to the utilization of research." Administrative Science Quarterly, 27: 623-640.

Davis, P. and P. Howden-Chapman P. 1996. "Translating research findings into health policy." Social Science and Medicine 43: 865-872.

Frenk, J. 1992. "Balancing relevance and excellence: organizational response to link research with decision making." Social Science and Medicine 35: 1397-1404.

Goldstein, M. S., A. C. Marcus, N. P. Rausch. 1978. "The non-utilization of evaluation research." Pacific Sociological Review 21: 21-44.

Haaga, J. G. and R. M. Maru. 1996. "The effect of operations research on program changes in Bangladesh.” Studies in Family Planning 27: 76-87.

Hegazi, S. 1997. Utilization of Operations Research in Egypt. Special Report. Cairo: The Population Council.

IFPRI. 2001. Impact Evaluation: Assessing the impact of Policy-oriented Social Science Research. Washington, D. C.: International Food Policy Research Institute.

Sigel, K. and P. Tuckel. 1985. "The utilization of evaluation research." Evaluation Review 9: 307-328.

Solo, J., A. Cerulli, R. Miller, I. Askew, and E. Pearlman. 1998. Strengthening the Utilization of Family Planning Operations Research: Findings from Case Studies in Africa. Washington, D. C.: The Population Council.

Trostle, J., M. Bronfman, and A. Langer. 1999. "How do researchers influence decisionmakers? Case studies of Mexican policies." Health Policy and Planning 12: 103-114. 
Weiss, C. H. and M. J. Bucuvalas. 1980. "Truth tests and utility tests: decision-makers' frames of reference for social science research." American Sociological Review 45: 302-313. April 1980. 


\section{Appendix A: Critical Review of Literature on Utilization of Research Results}

\begin{tabular}{|c|c|c|c|}
\hline $\begin{array}{l}\text { Author / } \\
\text { Study Title / } \\
\text { Publication Date }\end{array}$ & $\begin{array}{l}\text { Location / } \\
\text { Program Description / } \\
\text { Target Population }\end{array}$ & $\begin{array}{l}\text { Sample / } \\
\text { Design / } \\
\text { Analytic Methods }\end{array}$ & $\begin{array}{l}\text { Results: Change in Outcome/Impact } \\
\text { Conclusions / } \\
\text { Implications }\end{array}$ \\
\hline \multicolumn{4}{|c|}{ I. Operations / Evaluation Research } \\
\hline $\begin{array}{l}\text { Askew et al. "Using } \\
\text { operations research } \\
\text { for producing \& } \\
\text { communicating } \\
\text { knowledge about } \\
\text { reproductive health } \\
\text { services in sub- } \\
\text { Saharan Africa." Pop } \\
\text { Council. } 2001 .\end{array}$ & $\begin{array}{l}\text { Country: Sub-Saharan } \\
\text { Africa } \\
\text {-Two decades (since } \\
\text { 1979-) } \\
\text {-USAID funded OR } \\
\text { program. }\end{array}$ & $\begin{array}{l}\text {-Paper reviews the OR program in order } \\
\text { to inform policymakers, program } \\
\text { managers, donors \& technical assistance } \\
\text { organizations how to strengthen delivery } \\
\text { of information \& services in reproductive } \\
\text { health issues. }\end{array}$ & $\begin{array}{l}\text { Use of OR: not much } \\
\text {-The paper mainly presents some negative findings of OR programs and the consequences of such findings. } \\
\text { Facilitators/Barriers: not addressed } \\
\text { Other: } \\
\text {-OR program is expected to provide answers to questions raised by service program managers. OR program is subjected to } \\
\text { assessment \& justification in terms of the extent to which this knowledge has not been produced to a high scientific } \\
\text { standard, but also how the results are utilized } \\
\text {-OR in SSA has moved from producing knowledge primarily for political purposes to introduce contentious health service } \\
\text { (e.g. FP), to designing ways to integrate FP services into PHC programs, to serving as an assistant to USAID \& its TA } \\
\text { organization to systematically develop \& test strategies to provide broader range of reproductive health services. } \\
\text {-A significant increase over the past decade in the attention given \& funding allocated to communication is noted. } \\
\text {-There is an increase in the need for the OR program to justify the funding it receives. This has evolved from funding } \\
\text { agencies thinking that research funds are investments and concrete payback is expected from these investments. } \\
\text {-Early in the OR program benefit was seen in terms of knowledge produced that could help FP programs become accepted } \\
\& \text { established. Now payback is evaluated in terms of how research is used, and at what cost. }\end{array}$ \\
\hline
\end{tabular}




\begin{tabular}{|c|c|c|c|}
\hline $\begin{array}{l}\text { Haaga et al. "The } \\
\text { effect of operations } \\
\text { research on program } \\
\text { changes in } \\
\text { Bangladesh." Studies } \\
\text { in Fam. Plan. } 1996 .\end{array}$ & $\begin{array}{l}\text { Country: Bangladesh } \\
\text {-rural community } \\
\text {-10 year operations } \\
\text { research project in } \\
\text { Matlab }\end{array}$ & $\begin{array}{l}\text { - Assessed how and what circumstances } \\
\text { contributed to change in large-scale } \\
\text { public programs from research-based } \\
\text { advice and results of pilot projects. }\end{array}$ & $\begin{array}{l}\text { Use of OR: yes } \\
\text {-Findings pertain mainly to the issues of the national FP program. } \\
\text {-Research, policy decision, \& implementation can occur in any sequence. } \\
\text {-OR can produce useful changes in organizational behaviour, even when large-scale problems remain. } \\
\text {-Policymakers have multiple objectives to fulfill, and they take advice selectively. } \\
\text { - Greatest effect that research had upon was the decision to expand the work force of female field workers. } \\
\text {-Delivery of injectable contraceptives: The govt. continued to expand the program based on Matlab findings which } \\
\text { compared favorably with the govt. program. } \\
\text {-Management information: Project worked with the MIS unit of the FP Directorate and simplified \& consolidated formats } \\
\text { \& helped devise \& test feedback reports. } \\
\text {-Field-workers use of service registers: single algorithm worked better and was added to the govt. FWA field book. } \\
\text {-Satellite clinics are held the same day as immunization outreach sites to reach more women with FP methods. } \\
\text { Facilitators: } \\
\text {-Large scale testing can create its own momentum, as research design is forgotten \& new practice becomes part of routine. } \\
\text {-Policy advice that is consonant with existing power relations is the easiest to implement. } \\
\text { Barriers: } \\
\text { - Policy advice that disrupts long-standing power relationships \& organizational culture takes more effort to implement. } \\
\text {-Recruitment \& training of field-workers: initial performance gains dissipated after outside support was withdrawn. } \\
\text { Other: } \\
\text { - OR often concerns adjustments to programs \& deals with issues of policy implementation rather than with great policy } \\
\text { questions. } \\
\text {-Field supervision: results are mixed; managers often adopt one element of a package enthusiastically and ignored the } \\
\text { others. } \\
\text {-Contraceptive user fees: findings were negative, yet govt. kept user fees. }\end{array}$ \\
\hline $\begin{array}{l}\text { Hegazi. "Utilization of } \\
\text { operations research in } \\
\text { Egypt." Pop Council } \\
1997 .\end{array}$ & $\begin{array}{l}\text { Country: Egypt } \\
\text { FP \& RH programmes } \\
\text { FHI projects (1989- } \\
\text { 1992) } \\
\text { PC projects (1992-1997) }\end{array}$ & $\begin{array}{l}\text { Descriptive study } \\
\text { OR Projects: } 12 \text { (diagnostic, } \\
\text { intervention, evaluation, experimental, } \\
\text { quasi-experimental, observational) } \\
\text { Respondents: } 18 \text { (sr. govt. policymakers, } \\
\text { donors, program managers, service } \\
\text { providers, cooperating agencies) } \\
\text { Data: qualitative (in-depth interview) }\end{array}$ & $\begin{array}{l}\text { Use of OR: Yes } \\
\text {-Internal project evaluation is usually the sole mechanism to learn about the impact of OR. Hence, this study undertaken. } \\
\text { Study had } 4 \text { immediate objectives: } \\
\text {-Impact of process utilization \& evidence of OR utilization: } \\
\text {.e.g. The Raidat Refiat study was useful because the recommendations were used to - a) prepare \& use a working guide } \\
\text { for every Raidat, b) unified record keeping system established, c) on the job-training added to programme. } \\
\text { e.g. post-abortion care projects contributed to the design of USAID/Egypt FP \& RH programme. } \\
\text {-Factors fostering utilization: } \\
\text { relevance of the research (based on emerging need from the field) } \\
\text { quality of OR study } \\
\text { active involvement at all stages by the various partners } \\
\text { using appropriate methodologies } \\
\text { raising practical recommendations (e.g. present practical solutions) } \\
\text {-Identify barriers to utilization: } \\
\text { transfer of research skills to enable continuity of work when external TA phases out } \\
\text { technical \& management skills of local research institutions } \\
\text { dissemination (e.g. final reports should not be in English only; translate into Arabic for local policymakers) } \\
\text { systematic follow up activities } \\
\text { Other: } \\
\text {-Define directions to guide future efforts of utilization (e.g. continue dialogue with partners) }\end{array}$ \\
\hline
\end{tabular}




\begin{tabular}{|c|c|c|c|}
\hline $\begin{array}{l}\text { Masulit et al. } \\
\text { "Influencing } \\
\text { reproductive health } \\
\text { policy \& programs in } \\
\text { the Philippines." Pop } \\
\text { Council. 2001. }\end{array}$ & $\begin{array}{l}\text { Country: Philippines } \\
4 \text { regions } \\
\text { FP program }\end{array}$ & $\begin{array}{l}\mathrm{N}=21 \text { policy champions ( } 4 \text { teams) } \\
\text { comprising of govt., nongovt. workers. } \\
\text { Tested a model of OR targeting program } \\
\text { managers. } \\
\text { Model combined capacity building \& } \\
\text { advocacy approaches. } \\
\text { Objective: promote utilization of } \\
\text { research for decision making \& program } \\
\text { improvement. }\end{array}$ & $\begin{array}{l}\text { Use of OR: no } \\
\text { Facilitators: } \\
\text { - Level of maturity of the OR result is an important variable in the OR advocacy \& utilization equation. } \\
\text { - Necessary institutional support system is a critical factor in the assimilation and utilization of a research result. } \\
\text { Barriers: not specifically addressed } \\
\text { Other: } \\
\text { - There is no single strategy or approach to effective advocacy. } \\
\text { - HOWEVER, program changes for the OR project were measured in terms of the adoption \& pilot-testing of the } \\
\text { Community-based MIS in selected areas of the } 2 \text { of the } 4 \text { regions where CBMIS is not yet installed, and the pledge to } \\
\text { sustain the use of CBMIS in } 2 \text { cities where the system is already being implemented. }\end{array}$ \\
\hline $\begin{array}{l}\text { Ross et al. } \\
\text { "Perspectives on } \\
\text { operations research." } \\
\text { Int. Fam. Plan. Persp. } \\
1987 .\end{array}$ & Review article on OR. & & $\begin{array}{l}\text { Use of OR: not addressed in article } \\
\text {-Application of results: The application of research results can never be guaranteed, since outcomes are unpredictable and } \\
\text { sometimes negative. More importantly, managers must embrace the results \& devote their energies to applications, or the } \\
\text { study will make little difference. } \\
\text { Facilitators: } \\
\text { For wide implementation of results, research \& results should be under govt. auspices. Example of CBD programs in } \\
\text { Sudan \& Nigeria given as to how govt. was not receptive at earlier phases of project but became fully receptive \& } \\
\text { operating (as in Nigeria) when project showed positive results. } \\
\text { Barriers: } \\
\text { One serious flaw in many projects is the withdrawal of donor support at the point when the research has been concluded } \\
\text { and the results can be applied. } \\
\text { Other: } \\
\text {-OR definition: application of research methods to improve action programs. } \\
\text {-Then discusses: research methods, choosing priority topics, using the private sector, application of results, building } \\
\text { research capability, donor cooperation, the recipients perspective. }\end{array}$ \\
\hline
\end{tabular}




\begin{tabular}{|c|c|c|c|}
\hline $\begin{array}{l}\text { Solo et al. } \\
\text { "Strengthening the } \\
\text { utilization of family } \\
\text { planning operations } \\
\text { research: findings } \\
\text { from case studies in } \\
\text { Africa." Pop Council } \\
1998 \text {. }\end{array}$ & $\begin{array}{l}\text { Country: Burkina Faso, } \\
\text { Mali, Gambia, Kenya, } \\
\text { Tanzania } \\
\text { OR projects (1989- } \\
\text { 1993) }\end{array}$ & $\begin{array}{l}\text {-Case study: } 10 \text { projects (diagnostic, } \\
\text { evaluative, experimental) } \\
\text {-Sample size: } 64 \text { respondents } \\
\text { (policymakers \& researchers) } \\
\text {-Data: qualitative analysis } \\
\text {-Used indicators proposed by the OR } \\
\text { working group of USAID } \\
\text { process indicators } \\
\text {.effect indicators }\end{array}$ & $\begin{array}{l}\text { Use of OR: yes } \\
\text {-Report addresses need for greater understanding of how information from OR studies is utilized. } \\
\text {-Most OR projects tend to be implemented as fairly discrete activities due to financial, administrative \& organizational } \\
\text { reasons. } \\
\text { Study objectives: } \\
\text {-Assess the extent to which information from OR studies is utilized - } \\
\text {.result: all case studies report some level of utilization (e.g. change in service delivery, change in policy) } \\
\text {-Factors influencing utilization of study results } \\
\text {.result: identification of problem has to be internal, good interaction between researchers \& decision makers, political \& } \\
\text { programmatic context, OR study quality (e.g. design, implementation), dissemination activities (more the dissemination } \\
\text { more the utilization e.g. Mali CBD study); development of study recommendations (e.g. involvement of service providers, } \\
\text { clear-specific-detailed); efforts to promote utilization of study findings (e.g. researchers should be involved); sustainability } \\
\text { (e.g. if intervention effective feasible to expand, donor funding) } \\
\text { Other: } \\
\text {-Present recommendations to OR practitioner, donors \& users of OR actions. } \\
\text { extensive dissemination essential; high quality of study; good interpersonal relations between researchers \& decision } \\
\text { makers; greater participation in developing recommendations. }\end{array}$ \\
\hline $\begin{array}{l}\text { Vernon. "Operations } \\
\text { research on promoting } \\
\text { vasectomy in three } \\
\text { Latin American } \\
\text { Countries." Int. Fam. } \\
\text { Plan. Persp. 1996. }\end{array}$ & $\begin{array}{l}\text { Country: Latin } \\
\text { America - Brazil, } \\
\text { Colombia, Mexico } \\
\text { Reviews } 6 \text { OR projects }\end{array}$ & & $\begin{array}{l}\text { Use of OR: not addressed } \\
\text {-The paper does not actually measure the utilization of the results of the } 6 \text { OR projects, but only makes } \\
\text { assumptions/recommendations on what can be done to increase service use. } \\
\text { Facilitators/Barriers: not addressed } \\
\text { Other: } \\
\text {-Mainly reviews the } 6 \text { projects and gives conclusions about who the clients are (young, well-educated men, with small } \\
\text { families \& already practicing contraception), who influences them (wives, other vasectomized men), and what can be done } \\
\text { to promote more vasectomy (mass media campaigns). }\end{array}$ \\
\hline $\begin{array}{l}\text { Agarwala-Rogers. } \\
\text { "Why is evaluation } \\
\text { research not utilized." } \\
\text { Evaluation Studies } \\
\text { Review Annual. } 1977 .\end{array}$ & $\begin{array}{l}\text { Review article that } \\
\text { addresses only } \\
\text { practitioner need and } \\
\text { use of research results. }\end{array}$ & & $\begin{array}{l}\text { Use of research: not addressed } \\
\text { Facilitators/Barriers: } \\
\text {-evaluation research better utilized if program officials participate in the evaluation process. } \\
\text {-likelihood of utilization of evaluation research increases when evaluations are insiders to organization as that reduces } \\
\text { anxiety associated with evaluation. } \\
\text {-Identified possible barriers based on literature: } \\
\text {.lack of administrator's participation in evaluation process; } \\
\text {.conflicting interests of program officials \& evaluators; } \\
\text {.lack of 'needs' identification between users \& evaluators; } \\
\text {.lack of trained specialists to act as liaison between programme administrators \& evaluators; } \\
\text { lack of recommendations provided to solve problem identified; } \\
\text {.over emphasis on negative aspects of program; } \\
\text {.timely dissemination of evaluation findings. }\end{array}$ \\
\hline
\end{tabular}




\begin{tabular}{|c|c|c|c|}
\hline $\begin{array}{l}\text { Goldstein et al. "The } \\
\text { nonutilization of } \\
\text { evaluation research." } \\
\text { Pacific Soc. Review. } \\
1978 .\end{array}$ & Review article & $\begin{array}{l}\text { Extensive literature review. } \\
\text { Identify frequently cited reasons \& } \\
\text { solutions for non-utilization, and to } \\
\text { integrate them with a perspective that } \\
\text { sees research as a social process, itself in } \\
\text { need of sociological analysis. }\end{array}$ & $\begin{array}{l}\text { Use of research: yes and no } \\
\text {-research findings not used but programme continued e.g. Head Start programme } \\
\text {-previously little resources spent on evaluation of programmes, now millions are being spent. } \\
\text { Barriers: } \\
\text {-poor methodology \& design } \\
\text {-lack of excellence of researchers } \\
\text {-failure to measure the most important variables } \\
\text {-sometimes the outcomes measured are so abstract (specially in mental field) as to provide few implications for } \\
\text { modification of intervention strategies } \\
\text {-programme staff feeling threatened (specially with negative findings) } \\
\text {-lack of information/studying the dynamics of programme process } \\
\text {-communication problems: final reports are too technical \& not understandable to users; not enough communication } \\
\text { between researcher and user } \\
\text {-lack of timeliness of availability of study findings, not early enough for programmers } \\
\text {-lack of interest by stakeholders: personal \& professional (program administrators, policymakers) }\end{array}$ \\
\hline $\begin{array}{l}\text { Sigel et al. "The } \\
\text { utilization of } \\
\text { evaluation research." } \\
\text { Evaluation Review. } \\
1985 .\end{array}$ & $\begin{array}{l}\text { Country: USA } \\
\text { Evaluates two studies of } \\
\text { the Community Mental } \\
\text { Health Centres } \\
\text { Programme established } \\
\text { in } 1963 \text {. } \\
\text { The studies were } \\
\text { conducted by: } \\
\text {-General Accounting } \\
\text { Office (1971, 1974) } \\
\text {-Ralph Nader-directed } \\
\text { Centre for Study of } \\
\text { Responsive Law }\end{array}$ & $\begin{array}{l}\text { Explored the impact of evaluation } \\
\text { research findings on policy formulation. }\end{array}$ & $\begin{array}{l}\text { Utilization of results: yes } \\
\text {-But no specific examples were cited as to how the evaluation findings were actually used. } \\
\text { Facilitators/Barriers: } \\
\text {-Numerous factors, some nonrationale, determine the policy consequences of evaluation studies. } \\
\text {-Nature of recommendation (e.g. incremental changes meet less opposition than fundamental/global changes; language } \\
\text { used should be objectively-neutral \& not characterized by stridency; recommendations that state goals are more effective } \\
\text { than those that delineate specific courses of action b/c this provides users latitude in selecting ways to achieve the goals } \\
\text { recommended). } \\
\text {-Methodology \& credibility of researcher (e.g. rigorous methodology should be used for all scientific research; evaluators } \\
\text { should be highly trained \& knowledgeable). } \\
\text {-Timing of presentation of findings (the period when a programme is being reformulated or reviewed is a fortuitous time } \\
\text { for policy research). } \\
\text {-Organizational resistances to proposed changes (e.g. organizational needs \& commitments to deeply held beliefs \& values } \\
\text { play an important role in affecting the policy outcome of evaluation studies). } \\
\text {-Communication between researcher \& potential users (in the absence of dialogue, policy researchers develop unrealistic } \\
\text { notions about kinds of policy changes that are feasible). } \\
\text {-Dissemination of findings (policy researcher should spend significant amount of time \& energy in disseminating findings; } \\
\text { e.g. GAO sent early reports to stakeholders \& stakeholders sent their input on correcting problems that were initiated, no } \\
\text { specific example cited about what the problem was \& what correctional step taken; However, the Nader report was } \\
\text { disseminated to mainly non-NIMH people and recommendations were not used). }\end{array}$ \\
\hline
\end{tabular}




\begin{tabular}{|c|c|c|c|}
\hline $\begin{array}{l}\text { Anderson et al. "The } \\
\text { use of research in } \\
\text { local health service } \\
\text { agencies." Soc. Sci. } \\
\text { Med. } 1999\end{array}$ & $\begin{array}{l}\text { Country: Canada: } \\
\text { Kinston area }\end{array}$ & $\begin{array}{l}\text { Semi-structured interviews: } 24 \\
\text { respondents (directors of community- } \\
\text { based non-profit health or social service } \\
\text { organizations) } \\
\text { FGD: } 1 \text { (8 directors as above) } \\
\text { Time: fall } 1996\end{array}$ & $\begin{array}{l}\text { Use of research: not addressed } \\
\text {-No specific examples given only quoted from reviewed literature. } \\
\text {-Mixes up the findings of their study with what the literature says. } \\
\text { Facilitators: } \\
\text {-Identified variables that effect how useful research is to the user (e.g. relevance, level of communication, user } \\
\text { involvement, information processing). } \\
\text { Barriers: } \\
\text {-Lack of resources, expertise, and time to conduct the required research. } \\
\text {-Little connection between research projects \& the day to day activities of the agencies. } \\
\text {-Lack of full awareness of the research needs of the agencies or the research interests of the research community. } \\
\text {-Not effective fit between academic-driven research projects and the agencies service delivery mandate. } \\
\text { Other/Recommendations: } \\
\text {-Transfer of research findings more to local organizations that deliver services to the community is neglected as transfer of } \\
\text { research use focuses on policy and clinical environments. } \\
\text {-Identified purpose of research as programme evaluation, improve services, enhance accountability, improve } \\
\text { administration. } \\
\text {-Identified the process of conducting research as highly important. } \\
\text {-Need help with developing an awareness of the need \& ideas about research \& have them communicated effectively. } \\
\text {-Integrate research into the day to day operations of the agency. }\end{array}$ \\
\hline $\begin{array}{l}\text { Corwin et al. } \\
\text { "Organizational } \\
\text { barriers to the } \\
\text { utilization of } \\
\text { research." Adm. Sci. } \\
\text { Quart. 1982. }\end{array}$ & $\begin{array}{l}\text { Country: USA } \\
\text { Evaluated two education } \\
\text { programmes operating } \\
\text { in the National Institute } \\
\text { of Education: } \\
\text {-Research \& } \\
\text { Development } \\
\text { Utilization Program } \\
\text { (1976-1979) } \\
\text {-Experimental School } \\
\text { Program (rural; 1971- } \\
\text { 1978) }\end{array}$ & $\begin{array}{l}\text {-Use of research associated with the } \\
\text { RDU \& rural ES programmes. } \\
\text {-Secondary analysis of case materials. } \\
\text { e.g. interviews with NIE staff members, } \\
\text { telephone interviews with school } \\
\text { administrators, site visit reports, } \\
\text { retrospective interviews with key actors } \\
\text { in the program, etc. }\end{array}$ & $\begin{array}{l}\text { Use of research: } n o \\
\text { Barriers: } \\
\text {-Policy vacuum: which occurs in absence of } \\
\text { a) an organizational constituency of policy-makers, } \\
\text { b) identifiable policy issues \& research questions, } \\
\text { c) consistent policies \& clear policy options, } \\
\text { d) coordination among the independent agencies responsible for a policy area, } \\
\text { e) an ongoing, operational program that can make use of the findings. }\end{array}$ \\
\hline
\end{tabular}




\begin{tabular}{|c|c|c|}
\hline $\begin{array}{l}\text { Davis et al. } \\
\text { "Translating research } \\
\text { findings into health } \\
\text { policy." Soc. Sci. } \\
\text { Med. } 1996 .\end{array}$ & Review article & $\begin{array}{l}\text { Use of research: not addressed } \\
\text {-Public health research is more influential if topical, timely, well-funded and carried out by a collaborative team. } \\
\text {-Impact of research on evidence-based medicine: mixed results, some studies show there is impact while others show no } \\
\text { impact. } \\
\text {-Impact of research on health reforms: scant evidence. } \\
\text { Facilitators of successful dissemination: } \\
\text {-There is evidence of dissemination \& factors that influence dissemination, but that does not necessarily mean use of } \\
\text { research findings. } \\
\text { addresses an issue that is topical, precisely defined, of national significance, gains the commitment of those carrying out } \\
\text { the research, has university involvement, has substantial funding, has team structure, has experienced investigators } \\
\text { applying appropriate methods and working in a stable, professionally supportive environment to realistic time scales. } \\
\text { Barriers to successful dissemination: } \\
\text {-Purpose of research is unclear; the questions considered too broad or numerous; methods were hastily contrived/not } \\
\text { innovative/not pilot tested; researchers were inexperienced, subject to turnover; funding was inadequate; time scale was } \\
\text { unrealistic; political difficulties; and unplanned personnel change. }\end{array}$ \\
\hline $\begin{array}{l}\text { Frenk. "Balancing } \\
\text { relevance and } \\
\text { excellence: } \\
\text { organizational } \\
\text { response to link } \\
\text { research with decision } \\
\text { making." Soc. Sci. } \\
\text { Med. 1992. }\end{array}$ & Review article. & $\begin{array}{l}\text { Use of research: not addressed } \\
\text { Barriers: } \\
\text {-Research faces the challenge of balancing relevance to decision-making \& excellence in the strict adherence to the norms } \\
\text { of scientific enquiry. } \\
\text {-Organizational responses can be undertaken to promote integration of relevance with excellence. } \\
\text {-Have to create new organizational formulas to balance relevance and excellence in research. } \\
\text {-There are structural barriers to effective communication between researchers \& decision-makers: e.g. } \\
\text {.differences in priorities (resolved by presence of decision-makers in governing or consulting bodies of research centers), } \\
\text {.time management (resolved by collaboration between researchers \& decision-makers since early planning stages of a } \\
\text { project; identification of intermediate products of research), } \\
\text {.language (resolved by executive syntheses, 'translators' of research into policy, joint seminars), } \\
\text {-means of communication, } \\
\text {.integration of findings (resolve by meta analysis, mission-oriented research), } \\
\text {.definition of the final product of the research (discovery vs. decision: greater weight to relevance in evaluation of } \\
\text { researchers), } \\
\text {-Three approaches that can address the structural barriers: e.g. academic subordination, segregation, integration } \\
\text {-Strategy to promote research must include a set of incentives to prevent 'internal brain drain' i.e. tendency of researchers } \\
\text { to move to managerial positions. Solution to this problem maybe four fold: } \\
\text { e.g. parallel careers, academic autonomy, administrative sacrifice, inverted incentives. }\end{array}$ \\
\hline
\end{tabular}




\begin{tabular}{|c|c|c|c|}
\hline $\begin{array}{l}\text { Trostle et al. "How do } \\
\text { researchers influence } \\
\text { decision-makers? Case } \\
\text { studies of Mexican } \\
\text { policies." Hlth. Pol. } \\
\text { Plan. } 1999 .\end{array}$ & $\begin{array}{l}\text { Country: Mexico } \\
4 \text { vertical programmes: } \\
\text { cholera, immunization, } \\
\text { FP, AIDS }\end{array}$ & $\begin{array}{l}\text { Sample: } 67 \text { researchers and officials } \\
\text { (decision/policy-makers) } \\
\text { Method: in-depth interviews } \\
\text { Time: Nov. 1994- Jun. } 1995\end{array}$ & $\begin{array}{l}\text { Use of research: sometimes } \\
\text {-Multiple forces affect policy \& research is only one aspect. } \\
\text { Facilitators/Barriers: } \\
\text { The study identified } 4 \text { areas of factors that promoted or impeded research use in policy-making: } \\
\text { content, actors, process and context. } \\
\text { Content } \\
\text { Promote: Quality (determined by identity/fame of researcher, reputation of journal, judgment of decision-maker); More } \\
\text { attention to biomedical rather than social science research; Research targeting specific issues, offering short-term, } \\
\text { concrete \& applicable results; Research recommendations which are low cost \& provide high benefits. } \\
\text { Impede: vocabulary of researchers difficult to understand by decision-makers; mutual intellectual disdain. } \\
\text { Actors } \\
\text { Promote: groups of researchers \& decision-makers who have identified priority problems, international support for } \\
\text { research } \\
\text { Impede: lack of technical background of both decision-makers and mass media; favouring experience over research, } \\
\text { outside interest group pressure (agenda of private industry/special constituencies - financial). } \\
\text { Process } \\
\text { Promote: informal ties, balanced interests, formal communication channels. } \\
\text { Impede: narrow professional interests. } \\
\text { Context } \\
\text { Promote: long life \& stability of the PRI, rotation of researchers into policy-making positions, small size \& homogeneity } \\
\text { of research community, urgency of a particular health problem. } \\
\text { Impede: excessive State centralization, hierarchical management of information, changes in top-level management of the } \\
\text { health system with each sexennial change of government, restricted economic resources. }\end{array}$ \\
\hline \multicolumn{4}{|r|}{ 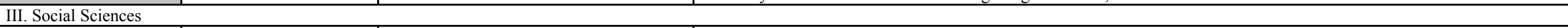 } \\
\hline $\begin{array}{l}\text { Albaek. "Between } \\
\text { knowledge and power: } \\
\text { utilization of social } \\
\text { science in public } \\
\text { policy making." } \\
\text { Policy. 1995. }\end{array}$ & $\begin{array}{l}\text { Hypothetical/philosophi } \\
\text { cal discussion based on } \\
\text { two models: posivist } \\
\text { and rationalist. }\end{array}$ & & $\begin{array}{l}\text { Use of research/facilitators/barriers: not addressed } \\
\text { Other: } \\
\text { - There's a false dichotomy between (legitimate) rational research utilization and (illegitimate) political research utilization. } \\
\text { This dichotomy must be overcome. } \\
\text {-Discusses how knowledge/research knowledge used/not used by politico-administrative decision-makers. } \\
\text {-Find the right place for both theory \& practice. There is no science without interests \& no politics without analytical } \\
\text { reflection. } \\
\text {-Critical research must be based on the rules and procedures of testing the validity of scientific hypothesis which exist in } \\
\text { the research communities. This does not necessarily make research popular with the court and the king. But it benefits } \\
\text { public debate. And it safeguards the self-respect of research. }\end{array}$ \\
\hline
\end{tabular}




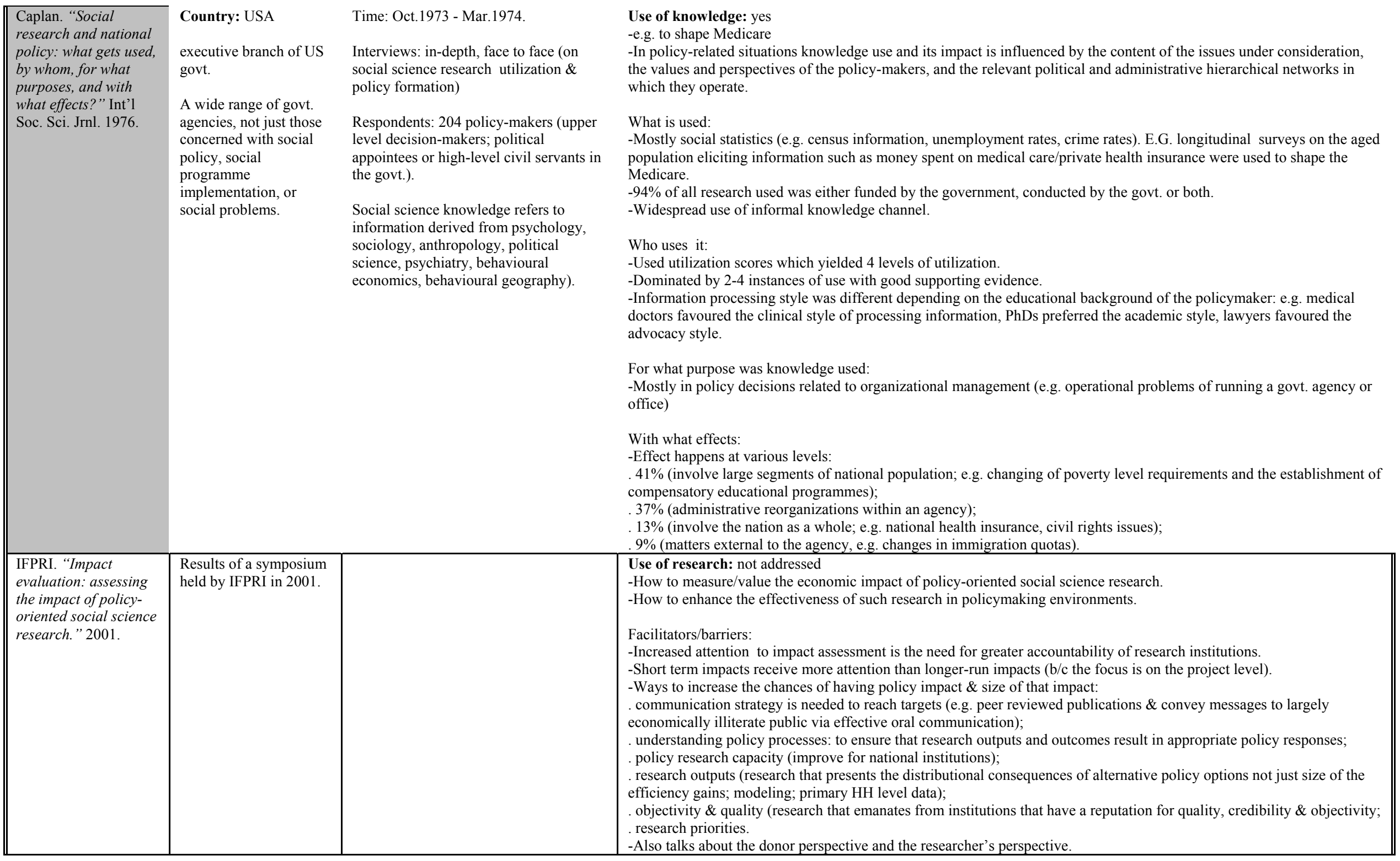




\begin{tabular}{|c|c|c|c|}
\hline $\begin{array}{l}\text { Landry et al. } \\
\text { "Climbing the ladder } \\
\text { of research utilization: } \\
\text { evidence from social } \\
\text { science research." } \\
\text { Conference } \\
\text { presentation. } 1999 .\end{array}$ & Country: Canada & $\begin{array}{l}\text { Data: } \\
1229 \text { faculty members from } 55 \text { Canadian } \\
\text { universities in departments of } \\
\text { anthropology, economics, industrial } \\
\text { relations, political science, social work } \\
\text { and sociology. } \\
\text { Questionnaire mailed to the respondents. } \\
\text { Knowledge utilization measured using a } \\
\text { validated modified Knott \& Wildavsky } \\
\text { scale with following process of } \\
\text { cumulative stages of use: transmission, } \\
\text { cognition, reference, effort, influence and } \\
\text { application. }\end{array}$ & $\begin{array}{l}\text { Use of Research: not directly addressed } \\
\text { Facilitators/Barriers: } \\
\text {-Identified five levels in the ladder of knowledge utilization } \\
\text {.from the echelon of no transmission to the echelon of transmission: this is the crucial stage } \\
\text {.from the stage of transmission to that of cognition } \\
\text {.from cognition to reference } \\
\text {.from reference to effort } \\
\text {.from effort to influence } \\
\text {.from influence to application. } \\
\text {-There are barriers to entry and these are primarily located between the stage of no transmission and stage of transmission. } \\
\text { Other: } \\
\text {-Four types of knowledge utilization models listed: technological, economic, institutional, social interaction. }\end{array}$ \\
\hline $\begin{array}{l}\text { Weiss. "The many } \\
\text { meanings of research } \\
\text { utilization." Pub. } \\
\text { Adm. Rev. } 1979 .\end{array}$ & Review paper & & $\begin{array}{l}\text { Use of research: yes } \\
\text {-Describes what 'using research' actually means from available literature. } \\
\text { Types of research use: } \\
\text { There are seven different types of models on use of research. They are: } \\
\text {.Knowledge-driven model } \\
\text {.Problem-solving model } \\
\text {.Interactive model } \\
\text {.Political model } \\
\text {.Tactical model } \\
\text {.Enlightment model } \\
\text {.Research as part of the intellectual enterprise of the society. }\end{array}$ \\
\hline $\begin{array}{l}\text { Weiss et al. "Truth } \\
\text { tests and utility tests: } \\
\text { decision-makers' } \\
\text { frames of reference for } \\
\text { social science } \\
\text { research." Amer. } \\
\text { Soc. Rev.1980. }\end{array}$ & $\begin{array}{l}\text { Country: USA } \\
\text { Mental health field }\end{array}$ & $\begin{array}{l}\text { Sample: } 155 \text { decision-makers (federal, } \\
\text { state \& local officials from National } \\
\text { Institute of Mental Health, National } \\
\text { Institute of Drug Abuse, National } \\
\text { Institute of Alcohol abuse and } \\
\text { Alcoholism, Alcohol, Drug Abuse, \& } \\
\text { Mental Health Administration) } \\
\\
\text { Based on their reading two reports out of } \\
50 .\end{array}$ & $\begin{array}{l}\text { Use of research: yes } \\
\text {-specific example not cited. } \\
\text { Facilitators/barriers: } \\
\text {-Frames of reference were created: } \\
\text {.research quality (multiple sub-issues) } \\
\text {.practicality of implementing the findings/Action Orientation (multiple sub-issues) } \\
\text {.compatibility with what users know \& believe/Conformity of User Expectations (multiple sub-issues) } \\
\text {.operation of institutions/Challenge to the Status Quo (multiple sub-issues) } \\
\text {.timeliness of study \& priority of issue/Relevance (multiple sub-issues) } \\
\text {-All frames are positively associated with perceived likelihood of using a study. } \\
\text {-The way in which they apply research conclusions to their work is a broader, more diffuse, \& wider ranging process than } \\
\text { recognized in earlier investigations. }\end{array}$ \\
\hline
\end{tabular}




\begin{tabular}{|c|c|c|c|}
\hline $\begin{array}{l}\text { Barta. "Information } \\
\text { seeking, research } \\
\text { utilization, and } \\
\text { barriers to research } \\
\text { utilization of Pediatric } \\
\text { nurse educators." } \\
\text { Journal of Professional } \\
\text { Nursing. } 1995 .\end{array}$ & $\begin{array}{l}\text { Country: USA } \\
\text { Used Roger's diffusion } \\
\text { of innovations model }\end{array}$ & $\begin{array}{l}\text { - Sample: instrument mailed to } 409 \\
\text { nurses (response rate } 52 \% \text { ) } \\
\text {-Level of research utilization estimated } \\
\text { using Nursing Practice Questionnaire- } \\
\text { Education (NPQ-E) } \\
\text {-Anonymous self report instrument used } \\
\text { to collect data } \\
\text {-1991 national League for Nursing }\end{array}$ & $\begin{array}{l}\text { - Factors fostering research utilization were: } \\
\text {. nurses who read more nursing journals had higher research utilization scores. } \\
\text { - Barriers to research utilization were: } \\
\text {. characteristics of the nurse } \\
\text {. characteristics of the setting } \\
\text { the presentation } \\
\text { the research }\end{array}$ \\
\hline $\begin{array}{l}\text { Champion et al. } \\
\text { "Variables related to } \\
\text { research utilization in } \\
\text { nursing: an empirical } \\
\text { investigation." Journal } \\
\text { of Advanced Nursing. } \\
1989 .\end{array}$ & $\begin{array}{l}\text { Country: USA: } \\
\text { Southwest region }\end{array}$ & $\begin{array}{l}\text { - Correlational study } \\
\text { - Sample: convenience, } 59 \text { nurses ( } 59 \% \\
\text { response rate, community hospital) } \\
\text { - Instrument: summated Likert scale } \\
\text {. independent variables - support ( } 7 \\
\text { items), availability ( } 8 \text { items), attitude } \\
\text { ( } 21 \text { items) } \\
\text {.dependent variable: use (3 items) }\end{array}$ & $\begin{array}{l}\text { Use of research: somewhat } \\
\text { Facilitators/Barriers: } \\
\text { - Identified variables related to research utilization in clinical area: (1) Attitude of nurse practitioner \& availability of } \\
\text { research findings related to research utilization }(\mathrm{R}=0.65, \mathrm{p}=<0.00) \text {; (2) Support of administrations. } \\
\text {-Demographic variables not significantly correlated to research utilization. } \\
\text {-Positive association between the individual determinant beliefs \& attitudes of adopters (e.g. nurses) with research } \\
\text { utilization. }\end{array}$ \\
\hline $\begin{array}{l}\text { Estabrooks et al. } \\
\text { "Individual } \\
\text { determinants of } \\
\text { research utilization: a } \\
\text { systematic review." } \\
\text { Jnl. of Adv. Nurs. } \\
\text { 2003. }\end{array}$ & Review article & & $\begin{array}{l}\text { Facilitators: } \\
\text {-There is a positive association between the individual determinant beliefs and attitudes of adopters (e.g. nurses) with } \\
\text { research utilization. The review found no evidence of influence of the other individual determinants such as involvement } \\
\text { in research activities, information seeking, professional characteristics, education and socio-economic factors. }\end{array}$ \\
\hline $\begin{array}{l}\text { Funk et al. "Barriers: } \\
\text { the barriers to } \\
\text { research utilization } \\
\text { scale." Applied } \\
\text { Nursing Research. } \\
\text { 1991a. }\end{array}$ & $\begin{array}{l}\text { Country: USA } \\
22 \text { states } \\
\text { Nursing } \\
\text { Nurse: clinician, } \\
\text { administrator } \\
\text { Study rationale: } \\
\text { The nursing profession } \\
\text { openly acknowledges } \\
\text { that there is a research- } \\
\text { practice gap and this } \\
\text { drives the nurse } \\
\text { practitioners' movement } \\
\text { for evidence-based } \\
\text { practice. }\end{array}$ & $\begin{array}{l}\text { - Sample: } 5000 \text { nurses (1989 returned } \\
\text { questionnaires, } 40 \% \text { response rate), } \\
\text { randomly selected, } 1987 \text { ANA } \\
\text { membership roster; } 924 \text { clinicians, } 414 \\
\text { clinical administrators } \\
\text { - Factor analytic procedures } \\
\text { - Scale (1 to 4) } \\
\text { - Barriers scale ( } 28 \text { items) developed } \\
\text { from literature \& CURN questionnaire: } \\
\text { characteristics of adopter, } \\
\text { organization/setting, innovation/research, } \\
\text { communication/presentation } \\
\text {-CURN: conduct \& utilization of } \\
\text { research in nursing }\end{array}$ & $\begin{array}{l}\text { Use of research: yes (but does not give any specific examples) } \\
\text { Facilitators: } \\
\text {-There is a positive association between the individual determinant beliefs and attitudes of adopters (e.g. nurses) with } \\
\text { research utilization. } \\
\text {-Availability and support of administration also foster research utilization. } \\
\text { Barriers: } \\
\text {-Characteristics of the adopter - nurses research values, skills and awareness. } \\
\text {-Characteristics of the organization/setting - setting, barriers and limitations. } \\
\text {-Characteristics of the innovation/research - qualities of research. } \\
\text {-Characteristics of the communication/presentation - presentation and accessibility of the research. }\end{array}$ \\
\hline
\end{tabular}




\begin{tabular}{|c|c|c|c|}
\hline $\begin{array}{l}\text { Funk et al. "Barriers } \\
\text { to using research } \\
\text { findings in practice: } \\
\text { the clinician's } \\
\text { perspective." App. } \\
\text { Nurs. Res. } 1991\end{array}$ & $\begin{array}{l}\text { Country: USA } \\
22 \text { states } \\
\text { Nursing } \\
\text { Sub-sample of above } \\
\text { study. }\end{array}$ & - Sample: 924 nurse clinicians & \\
\hline $\begin{array}{l}\text { Funk et al. } \\
\text { "Administrators' view } \\
\text { on barriers to research } \\
\text { utilization." App. } \\
\text { Nurs. Res. } 1995\end{array}$ & $\begin{array}{l}\text { Country: USA } \\
22 \text { states } \\
\text { Nursing } \\
\text { Sub-sample of } 1^{\text {st }} \text { Funk } \\
\text { Barriers study. }\end{array}$ & - Sample: 414 nurse administrators & \\
\hline $\begin{array}{l}\text { Funk et al. "Barriers } \\
\& \text { facilitators of } \\
\text { research utilization. } \\
\text { An integrative } \\
\text { review." Nursing } \\
\text { Clinics of North } \\
\text { America. } 1995 .\end{array}$ & $\begin{array}{l}\text { Country: USA } \\
22 \text { states } \\
\text { Nursing } \\
\text { Sub-sample of } 1^{\text {st }} \text { Funk } \\
\text { Barriers study. }\end{array}$ & - Sample: 924 nurse clinicians & \\
\hline $\begin{array}{l}\text { Dunn et al. "Using } \\
\text { research for practice: } \\
\text { a UK experience of the } \\
\text { Barriers Scale." Jrnl. } \\
\text { Adv. Nurs. } 1998 .\end{array}$ & $\begin{array}{l}\text { Country: UK } \\
\text { Nursing } \\
\text { Replicated the Funk } \\
\text { study. }\end{array}$ & $\begin{array}{l}\text { - Sample: convenience, } 316 \text { nurses } \\
\text { (broad spectrum) } \\
\text { - Used BARRIERS Scale developed by } \\
\text { Funk et al. }\end{array}$ & $\begin{array}{l}\text { - Items in BARRIERS scale consistently perceived as strong or negligible barriers by both groups of nurses. } \\
\text { - There were differences with North American nurses (e.g. confidence in evaluating research, perception of the nurse's } \\
\text { authority to change patient procedure). }\end{array}$ \\
\hline $\begin{array}{l}\text { Parahoo. "Barriers to, } \\
\text { and facilitators of, } \\
\text { research utilization } \\
\text { among nurses in } \\
\text { Northern Ireland." } \\
\text { Jrnl. Adv. Nurs. } 2000 .\end{array}$ & $\begin{array}{l}\text { Country: Northern } \\
\text { Ireland } \\
\text { Nursing } \\
\text { Replicated the Funk } \\
\text { study. }\end{array}$ & $\begin{array}{l}\text { - Sample: convenience, } 2600 \text { nurses } \\
\text { (1368 responded, } 53 \% \text { response rate), } 23 \\
\text { hospitals. } \\
\text { - Used BARRIERS Scale developed by } \\
\text { Funk et al. }\end{array}$ & $\begin{array}{l}\text { Barriers: } \\
\text { 'the nurse does not feel s/he has enough authority to change patient procedures' } \\
. \text { 'statistical analyses are not understandable' } \\
.7 \text { out of the top } 10 \text { barriers were related to 'setting' }\end{array}$ \\
\hline
\end{tabular}




\section{Bibliography}

Operations Research

Askew I, Miller R, Solo J. Using operations research for producing and communicating knowledge about reproductive health services in sub-Saharan Africa. Paper presented at the IUSSP seminar on 'The production and circulation of Population Knowledge'. March 2001. Brown University, USA.

Askew I, Matthews Z, Partridge R. Going beyond research. A key issues paper raising discussion points related to dissemination, utilization and impact of reproductive and sexual health research. 2002. University of Southampton, UK.

Bertrand JT, Magnani RJ, Rutenberg N. Handbook of indicators for family planning program evaluation. December 1994. The Evaluation Project. University of North Carolina at Chapel Hill.

Haaga JG, Maru RM. The effect of operations research on program changes in Bangladesh. Studies in Family Planning. March/April 1996. 27 (2): 76-87.

Hegazi S. Utilization of operations research in Egypt. Special Report. October 1997. The Population Council, Cairo.

Iskandar MB, Indrawati S. Indonesia: utilization of completed operations research studies. Final Report. November 1996. The Population Council.

Leon FR. Utilizing operations research solutions: the case of DMPA in Peru. March 2001. The Population Council, Peru.

Marin MC, Bertrand JT. Evaluation manual. Evaluating operations research utilization: guidelines for assessing process and impact. Frontiers in Reproductive Health, Population Council, Family Health International, Tulane University. 2002.

Masulit S, Costello M, Hegazi S. Influencing reproductive health policy and programs in the Philippines: implementing and advocacy model for utilization of operations research. Frontiers in Reproductive Health, the Population Council. December 2001.

Solo J, Cerulli A, Miller R, Askew I, Pearlman E. Strengthening the utilization of family planning operations research: findings from case studies in Africa. June 1998. The Population Council.

Ross JA, Donayre J, McNamara R. Perspectives on operations research. International Family Planning Perspectives. Vol. 13, No. 4 (Dec. 1987), 128-136.

Vernon R. Operations research on promoting vasectomy in three Latin American Countries. International Family Planning Perspectives. 22:26-31. 1996. 
Evaluation Research

Agarwala-Rogers R. Why is evaluation research not utilized. Edited by M Guttentag. Evaluation Studies Review Annual. 1977. 2: 327-333.

Bardach E. The dissemination of policy research to policy makers. Knowledge: Creation, Diffusion, Utilization. December 1984. 6 (2): 125-144.

Dunn WN, Dukes MJ, Cahill AG. Designing utilization research. Knowledge: Creation, Diffusion, Innovation. March 1984. 5 (3): 387-404.

Goldstein MS, Marcus AC, Rausch NP. The non-utilization of evaluation research. Pacific Sociological Review. 1978. 21: 21-44.

Greenberg DH, Mandell MB. Research utilization in policymaking: a tale of two series (of social experiment). Journal of Policy Analysis and Management. 1991. 10 (4): 633-656.

Sigel K, Tuckel P. The utilization of evaluation research. Evaluation Review. 1985. 9: 307-328.

Health Systems/Policy

Anderson M, Cosby J, Swan B, Moore H, Broekhoven M. The use of research in local health service agencies. Social Science and Medicine. 49 (1999): 1007-1019.

Corwin RG, Louis KS. Organizational barriers to the utilization of research. Administrative Science Quarterly. Vo. 27, No. 4 (Dec. 1982). P.623-640.

Davis P, Howden-Chapman P. 1996. Translating research findings into health policy. Social Science and Medicine. 43 (5): 865-872.

Frenk J. Balancing relevance and excellence: organizational response to link research with decision making. Social Science and Medicine. 1992. 35: 1397-1404.

Hanney SR, Gonzalez-Block MA, Buxton MJ, Kogan M. The utilization of health research in policy-making: concepts, examples and methods of assessment. Health Research Policy and Systems. 2003, 1:2, p.1-28.

Lomas J. Finding audiences, changing beliefs: the structure of research use in Canadian health policy. Journal of Health Politics, Policy and Law. Fall 1990. 15 (3): 525-542.

Trostle J, Bronfman M, Langer A. How do researchers influence decision-makers? Case studies of Mexican policies. Health Policy and Planning. 12 (2): 103-114. 1999.

Social Sciences: sociology, education, economics

Albaek E. Between knowledge and power: utilization of social science in public policy making. Policy Sciences. 28: 79-100. 1995. 
Christie CA, Alkin MC. Further reflections on evaluation misutilization. Studies in Educational Evaluation. 25 (1999) 1-10.

Caplan N. 1976. Social research and national policy: what gets used, by whom, for what purposes, and with what effects? International Social Science Journal. 28: 187-194.

Deshpande R, Zaltman G. Factors affecting the use of market research information: a path analysis. Journal of Marketing Research. February 1982. XIX: 14-31.

Gray A. Evidence-based policies and indicator systems: from profane arithmetic to a sacred geometry. Third International, Inter-disciplinary Evidence-based Policies and Indicator Systems Conference. CEM Centre, University of Durham. UK. July 2001.

IFPRI. Impact evaluation: assessing the impact of policy-oriented social science research. International Food Policy Research Institute. USA. 2001.

Kanefsky J. Research impact and the ESRC teaching and learning research programme. Paper to British Educational Research Association Annual Conference, University of Leeds. September 2001.

Landry R, Amara N, Lamari M. Climbing the ladder of research utilization: evidence from social science research. Paper presented at annual meeting of the Society for Social Studies of Science. October 1999.

Landry R, Lamari M, Amara N. The extent and determinants of the utilization of university research in government agencies. Public Administration Review. March/April 2003. 63 (2): 192-205.

Weiss C. The many meanings of research utilization. Public Administration Review. 29: 426431. Sep/Oct 1979.

Weiss CH, Bucuvalas MJ. Truth tests and utility tests: decision-makers' frames of reference for social science research. American Sociological Review. 45 (2): 302-313. April 1980.

Nursing

Barta KM. Information-seeking, research utilization, and barriers to research utilization of Pediatric nurse educators. Journal of Professional Nursing, Vol. 11 (1), 1995: p.49-57.

Burrows, DE, McLeish K. A model for research-based practice. Journal of Clinical Nursing. July 1995. 4 (4): 243-247.

Champion VL, Leach A. Variables related to research utilization in nursing: an empirical investigation. Journal of Advanced Nursing. 1989. 14, 705-710.

Dunn V, Crichton N, Roe B, Seers K, Williams K. Using research for practice: a UK experience of the BARRIERS scale. Journal of Advanced Nursing. 1998. 27, 1203-1210. 
Estabrooks CA, Floyd JA, Scott-Findlay S, O'Leary KA, Gushta M. Individual determinants of research utilization: a systematic review. Journal of Advanced Nursing. 43 (5), 506-520; 2003. Blackwell Publishing Ltd.

Funk SG, Tornquist EM, Champagne MT. Barriers and facilitators of research utilization. An integrative review. Nursing Clinics of North America. Vol.30 (3), 395-407. 1995.

Funk SG, Champagne MT, Wiese RA, Tornquist EM. The barriers to research utilization scale. Applied Nursing Research. 1991. 4 (1), 39-45.

Funk SG, Champagne MR, Wiese RA, Tornquist EM. Barriers to using research findings in practice: the clinician's perspective. Applied Nursing Research, Vol. 4 (2), 1991: 90-95.

Funk SG, Champagne MR, Tornquist EM, Wiese RA. Administrators' view on barriers to research utilization. Applied Nursing Research, Vol. 8 (1), 1995: 44-49.

Parahoo K. Barriers to, and facilitators of, research utilization among nurses in Northern Ireland. Journal of Advanced Nursing, 2000, 31 (1): 89-98.

Parahoo K. Research utilization and research related activities of nurses in Northern Ireland. International Journal of Nursing Studies, 1998, 35: 283-291.

Valizadeh L, Zamanzadeh V. Research utilization and research attitudes among nurses working in teaching hospitals in Tabriz, Iran. Journal of Clinical Nursing. 2003; 12: 928-930.

Other

Braskamp LA Brown RD, Newman DL. Studying evaluation utilization through simulations. Evaluation Review. February 1982. 6 (1): 114-126.

Mandell MB. Simulation models and the study of information utilization in public sector decision making. Knowledge: Creation, Diffusion, Utilization. March 1989. 10 (3): 202214.

Marks DF. Perspectives on evidence-based practice. City University, London, UK. October 2002. 1-72.

Reid F. Evidence-based policy: where is the evidence for it? School for Policy Studies Working Paper Series. Paper no. 3. University of Bristol, UK. May 2003.

Wiggins A, Tymms P. Evidence-based policies: the effect of key performance indicators. Paper presented at the Third International, Inter-disciplinary Evidence-based Policies and Indicator Systems Conference. July 2001. 
Wilson T. Monitoring and evaluating information-related research. Paper presented at a European conference on funding research in the library and information studies field organized by the British Library R \& D Department. December 1994.

Zvieli A, MacGregor SK, Shapiro JZ. Design of an expert system for utilization research. Louisiana State University, Baton Rouge. 1986.

$\underline{\text { Inter-rater }}$

Sinacore JM, Connell KJ, Olthoff AJ, Friedman MH, Gecht MR. A method for measuring interrater agreement on checklists. Evaluation Health Professional. June 1999. 22 (2): 221-34.

McGraw SA, Sellers DE, Stone EJ, Bebchuk J, Edmundson EW, Johnson CC, Bachman KJ, Luepker RV. Using process data to explain outcomes. An illustration from the Child and Adolescent Trial for Cardiovascular Health (CATCH). Evaluation Review. June 1996. 20 (3): 291-312.

Burchard KW, Rowland-Morin PA, Coe NP, Garb JL. A surgery oral examination: interrater agreement and the influence of rater characteristics. Academic Medicine. November 1995. 70 (11): 1044-6.

Steinijans VW, Diletti E, Bomches B, Greis C, Solleder P. Interobserver agreement: Cohen's kappa coefficient does not necessarily reflect the percentage of patients with congruent classifications. International Journal of Clinical Pharmacology Theory. March 1997. 35 (3): $93-5$. 


\section{Appendix B: Estimating Inter-rater Reliability}

The weighted kappa statistic was used to assess inter-rater reliability (Cohen, 1960). Weights in the form $w_{i j}=1-\{(i-j) /(k-1)\}^{2}$ were used, where $i$ and $j$ index the rows and columns of the rating by the two raters and $\mathrm{k}$ is the maximum number of ratings. The weights take into consideration the fact that there is a difference between two informants disagreeing whether the value of an indicator is "slightly/not at all" or "somewhat" and disagreeing whether it is "slight/not at all" or "a great deal". When both informants make the same assessment, a weight of 1 is assigned. A weight of 0.5 means the key informants are in half agreement while a weight of .75 means that they are in three-quarters agreement. This is the weight assigned when the raters are "two categories apart". Finally, when the raters are in complete disagreement, the weight is 0 .

The observed proportion of agreement is:

$$
\mathrm{p}_{\mathrm{o}}=\sum_{i=1}^{k} \mathcal{W}_{i i} p_{i i}
$$

where $p_{i j}$ is the fraction of rating $i$ by the first rater and $j$ by the second. The expected proportion of agreement is

$$
\mathrm{p}_{\mathrm{e}}=\sum_{i=1}^{k} \sum_{j=1}^{k}{w_{i i}}_{p_{i}} p_{j}
$$

$$
\text { where } p_{i}=\sum_{j} p_{i j} \text { and } p_{j}=\sum_{i} p_{i j}
$$

Kappa is given by $\hat{k}=\left(p_{o}-p_{e}\right) / 1-p_{e}$. The kappa statistic is zero when the agreement is what would be expected to be observed by chance, and 1 where there is perfect agreement. According to Landis and Koch (19xx), intermediate values can be interpreted as follows:

$\begin{array}{ll}<0.0 & \text { Poor } \\ 0.21-0.40 & \text { Fair } \\ 0.41-0.60 & \text { Moderate } \\ 0.61-0.80 & \text { Substantial } \\ 0.81-1.00 & \text { Almost perfect }\end{array}$




\section{Appendix C: Relationship between OR Process and Results Utilization}

Table A1 Percentage of OR studies associated with high utilization outcomes by type of outcome

\begin{tabular}{|c|c|c|c|c|c|}
\hline Process Index & $\begin{array}{l}\text { Participation } \\
\text { Index }\end{array}$ & $\begin{array}{l}\text { No Barrier } \\
\text { Index }\end{array}$ & $\begin{array}{l}\text { Acceptability } \\
\text { Index }\end{array}$ & $\begin{array}{l}\text { Research } \\
\text { Quality Index }\end{array}$ & $\begin{array}{l}\text { Dissemination } \\
\text { Index }\end{array}$ \\
\hline $\begin{array}{l}\text { Program Change } \\
\text { High } \\
\text { Low } \\
\text { Chi-square } \\
\text { N }\end{array}$ & $\begin{array}{l}96.3 \\
89.5 \\
\mathrm{~ns} \\
(46)\end{array}$ & $\begin{array}{l}87.5 \\
96.7 \\
\mathrm{~ns} \\
(46)\end{array}$ & $\begin{array}{l}95.7 \\
91.7 \\
\mathrm{~ns} \\
(35)\end{array}$ & $\begin{array}{l}100 \\
88.5 \\
\mathrm{~ns} \\
(40)\end{array}$ & $\begin{array}{l}100 \\
85 \\
* * \\
(44)\end{array}$ \\
\hline $\begin{array}{l}\text { Scale Up } \\
\text { High } \\
\text { Low } \\
\text { Chi-square } \\
\text { N }\end{array}$ & $\begin{array}{l}70.0 \\
76.9 \\
\mathrm{~ns} \\
(33)\end{array}$ & $\begin{array}{l}54.5 \\
81.8 \\
* \\
(33)\end{array}$ & $\begin{array}{l}76.5 \\
85.7 \\
\mathrm{~ns} \\
(24)\end{array}$ & $\begin{array}{l}80.0 \\
70.0 \\
\mathrm{~ns} \\
(30)\end{array}$ & $\begin{array}{l}81.3 \\
60.0 \\
\text { ns } \\
(31)\end{array}$ \\
\hline $\begin{array}{l}\text { Replication } \\
\text { High } \\
\text { Low } \\
\text { Chi-square } \\
\text { N }\end{array}$ & $\begin{array}{l}42.9 \\
50.0 \\
\text { ns } \\
(35)\end{array}$ & $\begin{array}{l}54.5 \\
41.7 \\
\mathrm{~ns} \\
(35)\end{array}$ & $\begin{array}{l}50.0 \\
57.1 \\
\text { ns } \\
(25)\end{array}$ & $\begin{array}{l}72.7 \\
33.3 \\
* * \\
(32)\end{array}$ & $\begin{array}{l}47.1 \\
50.0 \\
\text { ns } \\
(33)\end{array}$ \\
\hline $\begin{array}{l}\text { Policy Change } \\
\text { High } \\
\text { Low } \\
\text { Chi-square } \\
\text { N }\end{array}$ & $\begin{array}{l}63.0 \\
42.1 \\
\mathrm{~ns} \\
(46)\end{array}$ & $\begin{array}{l}50.0 \\
56.7 \\
\mathrm{~ns} \\
(46)\end{array}$ & $\begin{array}{l}65.2 \\
58.3 \\
\text { ns } \\
(35)\end{array}$ & $\begin{array}{l}64.3 \\
50.0 \\
\text { ns } \\
(40)\end{array}$ & $\begin{array}{l}54.2 \\
55.0 \\
\mathrm{~ns} \\
(44)\end{array}$ \\
\hline $\begin{array}{l}\text { New Funding } \\
\text { High } \\
\text { Low } \\
\text { Chi-square } \\
\text { N }\end{array}$ & $\begin{array}{l}51.9 \\
31.6 \\
\text { ns } \\
(46)\end{array}$ & $\begin{array}{l}37.5 \\
46.7 \\
\mathrm{~ns} \\
(46)\end{array}$ & $\begin{array}{l}47.8 \\
33.3 \\
\text { ns } \\
(35)\end{array}$ & $\begin{array}{l}42.9 \\
46.2 \\
\text { ns } \\
(40)\end{array}$ & $\begin{array}{l}41.7 \\
45.0 \\
\mathrm{~ns} \\
(44)\end{array}$ \\
\hline $\begin{array}{l}\text { USAID Decisionmaking } \\
\text { High } \\
\text { Low } \\
\text { Chi-square } \\
\text { N }\end{array}$ & $\begin{array}{l}37.0 \\
36.8 \\
\text { ns } \\
(46)\end{array}$ & $\begin{array}{l}12.5 \\
50.0 \\
* * \\
(46)\end{array}$ & $\begin{array}{l}47.8 \\
50.0 \\
\text { ns } \\
(35)\end{array}$ & $\begin{array}{l}21.4 \\
42.3 \\
\mathrm{~ns} \\
(40)\end{array}$ & $\begin{array}{l}37.5 \\
35.0 \\
\text { ns } \\
(44)\end{array}$ \\
\hline $\begin{array}{l}\text { Organizational Capacity } \\
\text { High } \\
\text { Low } \\
\text { Chi-square } \\
\text { N }\end{array}$ & $\begin{array}{l}66.7 \\
73.7 \\
\mathrm{~ns} \\
(46)\end{array}$ & $\begin{array}{l}68.8 \\
70.0 \\
\text { ns } \\
(46)\end{array}$ & $\begin{array}{l}60.9 \\
83.3 \\
\text { ns } \\
(35)\end{array}$ & $\begin{array}{l}57.1 \\
73.1 \\
\mathrm{~ns} \\
(40)\end{array}$ & $\begin{array}{l}62.5 \\
75.0 \\
\text { ns } \\
(44)\end{array}$ \\
\hline
\end{tabular}

$* * \quad \mathrm{p}<=.05$

* $\quad \mathrm{p}<=.10$ 